University of Louisville

ThinkIR: The University of Louisville's Institutional Repository

$12-1999$

\title{
A symbol for transcendence : the human figure in the visual arts as a symbol of psychological wholeness as related to the archetype of divine androgyny and the reconciliation of the anima- animus.
}

Mason Cowell

University of Louisville

Follow this and additional works at: https://ir.library.louisville.edu/etd

\section{Recommended Citation}

Cowell, Mason, "A symbol for transcendence : the human figure in the visual arts as a symbol of psychological wholeness as related to the archetype of divine androgyny and the reconciliation of the anima-animus." (1999). Electronic Theses and Dissertations. Paper 281.

https://doi.org/10.18297/etd/281

This Master's Thesis is brought to you for free and open access by ThinkIR: The University of Louisville's Institutional Repository. It has been accepted for inclusion in Electronic Theses and Dissertations by an authorized administrator of ThinkIR: The University of Louisville's Institutional Repository. This title appears here courtesy of the author, who has retained all other copyrights. For more information, please contact thinkir@louisville.edu. 


\title{
A SYMBOL FOR TRANSCENDENCE:
}

The Human Figure in the Visual Arts as a Symbol of Psychological Wholeness as Related to the Archetype of Divine Androgyny And the Reconciliation of the Anima-Animus

\section{By}

Mason Cowell

B.A., University of Kentucky, 1989

A.A., Atlanta Institute for Art, 1993

\author{
A Thesis \\ Submitted to the Faculty of the \\ Graduate School of the University of Louisville \\ in Partial Fulfillment of the Requirements \\ for the Degree of
}

Master of Arts

Division of Humanities

University of Louisville

Louisville, Kentucky

December 1999 
A SYMBOL FOR TRANSCENDENCE:

The Human Figure in the Visual Arts as a Symbol of Psychological Wholeness as Related to the Archetype of Divine Androgyny and the Reconciliation of the Anima-Animus

By

Mason Cowell

B.A., University of Kentucky, 1989

A.A., Atlanta Institute for Art, 1993

A Thesis Approved on

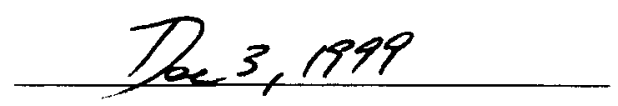

by the following Reading Committee:

Thesis Director 
Copyright 1999 by Mason Cowell All rights reserved 


\section{ACKNOWLEDGMENTS}

I would like to thank my thesis director, Professor Jay Kloner, for his guidance and patience. Likewise. many thanks to the other committee members, Professor Mary Ann Stenger and Professor Abby Calisch, for their comments, assistance and patience, and I express my appreciation to Professor Robert Douglas for his assistance. Furthermore, my family's patience and support during the last two years is greatly appreciated. Also, to all who may understand. I wish to acknowledge that unfavorable experiences often paradoxically generate favorable outcomes. In the winter of 1997, upon returning from London in low-spirits, I did not realize that anxiety and heartache could be alleviated through a positive and constructive focus such as graduate work at the University of Louisville. 


\section{ABSTRACT}

From a Jungian perspective, this thesis investigates the ideal of androgynous transcendence by identifying the Jungian anima-animus archetype within three specific artworks produced by three differing traditions. As a result, this thesis contributes to the discipline of art history by providing a nontraditional approach to the interpretation of visual art.

Although 'New Art History' is receptive to a Jungian approach in the analysis of visual art, this relatively recent and major new direction within art history does not readily embrace a Jungian understanding of the visual arts. A Jungian perspective towards the interpretation of visual art presents fascinating insights concerning Jung's understanding of the universal Transcendent Function in art.

Jung's scholarship teaches that 'archetypes' are patterns of ideas within the 'collective unconsciousness' that are inherent in the psyche and thus common to all peoples and all cultures. Therefore, varying themes found within art are understood as originating from this universally common source of the collective unconscious. Cross-cultural symbols for transcendence, found in art, are often manifestations of universal archetypes such as the coalesced anima and animus. Although Jung was by no means the first to grasp the transcendental power of the idea of these amalgamated male-female opposites, he was the first to connect this idea with the study of psychology.

Each of the following three artistic traditions that I have chosen for discussion and comparison offer an image which reflects this archetypally integrated anima-animus and the idea of divine androgyny. These principal world cultures, African, Eastern and Western, are each represented by one of these three artifacts. This thesis investigates the following artworks and their corresponding and confirming philosophies and mythologies: (1) The African tribal sculpture called Seated Couple reflects the archetypal ideal of the reconciliation of the anima-animus within an indigenous culture. (2) Representative of an Eastern culture, the Hindu erotic sculpture called Lovers also reflects this same ideal of the harmonized anima-animus. (3) William Blake's mixed-media illustration titled Satan Watching the Endearments of 
Adam and Evc represents a Western tradition, and is, like the other two artworks, representative of this same ideal of the unified anima and animus.

This thesis identifies, reflected within the visual arts, the idea of the reconciliation of male-female opposites through the identification of the Jungian universal archetype of the coalesced anima-animus also often seen reflected under the guise of divine androgyny. Since art history has not readily applied a Jungian viewpoint towards the interpretation of the visual arts, it is my hope that this thesis will encourage more serious thought in this area among specialists as well as non-specialists. 


\section{TABLE OF CONTENTS}

PAGE

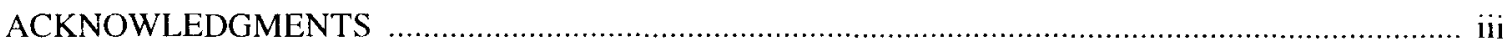

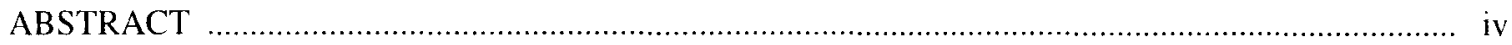

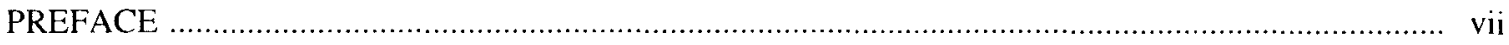

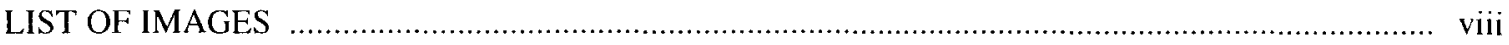

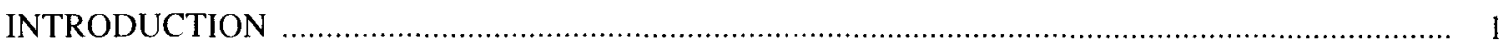

CHAPTER

I. African Dogon Mythology and the Sculpture of the 'Primordial Couple' ................................. 6

II. Tantric Meanings of the Erotic Mithuna Sculpture of India ................................................ 20

III. William Blake's Depiction of 'Adam and Eve' for Paradise Lost .......................................... 36

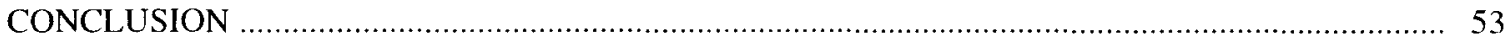

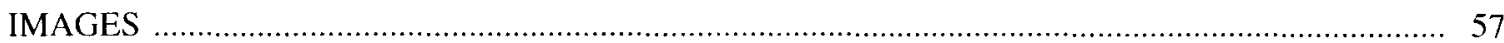

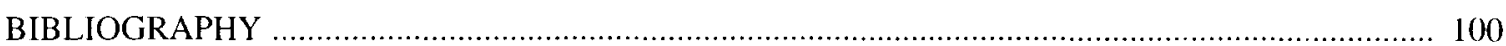

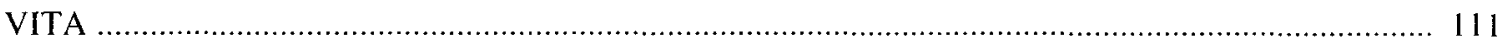




\section{PREFACE}

While enrolled in high school art classes, I discovered that I not only had an interest in drawing and painted portraiture, but also I had a substantial talent for sketching the figure. Over the years, my initial interest in portraiture shifted to include an interest in human anatomy, and now I have an interest in the overall depiction of the human figure in art. Because of this, within recent years I have become interested in the human figure's overall use and portrayal in the visual arts throughout world culture and history.

Through the past two years of research, I have been introduced to the many ways in which the human body has been symbolically used to communicate esoteric ideas intrinsic in the varying mythologies and religions of all ages. As Charles $\mathrm{H}$. Taylor declares, “...we [must] remember that throughout human history, sacred art. mythologems, and rituals have treated the body not primarily as matter but also as a symbolic object. As a whole and in its parts, the body thus becomes a template for images in which we may perceive larger meanings, reflections of those psychological and sacred depths from which the energy comes that powers fascination with our incarnate form" (Elder vii).

Before entering the University of Louisville's graduate program, I felt that the philosophical creativity of my art towards the use of the human figure was in a period of stagnation. But now, having nearly completed my graduate program, I have a vast and continuous reservoir of ideas from which to represent the symbolic human figure in art.

This thesis can be seen as a preliminary exercise whereby now I have acquired the necessary and increased competency to conduct professional research in the humanities, for the purpose of helping me conceive superlative contexts in which to design and produce figurative art. It is under this premise that I expect the philosophical creativity of my artwork to greatly improve within the future. 


\section{LIST OF IMAGES}

Imagc

1. The Seated Couple, or Primordial Couple. $16^{\text {th }}-20^{\text {th }}$ century. Mali, Africa. Wood with pieces of metal

2. The Seated Couple or Primordial Couple. Rear view

3. The Lovers, or Loving Couple (or generally called Mithuna). $11^{\text {th }}$ century. Khajuraho. Madhya Pradesh, India. Sandstone

4. Satan watching the Endearments of Adam and Eve. 1808. William Blake illustration

5. Carl Jung's Mandala, Window on Eternity

6. Pencil sketches for Satan Watching the Endearments of Adam and Eve

7. Stephen Rigaud's Adam and Eve in the Bower

8. James Basire's engraving of The Tower of the Winds

9. 1806 design for Satan Watching the Endearments of Adam and Eve

10. Adam and Eve in the bower compared with Hexagrams

11. Map of "London and neighboring villages as William Blake knew them." 1777

12. Alchemical image of "King and Queen, symbolized by sun and moon (in psychological concepts, animus and anima)"

13. Alchemical image of "An androgyne holding a $\mathrm{Y}$ "

14. The Lovers as it is displayed within the Cleveland Museum of Art collection

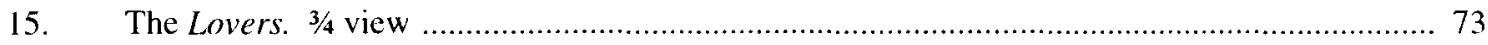

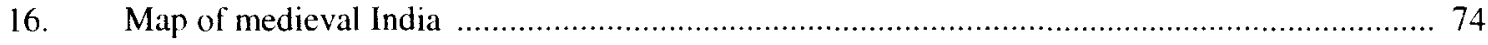

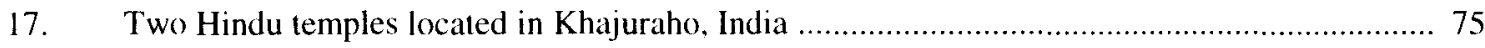

18. The Seated Couple, or Primordial Couple. Profile of female's bust ...................................... 76

19. The Seated Couple, or Primordial Couple. Front $3 / 4$ view …............................................ 77

20. The Original Couple, or Dogon Primordial Couple ........................................................... 78

21. Dogon Ancestor Pair, or Primordial Couple ....................................................................... 79

22. Dogon Seated Couple, or Primordial Couple …................................................................. 80

23. Dogon Funeral Group, symbolizing the male and female elements, or Primordial Couple ....... 81 
24. Dogon Nummo androgynous water-spirit

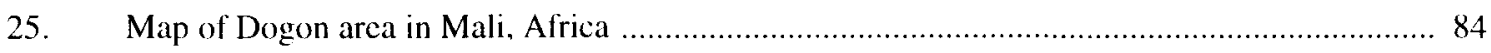

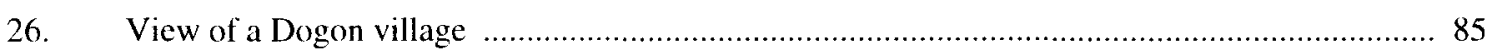

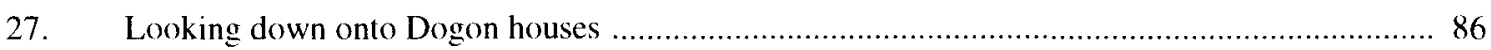

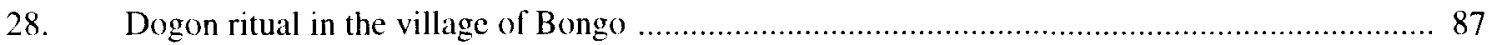

29. The Ancient Androgyne or Dogon hermaphrodite Nummo .................................... 89

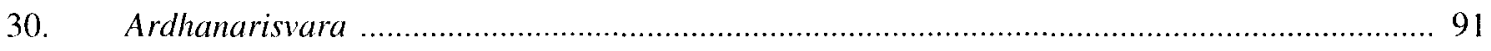

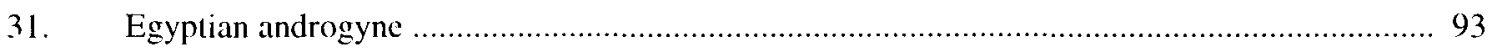

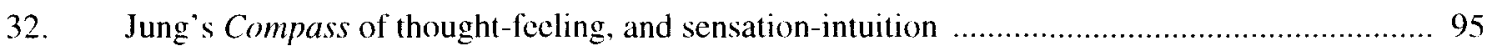

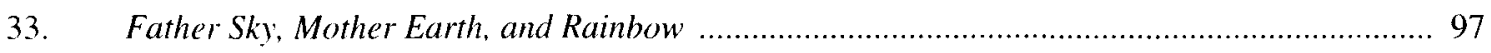

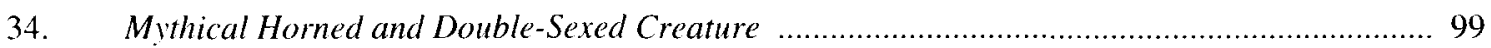




\section{INTRODUCTION}

This thesis deals with a Jungian psychoanalytic approach to art history. I will focus on and identify Carl Jung's renowned theory of the reconciliation of the archetypes of the 'anima and animus'l also often seen in his work as divine androgyny. Through the examination of three specific artworks produced within three differing traditions, and upon uncovering the meanings of these artworks, this thesis aims at identifying the theme of the reconciling of the 'anima' or female principle, with the 'animus' or male principle. The purpose of my thesis is to contribute to art history by providing a non-traditional methodology for understanding art and implementing art history.

Since the 1960's, the methodologies used for implementing the discipline of art history have become increasingly complex. In an effort to realize these shifting and unprecedented art history methodologies, ideologies, and practices, the annual meetings of the College Art Association ${ }^{2}$ have changed substantially in character since the mid-1980's. The variety of these new methodologies gives us some indication of how elaborate this 'New Art History' has become. Increasingly, the field of art history has begun to acknowledge its own relevance to a Jungian psychoanalytic approach, along with its relevance to such ideologies as semiotics, deconstruction, Marxism, feminist critiques and multiculturalist approaches.

Carl Jung taught that all cultures reveal themselves from within the human mind or psyche, ${ }^{3}$ from an origin in 'collective unconsciousness." The collective unconscious is seen as an aspect of the mind that is collective to all minds and is primordial--as old, at least, as the human race. Patterned ideas as manifestations from the collective unconscious appear in culture as universal motifs which Jung called 'archetypes.' One of his most compelling archetypes is the 'anima and animus.'

\footnotetext{
${ }^{1}$ Anima is the inner imaginative image of woman held by a man and conversely, animus is the inner imaginative image of man held by a woman. Both are considered opposites within the psyche. The anima and animus have been represented throughout history by such figures as Aphrodite, Athena, Mary, and Apollo, Hercules and Romeo.

- At the College Art Association's annual meetings art historians give talks or participate on panels, and artists mutually debate contemporary issues. Both artist and art historian discuss new approaches to art theory, history and art.

${ }^{3}$ Jung understood the psyche as the 'totality of all psychic processes, conscious as well as unconscious' (Samuels 115).

4 As Carl Jung taught, the unconscious is subdivided into the 'personal unconscious' and the 'collective unconscious.' Unlike the personal unconscious, the collective unconscious has never been in consciousness, and is related directly to the phylogenetic, instinctual bases of the human race. Jung sees the personal unconscious as a repository of repressed,
} 
Motifs and ideologies that underlie 'the arts' are understood as originating from this common and unifying source of the collective unconscious. Jung taught that because archetypes are inherent in the collective unconscious of the mind, they are common to all peoples and all cultures. How do these patterned ideas within the collective unconscious become expressed and manifested within culture and artwork? These ideas become "manifest" via symbolism. The archetype is a psychosomatic concept, linking psyche and body, instinct and image. Thus, as Jungians believed, cross-cultural symbols of transcendence, ${ }^{5}$ such as symbolic and artistic representations of the anima-animus, are manifestations of these universal archetypes that emanate from the psyche and the collective unconscious.

Jung taught that the anima or animus isolated by itself is inefficient, but when these opposingforces are joined together, then the psyche becomes a realm of wholeness, health and ultimate happiness. The process of this synthesis of opposites Jung called 'Coniunctio. ${ }^{6}$ In art and myth, the ideal of malefemale integration has often been exemplified through the ideal and image of the coalesced anima-animus often seen as divine androgyny. In this sense, androgyny is seen as a condition of perfection. Over the centuries, in certain cultures, this ideal of divine androgyny has been used as a metaphor of spiritual perfection, harmony, health, and bliss.

Each chapter of this thesis examines how one of three world traditions has differently and similarly expressed this theme of divine androgyny through its art and culture. The tribal Dogon of west Africa, the ancient Tantra of India and William Blake's European mysticism all express the central importance of this imaginative ideal of divine androgyny for realizing spiritual rapport and ultimate happiness.

Although the 'New Art History' is receptive to a Jungian approach to the analysis of visual art, this major new direction within art history does not readily embrace a Jungian interpretation of the visual arts. Some art historians have viewed a psychoanalytic approach to art history as problematical and

infantile, and personal experiences-faded memories, which rests upon the universal collective unconsciousness, which is seen as collectively containing ideas that transcend time-space and all entities.

${ }^{5}$ The word 'transcendence' is derived from Latin and means to 'go beyond.' For the purpose of my thesis, transcendence means to go beyond mundane perception, growing toward a realization of higher perception.

6 "Coniunctio is an alchemical symbol of a union of unlike substances; a marrying of the opposites in an intercourse which has as its fruition the birth of a new element. This is symbolized by a child that manifests potential for greater wholeness by recombining attributes of both the opposing natures" (Samuels 35). 
frivolous. As Jack Spector explains, “. . . [The] Jungians have studied . . the symbols included in [the] occult and [in] mystical art of all ages. Their unhistorical approach . . . and their indifference to material context have made their work uninteresting to most art historians" (56). Currently, there is an apparent disparity of Jungian psychoanalytic thought within academia. Jungianism is embraced in disciplines such as art therapy, but it is not embraced in all other areas. A Jungian psychoanalytic methodology applied towards the study of the visual arts, however currently marginalized, will produce interesting conclusions concerning the understanding of the Transcendent Function ${ }^{7}$ in art.

According to Jung, the original state of a person's psyche upon birth is a condition of psychological health and wholeness. As we journey through life, this integrated wholeness becomes differentiated and fragmented. Expressed in this way, the achievement of conscious psychological wholeness and happiness may be regarded as the goal or purpose of life. Jung used the word "wholeness" as connotative of psychological integration, balance and completeness, and is seen as a qualitative rather than a quantitative achievement and condition.

Jung's favored symbol for the representation of this ideal of psychological harmony and wholeness was the ancient symbol of the mandala ${ }^{8}$ (see Image 5). Jung interpreted the mandala as a great symbol of psychological wholeness, and of Individuation." Individuation is the word used by Jung to indicate a psychological process towards a consciousness of psychological wholeness and happiness. Jung saw the mandala as symbolically representing the reconciliation or 'coniunctio' of all opposites within the psyche, not just the harmonizing of anima-animus opposites.

While Jung's visual metaphor for psychological balance, integration and wholeness was the mandala. many cultures have employed the very ancient metaphor of male-female unison, for representing individual and cosmic harmony. Thus, in some world cultures, the motif of divine androgyny is not only a

\footnotetext{
${ }^{7}$ Jung taught that the Transcendent Function made possible the task of linking man and God, or a person and their higher reality or ultimate potential by way of symbolism. such as in art. Through symbolism. the Transcendent Function can enable one to more nearly realize psychological wholeness and happiness. Jung considered the Transcendent Function to be the most significant factor in psychological processes. He believed that its intervention into one's psychological processes was due to conflict between opposites such as the ego and shadow or anima and animus.

${ }^{8}$ Mandala is a Sanskrit word meaning 'magic circle,' which refers to a geometric figure in which a circle is squared or a square encircled (the uniting of the opposites of the circle and square). Mandalas can express cosmic wholeness, which is how they have been viewed in various traditions.

${ }^{9}$ Individuation is defined as a person's becoming themselves, whole, individual and distinct from others-or distinct from collective psychology_but also having a good relation to these (Samuels 76).
} 
reflection of the archetype of the reconciled anima-animus, but is also reflective of Jung's ideal of the integration of all opposites into an ultimate wholeness and thus absolute bliss. Therefore, an artwork depicting the male-female in union is often a metaphor comparable to Jung's meaning for the mandala.

This thesis reveals that at least three unrelated artistic traditions have employed this particular metaphor, of the fused male-female opposites, as representative of the idea of this divine state of ultimate harmony and happiness. Through support from corresponding mythologies, philosophies and religions, the cultural intents of these three artworks have been to encourage a contemplation of this higher perception of "reality" via their symbolic imagery. These three artworks seek to guide the viewer down a contemplative path, which leads to the achievement of spiritual bliss via the imaginative realization of psychological wholeness.

(1) The African tribal carving called Seated Couple (Image 1 \& 2) reflects Jung's idea of the reconciled anima-animus and thus represents an ideal of transcendence and spiritual wholeness within an indigenous culture. (2) Representative of an Eastern tradition, the Hindu sculpture called Lovers (Image 3) likewise reflects the allied anima-animus and Jung's ideal for transcendence. (3) William Blake's illustration titled Satan Watching the Endearments of Adam and Eve (Image 4), being representative of a Western tradition, also reflects this ideal of Jung's coalesced anima-animus.

Jung's theory should not be seen as hetero-centric; the anima-animus is an attitude within the mind, not an aspect of our biology. According to some Jungians, since every person has an originally androgynous or bisexual psyche, same-sex lovers can experience a romantic wholeness in fundamentally the same way as heterosexuals. Therefore the interrelation of these male-animus and female-anima principles, according to some Jungians (Jackson), operates within homosexual relationships, as it essentially does in heterosexual ones.

Such an archetype as the divine androgyne and the integrated anima-animus is found to be common among differing cultures that have developed over the centuries unaccustomed to one another. The broader implication is that Jung's archetypes, often portrayed within the visual arts, are familiar to all cultures because these universal themes, such as the reconciliation of male-female opposites, originate from humankind's collective unconscious. 
Within the next three chapters, I will examine the three artworks above-mentioned. Since art history has not readily applied a Jungian viewpoint towards the interpretation of the visual arts, it is my hope that this thesis will encourage more thought in this area among more art historians as well as among those interested in the appreciation of art.

In regard to presentation, I should mention that the MLA format has been used. Numbers given in parenthesis within the text refer to the page numbers of cited works.

Finally, I wish to note that all illustrations are computer-scanned images. As such, I felt it was more accurate to label them throughout as "Images," rather than as "Figures." 


\section{THE SEATED COUPLE SCULPTURE}

In June of 1999, I traveled to New York City to visit the Metropolitan Museum of Art to view the

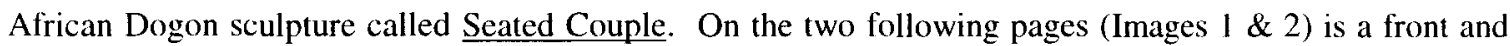
rear view of this sculpture. At the museum this masterpiece is prominently displayed in the museum's central room of the collection of The Arts of Africa and Oceania. As I approached this sculpture, I began writing my initial impressions. This section contains a brief description of my first impressions of this sculpture.

From a distance, as I approached the Seated Couple, this statue looked like a composite of twins. The theme of sameness or twinship is immediately thought of when the sculpture is viewed from a significant distance. Male-female variance only becomes evident as one approaches closer to this statue. While examining this sculpture, I understood the theme of twinship as an important and central Dogon ideology conveyed through this artwork. I can see how curiosity might invoke the following question of a viewer. Is this twin couple male-male, female-female or male-female? It is only upon closer inspection, and thereby the noticing of the male figure's penis, that my initial curiosity was resolved: this artwork appears to be a male-female twin couple. Upon close and prolonged examination, this central theme of twinship seems to expand to also include another important theme-a motif of dialectical tension between sameness and difference. This dialectical tension between similarity and difference seems to be exhibited as a complementary attribute for the couple. This pairing seems to suggest that opposites-such as malefemale-need each other to be functional and whole. The figures are identical yet different. It seems as though perhaps the sculptor has tried to stress that each figure is simultaneously identical and different and that each would be incomplete and thus diminished, without the other. In reflecting on my first impressions, I can see how most viewers of this Dogon statue would likely conclude that the idea of sameness and difference exhibited in this male-female couple is a central and important idea within Dogon thought. The torsos and limbs are extremely columnar, which seems to have been a very important stylistic element for the sculptor. Four humanoid figures that help to support the stool seem to be very important. Their bodies are buckled, with their joints bent under, supporting the weight of the predominant and central couple. 


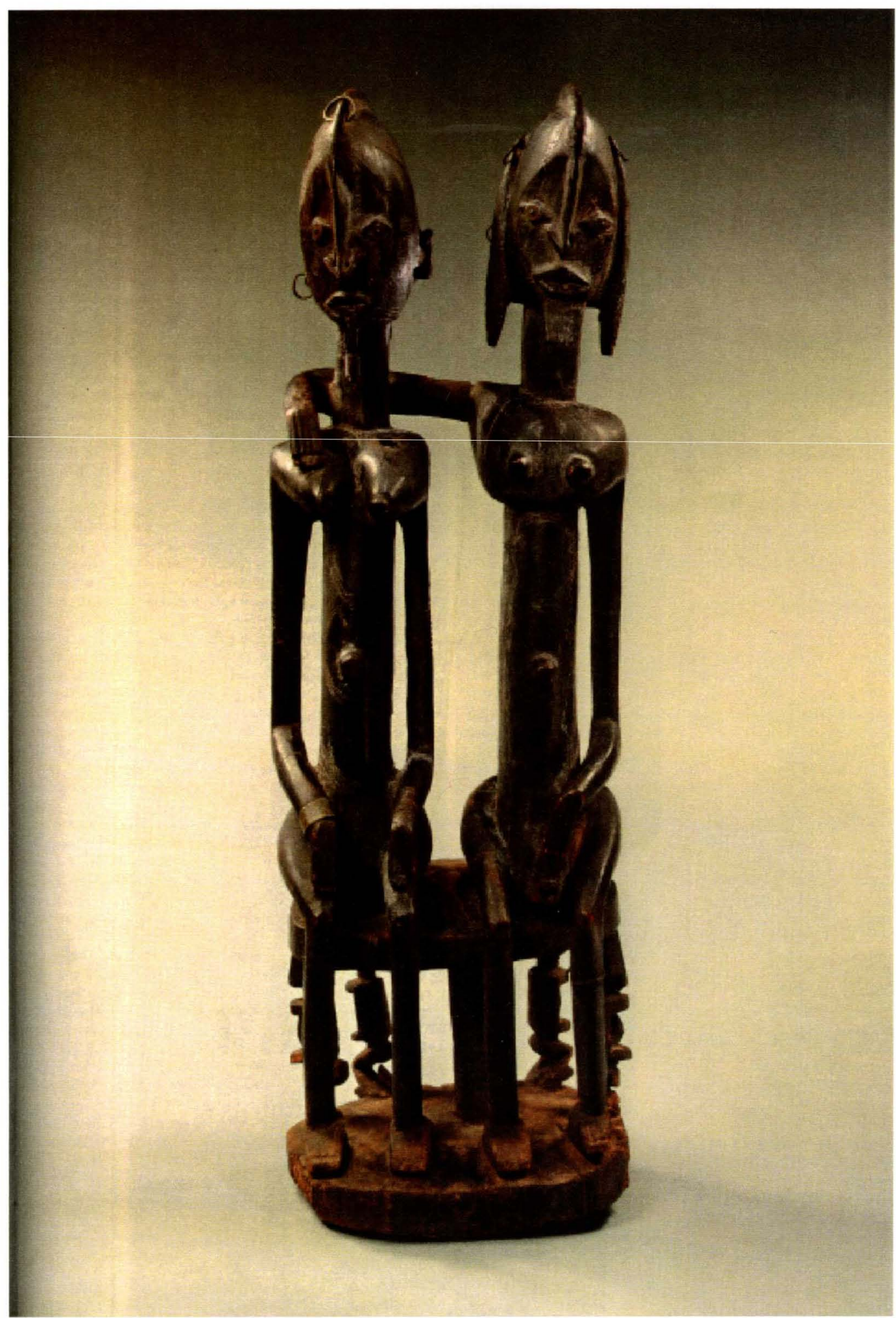

Image 1: The Seated Couple or Primordial Couple. 16th-20th century. Mali, Africa. Wood with pieces of metal.

Source: $\quad$ (Ezra, African 31) 


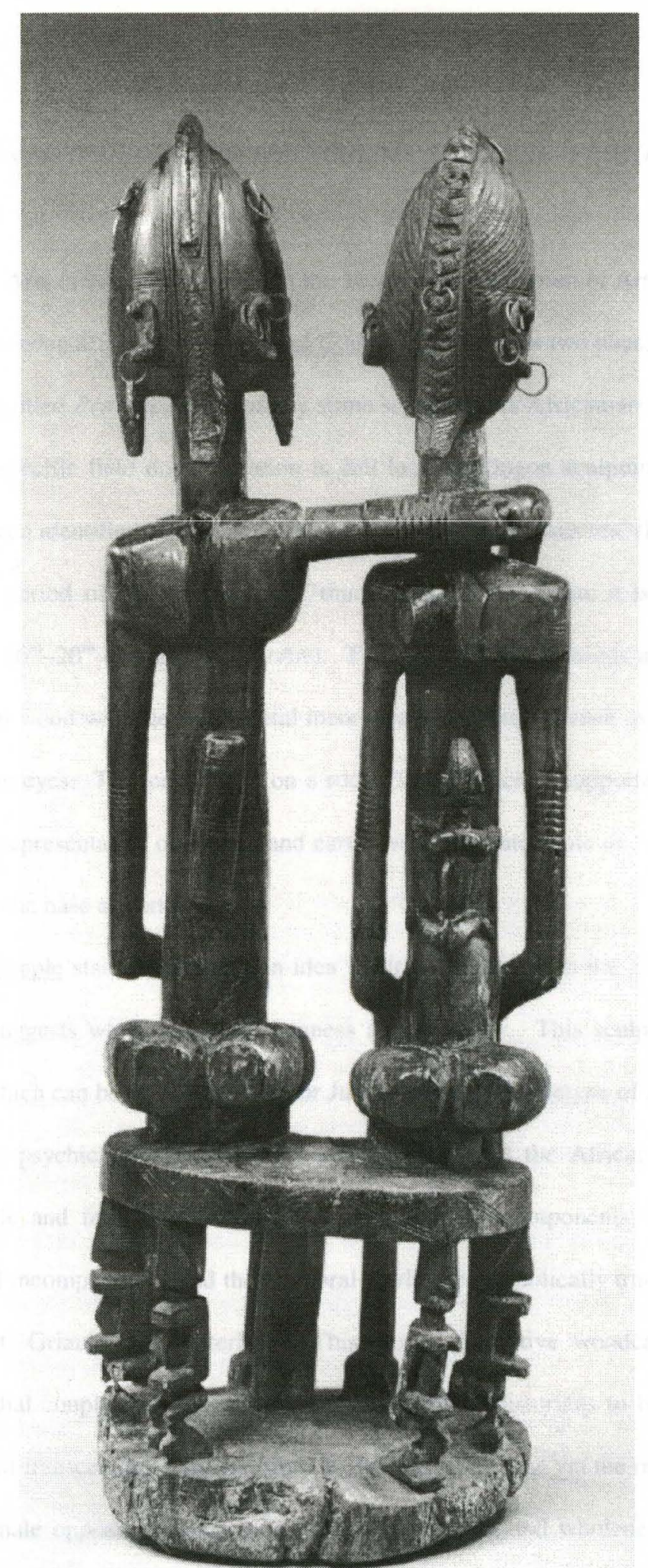

Image 2:

The Seated Couple or Primordial Couple. Rear view Source:

(Ezra, Art 65) 


\section{CHAPTER I}

AFRICAN DOGON MYTHOLOGY AND THE SCULPTURE OF THE 'PRIMORDIAL COUPLE'

Housed in the Arts of Africa Collection at the Metropolitan Museum of Art in New York City is an African Dogon-tribal wooden sculpture titled Seated Couple (see previous two pages-Images $1 \& 2$ ). This sculpture also has been titled Primordial Couple by some scholars. As African-art historian Kate Ezra has pointed out. although specific field documentation is still lacking, Dogon sculptural couples, such as this one. have commonly been identified by Western scholars as 'primordial ancestors' (Ezra, Art 65).

Although the period of the production of this artwork is uncertain, it is believed to date from sometime between the $16^{\text {th }}-20^{\text {th }}$ centuries (Ezra, Art). This $\underline{\text { Seated Couple stands approximately } 29 \text { inches }}$ high and is carved from wood with pieces of metal incorporated as features such as earrings, hair-rings and elements composing the eyes. This couple sits on a round stool, which is supported by four figures. The stool is believed to be representative of heaven and earth, with the center pole or "cosmic tree" connecting the seat as heaven with the base as earth.

This Seated Couple statue represents an idea for transcendence via the archetype of male-female consolidation, which suggests wholeness, completeness and harmony. This sculpture reflects an idea of androgyny as divine, which can be seen as a guise for Jung's universal archetype of the consolidated animaanimus or female-male psychic principles. A fundamental belief of the African Dogon people is that opposites, such as male and female, are temporal and incomplete components: by contemplating their amalgamation, spiritual incompleteness and the temporal world are symbolically transcended (Ezra, Art and Pacific; Flam; DeMott; Griaule and Dieterlen). This Dogon figurative woodcarving, also sometimes referred to as "primordial couple," is believed by many African-art historians to be representative of this particular Dogon idea of transcendence and spiritual health and wholeness via the reconciliation, union and integration of male-female opposites. Definitions of spiritual health and wholeness found within Dogon mythology are similar to Jung's definition of psychological health and wholeness because like the Dogon, Jung believed that the female principle-or what he called the anima, and the male principle—or what Jung 
called the animus, must be consciously reconciled and integrated into a condition of psychological androgyny for achieving spiritual harmony.

Many Dogon-art historians have stated that this statue exemplifies some of the primary functions of men and women in the tribal Dogon society of Mali in Western Africa. Within the imagery of this Seated Couple, the female figure supports a baby on her back while the male has attached to his back a hunter's or warrior's quiver. The man's embrace emphasizes his societal role as progenitor and protector but also suggests the woman's role as mother and nurturer. These themes, found in the sculpture of many sub-Saharan African peoples, serve to reinforce cultural stereotypes that strengthen the tribe's social organization and potential for survival. The columnar forms that are similar for the two figures, along with the horizontal components that connect them together, suggest that the life roles of men and women are complementary. The Seated Couple's "attenuated limbs and torsos, balanced frontal orientation and elongated angular figures reflect common stylistic features found within the art traditions" of many of the populations of the African Western Sudan (Ezra Pacific 64). Ezra describes the Seated Couple in the following way:

The characteristics and gestures of this seated couple illustrate Dogon beliefs about the nature of men and women and their mutual dependency. The figures are portrayed seated side by side, their balanced, frontal poses emphasizing virtually identical forms. Their elongated bodies have similar abdominal scarification and attenuated limbs, and their faces bear identical arrow-shaped noses. The figures are adorned with similar coiffures and jewelry, [with] the man's beard offset by the woman's cylindrical lip plug. The man's right arm wraps around the woman's shoulder, linking the two figures, while other gestures underscore their differences. The man's right hand rests on the woman's breast, while his left hand points toward his own genitals. Similarly, the man carries a quiver on his back while the woman carries an infant on hers. These details stress the ideal male role in Dogon society as progenitor, protector, and provider and the ideal female role as childbearer and nurturer ... (O'Neill 74).

A theme most prevalent in this style of statuary is the motif of "simultaneous unity and separation of male and femaleness." This theme suggests a complementary interdependency between the sexes. Similar to her above-description, Ezra writes in Art of the Dogon, the following:

Vertical and horizontal forms are linked together in this figure to create a tightly structured composition that makes evident the interdependence and symmetry of men's and women's roles in Dogon society. The two figures are almost identical. Their columnar torsos and thin cylindrical arms and legs are connected by the horizontal bridges created by the base and seat of the stool .... The man's chest echoes the woman's breasts, and in both figures the shoulder blades and buttocks are treated as equivalent forms .... The light tracing of incised scarification marks on their faces and torsos further unites the two figures, as do the metal rings they wear in their hair and ears.

The gestures and attributes of both figures are also equated . . . The close equation between male and female expressed in this sculpture refers not only to the dynamics of Dogon 
family life, but also to the pairing of male and female beings in Dogon mythology and the sexual duality the Dogon see as a spiritual component of every individual (Griaule. 1947b) (65).

This mythic idea of the complementary and interdependent coalition of the sexes, and the theme of divine androgyny, are found to be common in African culture. Lynn Mackenzie states that, "the belief that women and men (Dogon hermaphrodites), were once merged beings appears in several contexts in African art" (19. 20). As Jack Flam points out, the Seated Couple's central theme of the "simultaneous unity and separation of male and femaleness" as complementary and interdependent is a theme found common to African thought and this symbolism is "intense in the Sudan." Ezra also makes reference to how these Dogon themes in art are found to be often common to many African religious traditions. She writes, " . . This group [the Seated Couple] contains the iconographic elements of sculptured couples from all over Africa ..." (O’Neill 94). Flam and Ezra write the following:

. . . [the couple] as presented in this [the Seated Couple] and other Dogon twin-figure sculptures, [incorporates] a series of principles of interaction [that] unites and separates the twins; and [it seems] these ideas have their visual equivalent in the structure of the sculpture. It is precisely this special kind of simultaneous unity and separation of male and femaleness, so common to African thought and so intense in the Sudan, that was found in . . . these Dogon twins (Flam I46).

. . . these themes [of the complementary differentiation of the sexes through the] use of iconographic forms are found in the sculpture of many sub-Saharan African peoples and serve to reinforce cultural stereotypes that enhance the group's social organization. These elongated, angular figures, with their attenuated limbs and torsos, and balanced, frontal orientation, reflect stylistic features common in the art traditions of many peoples of the Western Sudan ... (Ezra Pacific 64).

The early twentieth century initial Western interpretations of Dogon sculpture have been reassessed over recent years, and these early interpretations have been claimed by some scholars to be problematic. Louis Desplagnes-around 1900-conducted the first Western interpretations of Dogon art. More Western interpretations emerged in the 1930's and 40's from the research conducted by French anthropologists Marcel Griaule, Germaine Dieterlen and their followers.

Even with so much research already conducted on Dogon art, there is yet further research presently being conducted into the meanings of this art and mythology. Relative to the many criticisms that have focused on these first Western interpretations of Dogon art, this reinterpretive and ongoing research has produced a central debate over the actual function and meaning of Dogon sculpture. Those earliest and socalled "problematic" interpretations from the early 'Griaule School' suggest that Dogon sculpture literally 
illustrates Dogon mythology and is thus dependent upon mythology. Under these initial interpretations, the 'Griauleans' have viewed the actual and explicit function and meaning of Dogon sculpture as being unequivocally dependent upon and resultant of particular mythological events found within Dogon cosmology (DeMott 30-6; Flam; Roy). On the other hand, the more recent reinterpretive school of thought suggests that Dogon art and mythology are independent of one another. According to this newer interpretation, Dogon sculpture merely and directly symbolizes important ideologies paramount within Dogon culture. The reinterpretive school claims that although these central Dogon ideologies may be expressed simultaneously in myth and art, both art and myth are independent of one another, because they are separate methods of cultural and ideological expression (DeMot 30-6; Flam; Roy).

Although this chapter is concerned with the Jungian archetype of the amalgamated anima-animus as seen reflected in the Seated Couple statuary, this leading debate between the Griaule School and the reinterpretive school, needs to be given recognition. Since this debate has been so central to the Western interpretation of Dogon sculpture and ongoing research, and especially since this debate surrounds the ultimate function and meaning of the Seated Couple, I believe it is necessary to present the basic profile of this debate.

Michael Kan gives us some reason for this ongoing debate and why the earlier Western interpretations of Dogon art have been problematic:

Interest in a culture's art form does not always insure the development of sound and objective scholarship, and after African art was "discovered," a number of opposing and equally erroneous schools developed, each with its own bias. Some were concerned only with esthetics and looked only for the African "masterpiece." Others were obsessed with the religious and mythical context of African objects to the exclusion of the myriad of other cultural contexts in which they played an important role. Inevitably, since anthropology was still in its infancy, most scholars, whether scientists or art historians, were severely limited by ethnocentric bias (76-7).

Ezra gives form to this debate and presents us with these two diametrical persuasions of thought. Within her discussion, Ezra reveals what she considers biases within the Griaule School, and presents us with why the earlier Griaulean interpretations of Dogon art have been questioned by later scholars:

Other than Griaule and his collaborators, few anthropologists and art historians have conducted field research on Dogon art (Imperato 1971, 1978a, 1978b; N'Diaye 1972, 1976), and it has been necessary to rely upon the work of the Griaule School. Some authors have attempted to reinterpret the material from different perspectives. such as structuralism or formal analysis (DeMott 1982; Flam 1970). Others, most notably Jean Laude (1973), have borrowed more fully from the Griauleans, applying the vast body of literature on Dogon culture to objects whose form, material. 
subject matter, or context of use suggest an association with some aspect of the Dogon system of thought as presented by them...

Several authors have criticized such [Griaulean] interpretations of Dogon art because [these interpretations] . . lack the evidence provided by detailed analyses of the context in which the object was used (Roy 1983; Ezra 1988). Walter van Beek's article on the functions of figurative sculpture ( $p 58$ ), based on his own recent field research, describes the situations in which they are used. It provides a view of Dogon sculpture that differs in many ways from previous interpretations... (32).

Barbara DeMott in her work on Dogon Masks presents the reader with what seems to be a very credible argument for Dogon art being independent of Dogon mythology. Through presentation, discussion and analysis of the contrast between the Griaule School and the newer reinterpretations, DeMott discredits the notion that Dogon art is dependent upon myth. She gives credence to the idea that Dogon art is independent of, but parallel to, mythology. It is within chapter 3, titled Dogon Sculpture, that DeMott addresses and clarifies this central debate of whether Dogon sculpture is dependent or independent of Dogon mythology. She exposes problems within the earlier Western interpretations of Dogon sculpture and presents the reader with a forthright and logical methodology. Because of her credibility and since her work paraphrases and quotes from a selection of Africa-art scholars, I have decided to draw upon her writing for much of this chapter.

DeMott proposes that "The image of the primordial couple [as seen in the Seated Couple (Images $1 \& 2)] \ldots$ is one of the most important and well-conceived themes in Dogon sculpture" (28). Michael Kan also cites the overall central importance of the Seated Couple to Dogon culture and cosmology. He presents us with some idea of how central and encompassing this idea of the primordial couple is to Dogon religious thought and culture:

Through the writings of Marcel Griaule. one is led to believe that the complex mythical system and cosmological beliefs of the Dogon play an enormous role in their art and institutions. The myths have many variants but one of the most common ones begins with Amma, the Creator-God who cohabits with Earth to produce the primordial ancestors of man. the bisexual twins called Nommos. These half-human, half-serpent water spirits were born with supple, unjointed limbs. The Primordial Couple is represented in sculpture as seated on a sacred stool, supported by four additional sets of Nommo twins representing the four heads of the clans from which all the Dogon descend (78).

DeMott suggests that the Griaule school's original viewpoint, that "Dogon sculpture illustrates myth, must be dealt with since it reflects a bias" (31). She suggests that such bias has influenced the many slanted writings that have propagated inaccurate and prejudiced interpretations of Dogon sculpture. DeMott notes 
that there is a "controversy over its [the Seated Couple's] meaning" and that clarification of its symbolic intent is needed (31).

DeMott contends, "The [Griaule School's] belief that Dogon sculpture may be interpreted by oneto-one correlations with mythic events is based in the misconception that art serves to illustrate myth"

... [Jack] Flam is able to present a more successful interpretation of the theme of the primordial couple because he recognizes the independence of sculpture and myth as media of cultural expression. Flam reveals that Dogon sculpture is not a direct translation of mythology. but rather a metaphorical visual statement of Dogon ideology. He interprets the primordial couple as a statement of sexual archetypes which express "this special kind of simultaneous unity and separation of male and femaleness so common in African thought and so intense in the Sudan" (Flam 1970: 146). He supports this interpretation with visual data. He notes (1970: 146-47) that the left arm of the female is shared visually by both figures, and the right arm of the male which wraps around the shoulders of the female unifies the couple in both visual and symbolic terms. According to Flam, the special formal rhythm seen in the arms and the torsos of the figures emphasizes their visual unity and expresses metaphorically the interdependence and complementarity of the sexes prominent in Dogon thought ... (31).

DeMott suggests that rather than literally illustrating the narration of any mythological event, Dogon sculpture symbolizes, through standardized form, structure and compositional patterns, ${ }^{1}$ those central ideologies considered of great importance to Dogon culture, such as the dual or bisexual nature of every person's spirit. She suggests that this is the simple function and particular meaning of the Seated Couple: to convey the central and important idea that the consolidation of the sexes creates harmony and thus maximizes the individual and tribe's health and survival. The chief theme of the Seated Couple is the idea of the reconciliation and integration of male and female components within the spirit or mind of every person. Dogon myth and tradition proposes that such an alliance of female and maleness, within the mind, propagates not only individual and societal but even cosmic harmony (Ezra, Art and Pacific; Flam; Griaule, Journal; Calame-Griaule).

According to DeMott, the most accurate method for interpreting Dogon statuary is from a structuralist approach, which is a style whereby the sculptors consistently use "ideal, static, and timeless forms" as an unchanging vocabulary and language for expressing divine and static meaning. In addition, unlike the Griauleans. DeMott contends that Dogon sculpted figures, such as the "primordial couple," do not represent characters from mythological events:

\footnotetext{
${ }^{1}$ By adhering to a particular "structure, form and pattern" DeMott infers that the sculptor faithfully adheres to a standardized, unchanging style and uses this as a language with which to communicate important ideologies. The use of numerology is considered an aspect of this consistent patterning, structure and form.
} 
.. Dogon sculpture depicts a limited number of ideal types or themes, which express meaning by pure, fully realized forms and compositional relationships. These themes relate meaning without reference to specific moments in time or space . . . The figures are not narrative since they do not make gestures that tell a story. Therefore, Dogon sculpture uses ideal, static, timeless forms to express meaning, and figures represent ideal human types rather than specific mythic personalities engaged in story-telling actions (32).

In addition to DeMott, according to such scholars as Flam, Ezra and Christopher Roy, the most accurate and plausible approach by which to interpret Dogon sculpture is from a perspective of structuralism and form analysis. DeMott paraphrases Flam as she discusses how Dogon sculptors have used unchanging forms and patterns of symbolism within consistent relational compositions to give credence and power to sacred themes through these highly consistent and traditionally formed sculptures. As seen in the Seated Couple, formal and consistent artistic style suggests "unity and balance between the sexes."

Flam's analysis of the theme of the primordial couple demonstrates that Dogon sculptures may be interpreted successfully as statements of ideology on the basis of their formal qualities. Such formal analysis reveals certain meanings . . . It shows that Dogon sculptors employ systems of interlocking horizontal and vertical volumes as well as qualities of stasis and symmetry to create an image of unity and balance between the sexes ... (32).

Within Dogon figurative sculpture, a central theme exemplified by this sculptural structure and form is the theme of the amalgamated union of male and female opposites. This union can be see as an equivalent to the theme of androgyny: ". . Dogon carvings appear consistently to combine male and female qualities into a single image. This thematic condensation is apparent not only in the primordial couple but also in the frequent representations of female figures carrying male attributes (DeMott 32)."

In the particular instance of the many Dogon figurative sculptures categorized under the genre heading of "primordial couple" (see Images 20,21, 22 \& 23) it is through this structuralism and form that the Dogon artist creates "an image of unity and balance between the sexes." DeMott and her colleagues suggest that this is a central theme found in the genre of Dogon carvings exhibiting male-female couples. DeMott explains in great detail the codified formula and configuration found within figurative sculpture seen in the primordial couples. She suggests that by understanding how Dogon artists have used an established vocabulary and language of structuralism and form, "it is possible to demonstrate how the primordial couple represents a complete image of human and cosmic order:"

[The Seated Couple or primordial couple] ... reveals the formal and symbolic devices that are found in varying degrees in all Dogon figural sculptures. The Dogon artist consistently carves within a repertoire of standard themes and their variations .... The Dogon artist uses the same formal and symbolic devices to suggest meaning in all sculptural subjects. These [devices] include 
a few simple gestures, numerology, and symbolic spatial diagrams as illustrated in the Primordial Couple (36).

.. the narration of mythic stories provides the inconographer with an understanding of the meaning of spatial relationships, numerology, and other symbolic associations that are a part of the artist's vocabulary. Dogon myths illustrate the concepts of both cosmic and human social order through the images of male and female pairs, three-part vertical and four part horizontal arrangements, and their combination in checkerboard formations, as well as through numerology emphasizing multiples of four. Using these concepts, it is possible to demonstrate how the primordial couple represents a complete image of human and cosmic order (35).

DeMott again paraphrases Jack Flam, who discusses how the primordial couple exemplifies the unity of the sexes, and how the formulated use of patterned carving "parallels, but does not illustrate" themes within Dogon myth:

As Flam (1970) suggests, the theme of the primordial couple implies the unity of the sexes by an image of pairing. This concept is underscored dramatically by the gesture and visual rhythms of the interlocked figures. In terms of Dogon numerology, the number two corresponds to the ideal of pairing. It parallels but does not illustrate other themes of pairing described in the myths of the Nummo (35).

Here again it is suggested that through form and structure, and being independent of mythic narration,

Dogon artists have created an ideal of reconciliation and harmony between the sexes via "a stable and symmetrical linkage of the two human figures."

The ideal of sexual unity is presented through visual means by the intermeshing of vertical and horizontal volumes which compose the couple and form the checkerboard patterns so common in Dogon myth and material culture. The arms and the shoulders of the seated couple may be read as a horizontal plane, which is joined to the horizontal plane of their buttocks by their elongated torsos. This arrangement of forms in the bodies of the figures represents a stylistic preference of Dogon carvers for depicting the human body as horizontal planes linked by columnar volumes. The interlocking of horizontal and vertical in the composition of human figures creates a checkerboard effect conceived three-dimensionally as the interpretation of solids and voids. It creates a stable and symmetrical linkage of the two human figures (35).

As DeMott states, the theme of "sexual unity regarded as cosmic completion" is conveyed through the use of numerology as part of the style that DeMott calls "structuralism and form." DeMott concludes at the end of the following quote that the particular use of numerology implies a message of male-female balance and unity between the sexes:

Numerology and its associated meanings also function in the sculpture to express sexual unity regarded as cosmic completion in Dogon thought. It is represented in the three-and four-part forms and rhythms in the seated pair. Their bodies are divided into three parts: shoulder and arms, torso, and buttocks and lower limbs. Each body part marks a change in orientation from horizontal to vertical to horizontal. The hands of the seated pair form a three-part rhythm created by their legs when the figures are viewed frontally. These three-and four-part alternations of hands and lower limbs enliven the frontality and symmetry of the figures and, in turn. the rigidity of the figures calls attention to the symbolic numerology brought into play by the formal arrangements . . . The interlocking of the three-and four-part cosmic diagrams parallels the interlocking of the horizontal and vertical volumes in the seated pair, and their portrayal in three-and four-part rhythms. Both imply a similar message of balance and sexual unity (35-6). 
Within the artist's formulated vocabulary, the number three is representative of masculinity, while four is representative of femininity. Once again. this use of established patterns of carving complements and parallels Dogon mythology, but Dogon sculpture does not narrate mythic events. The artist's complex systemized vocabulary conveys "the ideal unity of human couples," and through the symbolism of numerology and form "the human and cosmic levels. . . in a creative state of balance and harmony" are depicted.

The full complement of spatial symbolism and numerology expressed in the mythic stories of creation are depicted in the visual forms of the primordial couple. The numerology of forms depicts in three dimensions the symbolic associations of numbers in myth. Verticality, vertical movement, and masculinity are represented in the three-part vertical arrangements of forms. Horizontality, radial movement, and femininity are represented in the four-part. radial arrangements of forms. The interlocking of three and four, vertical and horizontal, vertical movement and radial movement, which constitute cosmic completion and the checkerboard image, correspond to the interlocking of the figures by gesture and sexual identity to represent the ideal unity of human couples. Together, the human and cosmic levels are depicted in a creative state of balance and harmony (DeMott 36).

DeMott underscores the complementary relation between Dogon art and myth, but nevertheless stresses the independence of these two dimensions. She states that the understanding of "both have served as the basis for the successful interpretation of the symbolism found in Dogon sculpture," such as found in the Seated Couple.

The primordial couple has been shown to reveal much of the same meaning as the stories of the Nummo pairs. This common meaning includes the concepts of creativity, pairing, and culturally productive action. The concept of creative order is expressed at its most basic level in art and myth by the interlocked vertical and horizontal cosmic diagrams and their associated qualities of sex and movement. It is further elaborated in myth by the stories of the Nummo's deeds. while it is further elaborated in visual art by the depiction of ideal formal relationships and human archetypes identified by their attributes and gestures. Although neither art nor myth serves to illustrate the other, the concepts that are common to both have served as the basis for the interpretation of the symbolism in Dogon sculpture (36).

Whether we perceive the Seated Couple from Griaule or DeMott's perspective, in the final analysis, both interpretations recognize the same central Dogon theme reflected by the Seated Couple. Both of these diametric interpretations, concerning the meaning of Dogon sculpture, champion the Dogon ideal that an amalgamation of the sexes leads to spiritual health and harmony, which ultimately leads to cosmic order. Dogon figurative sculptures carved in the same method as traditionally stylized primordial couples convey the same central message that spiritual health and happiness can be achieved by reconciling the sexes into an integrated whole. As DeMott, Flam, Griaule and others have proposed, in the instance of the primordial 
or Seated Couple statuary, both Dogon mythology and sculpture reveal the central theme of an amalgamation between male and femaleness. This coalescence not only brings individual harmony, but also ultimately brings cosmic harmony. DeMott paraphrases Flam to underscore this central theme:

Since they [myth and sculpture] are both artistic developments in the same culture, Dogon scuipture and myth must reveal the same cultural viewpoint. In fact, both of these media appear to emphasize the description of an ideal human and cosmic order. On one level, this ideal of order is expressed in depictions of the proper relations of the sexes, which, as Flam recognizes, is one of complementarity and interdependence. This is revealed equally in the stories of the Nummo pairs and in the sculptures combining male and female figures... (33).

It is evident that Dogon mythology, and those ideologies conveyed within Dogon statuary, communicate a deeply entrenched belief that humankind's soul is bisexual or androgynous. As both Dogon mythology and sculpture suggest, spiritual peace-of-mind, and ultimate world order are achieved through the amalgamation of the sexes. Dogon art and mythology suggest that man-or the male element-is incomplete without woman, just as woman - or the female element-is incomplete without man. Similar to Jung's teaching of the theory of anima-animus, Dogon art and myth likewise suggest that each person conceals within their spirit or psyche a male aspect and a female aspect as chief components to their soul. Denial or dissention from one's true psychic androgynous nature produces unfavorable outcomes, while acceptance and inner alliance of one's intrinsic androgynous nature produces harmony and bliss.

Dogon mythology portrays the development of world order by the narration of a creation myth, which has been well-documented in many of the publications of Griaule and his followers (Griaule and Dieterlen 1965). In this myth, the first offspring of the creator Amma is the pale fox. The pale fox is an unnatural and socially disruptive creature born without placenta and thus robbed at birth of his female counterpart. As Calame-Griaule (1965: 101) notes, the pale fox is a symbol of oneness, or male without his female complement, and the myths of the pale fox demonstrate the chaos resulting from this imbalance of male and female qualities .... In contrast, the proper working of the cosmos, the balance of male and female, is illustrated in the stories of the four Nummo pairs, symbols of social productivity, who were the later offspring of Amma [God]. The Nummo are androgynous couples who each embody the proper balance of the sexes (CalameGriaule 1965:94) .... Dogon mythology thus associates social order and creativity with the harmonious balance and unity of male and female qualities (DeMott 33).

Jung taught that archetypes, or patterned themes within the psyche, are universal and timeless. Jung considered the anima-animus, or female-male psychic opposites, to be one of the most compelling and central archetypes. It is suggested that 'archetypes' are universal and timeless because they emanate from the collective unconscious, which is conceived as a vast reservoir of ideas and knowledge collective to the mind of all of humanity. Jung believed that the reconciled anima-animus is a common theme found 
symbolized under differing guises in all cultures throughout history. This Jungian viewpoint explains how the common and central Dogon theme of the coalesced male-female opposites, exemplified in many Dogon figurative sculptures, is a timeless and universal emanation of the archetype of the integrated anima-animus.

The Scated Couple sculpture (Image $1 \& 2$ ) reflects this archetype of the harmonized animaanimus. Furthermore within Dogon tradition, this sculpture symbolizes a fundamental idea of transcendence through the contemplation of spiritual wholeness via the reconciliation and union of these male-female or anima-animus psychic components. A fundamental belief of the African Dogon people is that opposites, such as male and female, are temporal and spiritually incomplete, and that by contemplating their unification, the temporal world and spiritual incompleteness are symbolically transcended. The figurative woodcarving, titled Seated Couple is believed by most African-art historians to be representative of this particular Dogon idea of divinely fused opposites. This "Primordial Couple" is also seen to be metaphoric of cosmic harmony. Such contemplation and acceptance leads one towards spiritual harmony and ultimate happiness. Like the Dogon, Jung believed that the anima-or female principle, and the animus-or male principle, must be consciously reconciled, integrated and balanced into a state of spiritual androgyny for achieving psychological health and wholeness. 


\section{THE LOVERS BAS-RELIEF CARVING}

In June 1999 I traveled to Ohio to visit the Cleveland Museum of Art to view a Hindu sculpture titled Lovers, (see Image 3). Unfortunately this sculpure is displayed high above eye-level (see Image 14), but the museum likely has placed this sculpture exceedingly high because originally this carving would have been positioned high upon the exterior wall of a Hindu temple. As I approached this work, I hegan writing my initial impressions and this section contains excerpts from these notes.

From a great distance, and at first glance, the human figures portrayed in this carving appear as a

singular body or mass of surging energy. As I approached this bas-relief carving, one of my first impressions was that this sculpture contained body parts that seemed to be swirling or fusing. Only upon a closer inspection did I realize that this composite is a depiction of two figures making love. From an extended distance and straight-on view, the upper-half of this carving looks like a swirling mass of energy, and therefore gave me the impression of a mandala with asymmetrical rather than symmetrical components within. (It is obvious that this sculpture was intended to be viewed from a straight-on angle, because the side views are unattractive (see Image 15).) The foremost initial impression is that the woman and man interdependently are drawn to one another--they are unable to resist an overwhelming power of attraction. It seems that because of their fusing bodies, each is an integral part of the other. This seems to be a theme. As if each has found themselves in the other or found bliss in experiencing the other, and as if each is the other's missing half, this man and woman appear to be fulfilled to the ultimate. This partaking in bliss seems to be another theme. Their minds are lost in an experience of celestial and transcendental bliss. Another theme of this artwork is total engrossment. This couple is lost in the moment-they are lost in the experience and absorption of one another. They are intently drawn to one another. The woman appears to be much more ecstatically drawn to the man. who seems to be in control of his encounter. The woman seems to be controlled by her passions—of being enticed wildly to the male. The composition suggests that they are bound-up in their extraordinary world, which takes place more within their minds than their bodies. They are experiencing within their emotions "heaven"-an experience of mysterious and paradisical mental intoxication. Their experience seems not to be reliant upon place or time, but reliant upon a state-of-mind 
or attitude, which of course is natural to the passions of romantic love. His facial expression seems plain or stoic, while she has an exceedingly satisfied smile on her face.

From an anatomical viewpoint, it may be somewhat confusing as to which figure the foremost upper left arm and hand belongs. The upper left foremost arm-the one caressing the female's breastslooks like it could be her arm. However, from an anatomically functional standpoint, this arm belongs to the man. Perhaps this symbolically suggests that because the couple is fused or fusing, they do not know where their bodies end or start. This may symbolically suggest that they are so integrated both sexually and emotionally, that there is no distinguishing between the male and female's individuality. ${ }^{1}$ This upper left foremost arm may be symbolic of bisexuality or androgyny because symbolically this arm appears to be both his and her arm and hand caressing her breast. If I view the composition with an expectation of anatomical correctness, then the figures' anatomically incorrect arm and hand feel problematic and irritating. But, if I alter my expectation towards a more symbolically oriented perception, then the anatomically incorrect arm makes excellent expressional sense, and it no longer feels problematic or irritating. Understanding this possible symbolic intent causes me then to like the anatomical "incorrectness" of the arm.

Her left hand is holding something, which may be a flower. This seeming flower appears to have its stem growing out of the female's loincloth, which clings to her vaginal region. Symbolically, the flower gives an impression of growing from her vagina. I believe that because this flower seems to be growing from the woman's genital region, the symbolic intent may be to give a metaphoric meaning to her vagina as sacrosanct. The man very delicately and respectfully opens the female's loin cloth and reveals the uppermost opening of her vagina ${ }^{2}$ as if to suggest that he is revealing something sacred-and perhaps he reveals, through symbolism, his destiny towards an ultimate and final bliss-of where his fervid passions are leading him.

She is actually feverishly pulling on his hair. She has a hand-full of his hair, using it as a handle with which to direct his head. There is a balance of energy between the two. By revealing and giving

\footnotetext{
${ }^{1}$ See Jack Flam's quote on page 14 for comparison with a similar consideration of the Dogon Seated Couple.

${ }^{2}$ This is easily seen on the actual work, but can not be detected on the scanned image (Image 3 ).
} 
himself access to her genitalia, he is asserting himself, but she balances his assertions by forcefully grasping his hair as a sort of handle with which to direct the position of his face.

Perhaps customary to medieval Hindu India, their clothing seems similar, as if it could be interchangeable. Their accessories also are similar, which, along with their clothes, gives the two an androgynous air. What seems most odd is that the sculptor has given the female a fullness of erotic anatomical attributes, while any fullness of anatomical erotic attributes on the man's part is lacking. Rather, the male's slim form has an air of adolescence sensuousness and innocence. It seems as if the sculptor has invested more time and concern in carving her anatomy, which, of course, simply could be because he found the female anatomy more compelling. The carving of the female is much more erotic, curved and more "ideally" proportioned than the male. The carved figure of the male seems rather out of proportion. Her curvilinear body is very elegant and attractive--very aesthetic and erotic. Her figure seems classical in Indian tradition. Her large breasts and excellent figure, together-combined, gives her figure a simultaneously erotic and Neoplatonic sense. His figure does not have this "classical" effect, although the damage of the man's shoulder may have destroyed some of the originally intended classical anatomy. It should be noted that any symbolism originally portrayed in the lowest section of this bas-relief is now lost. because much of the original lower part is broken-off and missing.

Perhaps originally having been symbolic, the man's genitalia is missing. Anatomically, there should be some sort of protrusion, however insignificant, to represent the man's penis but there is no sign of male genitalia. The ornament between his legs, hanging from the belt, may be a symbolic reference to his penis. Also, his left leg seems to be positioned so that it is seen from an angle- -with a side view of his buttock - which may be partially broken off at the edge.

The issue of the "androgynous" arm and hand leaves me with a question: what was the artist's intention when he instilled this seemingly esoteric attribute into the conception? I feel very drawn to contemplating this work because it strikes within me a deep cord of an idea for a mysterious, eternal and divine bliss, certainly the central symbolic message of this sculpture. 


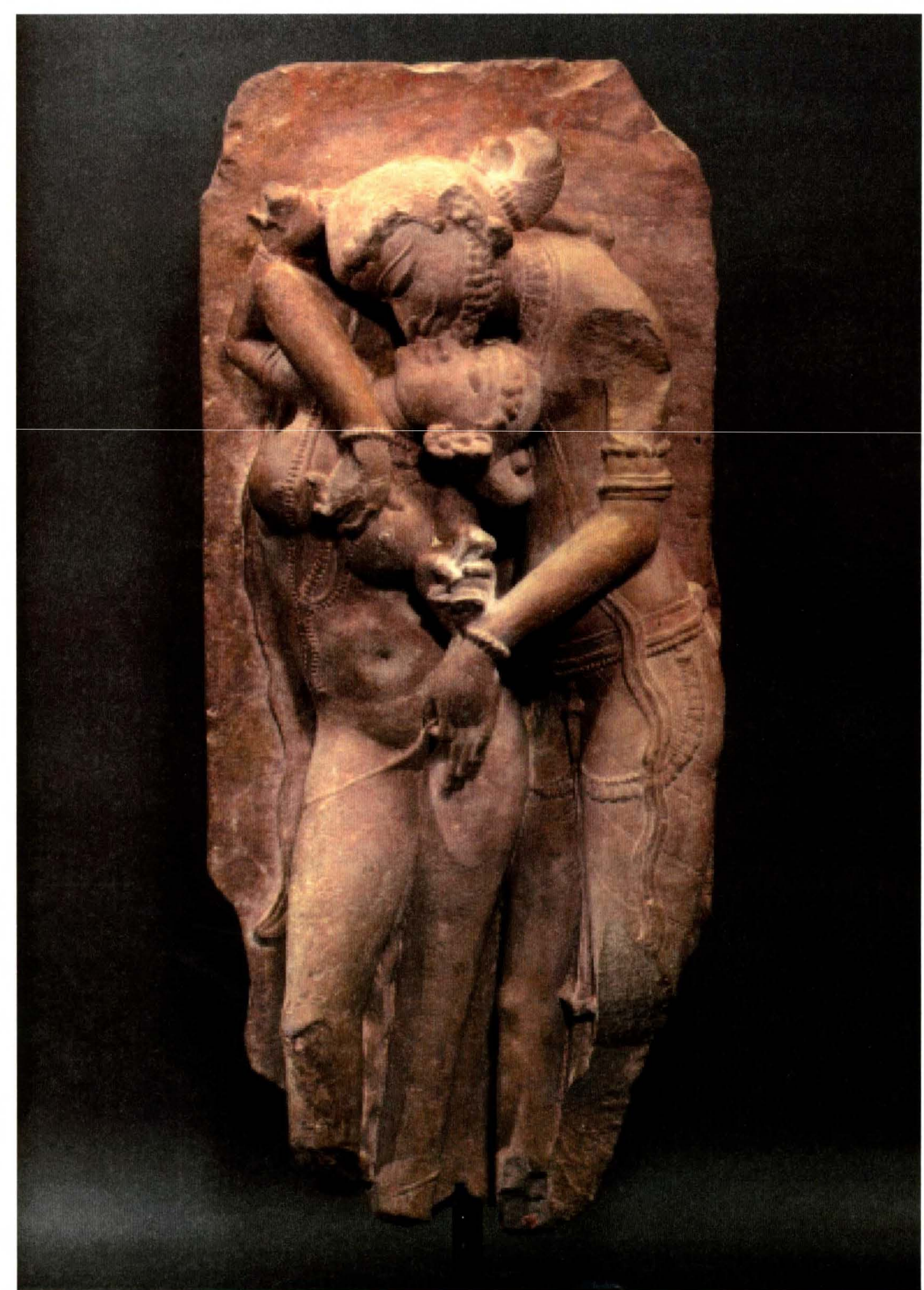

Image 3: $\quad$ The Lovers or Loving Couple (or generally called mithuna). 11th century. Khajuraho, Madhya Pradesh, India. Sandstone.

Source: $\quad$ (Brown 48) 


\section{CHAPTER II}

TANTRIC MEANINGS OF THE EROTIC MITHUNA SCULPTURE OF INDIA

Within the collection of the Cleveland Museum of Art is a bas-relief figurative carving titled. Lovers (see Image 3, the previous page). This rust-colored sandstone sculpture is believed to have originated from the exterior walls of one of the many Hindu Temples in the Indian town of Khajuraho in the former medieval province of Madhya Pradesh (see map, Image 16). But it is not known from which temple this Lovers statue originated. This work is believed to date from the eleventh century medieval Chandella Dynasty and represents the typical "Khajuraho style" of erotic figurative carving commonly referred to as "mithuna," "maithuna" or "amorous couple." Anapurna Garimella gives the following description of this mithuna statue:

The sculpture presents us with lovers in a moment of rapture . . . Both bejeweled and exquisitely dressed, each bearing the idealized marks of their gender, these figures are from the walls of a Chandella royal temple in Khajuraho, a town in north central India. He is taller, bearded, and represents perfected masculinity. She fits snugly into his space, offering herself up to his intentions. Her full breasts and curvaceous hips represent archetypal femininity and idealized beauty... (Brown 48).

As we shall see, this artwork symbolically can be seen as an "emblem of bliss" and spiritual wholeness within the Tantric tradition. These figures, being deeply absorbed in one another, offer the viewer an imaginative way to spiritual bliss and ultimacy. Through the rapture of erotic passion, time-space is symbolically and imaginatively nullified. Stanislaw Czuma has written the following in describing the

\section{Lovers:}

The two figures are totally engrossed in each other ... [This] sculpture represents a typical Khajuraho style. The couple is shown in an embrace, kissing, while the male, whose masculinity is emphasized by a beard and mustache, is about to disrobe his partner . . . Her passion is emphasized by the rapid twist of her body and the upward turn of her head. This rapid movement and the almost angular position of the limbs, which emphasizes the movement, are characteristic of the Khajuraho sculpture (Cunningham 142).

Through its symbolism, the Lovers reflects, within an Eastern culture, an idea for transcendence by way of the concept of the Jungian archetypal reconciliation of the animus-anima or male-female psychic principles.

\footnotetext{
3 "Both mithuna and maithuna mean coupling or pairing in general and sexual congress in particular" (Feuerstein 139).
} 
These mithuna sculptures depict a male and female either in various stages of uniting, through a loving embrace, or in united copulation. By contemplating this embracing couple, seen as a symbol of malefemale amalgamation, it is intended that the viewer's imagination be transcended towards an understanding of spiritual wholeness, harmony and bliss. Comparable to Dogon belief, the Indian Tantric tradition has perceived the idea of the reconciliation of opposites as being metaphoric of surpassing spiritual incompleteness and the temporal world. According to the ideology of Tantrism, the sacred act of sex and copulation unites and symbolically reconciles male-female opposites, which nullifies polarity and temporality, and symbolically facilitates the mind's transcendence to a realization of spiritual wholeness, harmony and bliss. In India, these erotic mithuna figurative sculptures are believed, by some scholars, to be representative of this particular Indian Tantric concept of the amalgamation of all opposites and thus the imaginative realization of ultimate spiritual health, wholeness and happiness.

Through this idea of the alliance of opposites, Tantric definitions of spiritual harmony and Jung's definitions of psychological health. wholeness and happiness are similar. As in Tantric philosophy, Jung believed that the female principle-or what he called the anima, and the male principle—or what Jung called the animus, must be reconciled, and balanced for achieving ultimate spiritual harmony and happiness.

Medieval Hindu sculpture was primarily employed to decorate the exterior walls of temples. Because a great variety and abundance of this erotic sculpture was produced, these Hindu temples had an exuberance unequaled in any other art. The erotic mithuna became a very popular genre of sculpture within medieval India. Annapurna Garimella and Stanislaw Czuma discuss the context in which the mithuna genre of sculpture, such as the Lovers, would have been exhibited.

This statue [of the Lovers] was originally placed high on the temple walls with numerous other figures. The starkness of this loving couple's activity would have been mitigated by the presence of hundreds of lovers, animals, gods, rulers, dancers, and mendicants . . . Even among representations of erotic love, degrees of sexual explicitness mark the status of lovers-divine couples are more clothed, while genre scenes of mortals present a wider exploration of human sexuality. In a museum setting, this statue is placed at eye level, but on a temple exterior it would be subject to the vagaries of changing light and choice of placement on the walls (Brown 48).

The function of many Hindu sculptures of the medieval, or Hindu dynasties period (from the sixth century onward) was to decorate the exterior walls of temples. A great profusion and variety of sculptures gave those monuments an exuberance unequaled during any other period . . . . The temples of Khajuraho in Madhya Pradesh, built under the auspices of the Candella dynasty (tenth to eleventh centuries) . . . are the best known monuments of erotic sculpture . . . The amorous couple is a very ancient and popular theme in Indian art. During the period of the Hindu dynasties. however, this subject takes on an especially erotic connotation to which various factors contributed. 
Some see it as the symbolic union of the soul and the divine stimulated to a degree by Tantric rituals and practices, others speculate that it was the result, or product, of a contemporary society. Practices such as temple prostitution and the popularity of the love-manual, Kamasutra, must have greatly contributed to the interest in this subject matter (Cunningham 142).

Although much has been written about these Indian erotic carvings, most scholars acknowledge that any definite meaning for the mithuna genre is unknown. Nevertheless, the very fact that medieval Hindu social conscience allowed the cultural use of these erotic sculptures suggests that the mithuna's traditional significance was once well understood. Although their original and authentic meaning is now lost, the erotic sculpture from Khajuraho and other surrounding towns has been ascribed various meanings over the years by scholars.

As Urmila Agarwal writes, "to understand the true meanings of these sculptures we must judge them from past standards rather than the present one, taking into account the traditions and beliefs of the time" (259). Czuma suggests: "The Hindu temple was a favorite community meeting place and these sculptures inspired and instructed the populace and were admired by thousands of viewers. The monuments which represent the erotic genre of sculpture, [were] very popular in medieval India" (Cunningham 142).

I believe it is important to present a variety of the most recurring interpretations for the meaning of the mithuna. Although scholars probably never will know, with absolute certainty, the true and original meanings of these erotic sculptures, we nevertheless can contemplate several of the most recurring interpretations theorized over the years.

Alain Danielou and other scholars have offered their readers several of the most common theories (Agarwal; Danielou; Dehejia; Deva; Krishan; Tripathi). Many of these theories seem closely related and appear to be extensions of one another. The following are a few of the most commonly cited interpretations of erotic mithuna sculpture.

(1) Some scholars have suggested that these erotic carvings were created to protect the temples from lightening and other natural and man-induced disasters. Some sects of Indians believed that because demons were prudish, erotic displays would give protection against the 'evil eye. ${ }^{44}$ Thus, it may have been believed that these erotic figures would produce a favorable effect, by repelling evil forces and thus making

\footnotetext{
4 "From the idea that the eyes of envious gods, demons and monsters had ... power to harm, developed the terrifying belief that the human eyes emit a ray which under certain circumstances could be highly dangerous to the person on whom it was focused-particularly if the onlooker was malicious or jealous" (Maple 822).
} 
sacred temples safe from earthquakes or protected from being dismantled by enemies. According to this particular belief, the more obscene the statues, the more effective their magical potency would be. It was believed that the thunder Goddess would be ashamed to come close to such erotic postures and that because Indra, the lord of the thunderbolt was such a great voluptuary, he would be disinclined to destroy these sexually stimulating temple images (Agarwal; Dehejia; Deva; Krishan; Tripathi).

(2) Another theory that Danielou has labeled "Touchstones of Renunciation" suggests that the mithunas were used for the testing of devotion. If the worshippers could pass into the sanctum without becoming affected by the erotic images, then their minds truly would be focused on the Godhead enshrined, and not on carnal and earthly matters. "The man who renounces the pleasures of love [meaning lust] must do so in full knowledge .... Thus erotic sculptures are the touchstones by which the man of renunciation can test if his will to chastity is genuine" (Danielou 88).

(3) The next theory, which Danielou has labeled "The All-pervading Divinity," can be summed-up as follows. Hindu scripture insists that there is no aspect of the world, animate or inanimate in which we should not perceive an imprint of the divine. To do so would be a dangerous attitude of dualism, ${ }^{5}$ where God becomes shut out from some aspects of existence. As Danielou puts it, "if in looking at any aspect of Nature, we cease to see the Divine underlying it, we follow the dangerous path of dualism. The obscure regions where we no longer see God may expand and gradually cover the whole horizon." Thus the mithuna may have educated that every aspect of the world and life falls under the divinity of creation; every aspect of the world is divine, even the most common or carnal practices such as the necessity for the reproduction of the species.

(4) Another interpretation of mithuna, can be identified as "Psychological Education." This theory suggests that an underlying sexual curiosity can cause one's mind to become overly preoccupied with worldly and lascivious fantasies. Thus perhaps the graphically erotic sculptures were intended to address and put to rest one's sexual curiosities so that a potential worshipper could then have the full mindfulness

\footnotetext{
${ }^{5}$ This particular use of "dualism" views the temporal world as partly divine and partly profane. According to some sects, because all aspects of the world are divine, any tendency toward dualism is an incorrect and dangerous attitude.
} 
and focus to move onto preoccupations with more divine matters. The erotic sculptures run the gamut from gentle playfulness to unusual positions in copulation, including coitus between animals and even bestiality.

(5) The theory of "Drawing Attention" suggests that the erotic sculpture may have been used as bait to draw worshippers into the temple setting. For those particular people who are most interested in worldly and sensuous interests, the erotic sculpture may have been intended to draw these people into spirituality via the temple mithuna. Some scholars suggest that perhaps it was hoped that in examining temple eroticism. these potential worshippers would be captured by the sacred dominion of the temple. Eventually such people might be overcome with devotion, forget the erotic figures, and sit in contemplation of the Godheads enshrined.

(6) The mithuna also has been presented as "The Symbol of Creation." In this way, it is suggested that the Indians of long ago very likely considered these carvings to be useful religious means of "creationist" education. Tantra suggests that polarity is the root of all tangible, time-space existence and that such polarity exhibits itself in our biological world as male and female forms. The mithuna or erotic coupling can be seen as representing polarity and thus, symbolically, the dynamism of creation.

(7) Likewise and conversely, the mithuna also can be seen as symbolically representing the divine, non-temporal and non-polar existence before the creation of time-space. In reference to this theory, Danielou labels erotic mithuna sculpture as "Erotic Emblems and the Syllable AUM." The syllable 'AUM' is an ancient auditory symbol that eastern monks (such as Tibetan monks) chant as a catalyst for more masterfully attaining the mindfulness required in achieving a superincumbent imaginative realization of the all-encompassing, specular nature and ultimacy of absolute reality and God. Symbolically, these mithuna carvings can be secn as metaphoric of the elimination of polarity through the sexual unification of male and female opposites. It is suggested that the attraction between all polar principles is the source of cosmic life and that in our manifest world these polarities are forever trying to reintegrate into the original divine and ultimate whole. Thus according to Tantra, lovemaking and sex are seen to be metaphorical of this reconciliation and reintegration of all polarities, and a return to original "perfection" and ultimacy. Hence, lovemaking and sex are seen to be representative of the divine, and the supreme bliss of the reconciled and integrated soul, and to a oneness with everything and God. Since polarity represents the tangible world and 
non-polarity represents a divine and ultimate reality beyond physical tangibility, then sex is seen as symbolizing the rejoining of polarities, offering a contemplative idea for non-temporal and transcendental

bliss. Danielou writes the following:

The Chhandogya Upanishad[ $[$ ] speaks of the symbolic equivalent of erotic images and the mystic syllable AUM. 'The union of the sexes is equivalent to the mystic syllable AUM. When the two sexes come together, each fulfils the desire of the other (Chhand. Up 1,1,6).' The commentary of Shankaracharya adds: 'This satisfying is the nature of the union of the sexes . . . In the world a man and woman unite. They both enjoy the pleasure that results from their union, they fulfil [sic.] each other's desire. So does the syllable AUM, through the conduction of its elements, fulfil all desire' (Danielou 88).

(8) Another theory, being an extension of the two immediately above, perceives the mithuna as "The Image of Supreme Bliss."

Beyond all manifestation lies the state of limitless Joy. Seekers of realization ever aim at dissolving into this indivisible Bliss ... . Nothing can give us an adequate idea of Eternal Bliss. Yet the keenest of our pleasures [sexuality] is naturally taken as its symbol. The act of love is [often] chosen to represent that ultimate state where the individual and the Universal ['Universal' meaning God as encompassing everythingl are no longer separate (Danielou 87).

This theory espouses that suffering ceases when our world of manifestation returns to a spiritual ultimate reality that is void of fission as seen in polarities and time-space existence. Contemplatively, "beyond all manifestation," beyond tangible existence, and all polarities, one is lead to the ultimate reality, a realization of divine bliss.

The theories cited above for the erotic mithuna temple carvings are only several of the most recurring theories. The mithuna has a long and ancient history within Indian culture (Moon 227; Agarwal 259; Dehejia 98). As Danielou suggests, no doubt an even greater extent of documents concerning the meaning of Tantric-Hindu erotic symbolism could be discovered upon investigation. As mentioned, some of these theories concerning the mithuna's significance overlap one another. Regarding these erotic sculptures, it appears unlikely that a singularly precise meaning would have been continually understood, but rather, just as symbols intrinsically have connotative meaning rather than denotative meaning, it seems most likely that the meanings of these erotic carvings would have had, over the centuries, a fluidity and multiplicity of meaning.

Originally, the loving-couple motif must have had a close tie with the liturgical life of the agricultural year and with the rites connected with the cultivation of domesticated animals and

\footnotetext{
${ }^{6}$ The sacred religious Hindu texts are called the Upanishad. This word translates as "sitting near one's spiritual teacher (guru) in a mood of devotion' (Mahoney 147).
} 
plants. Gradually, however, a number of related beliefs emerged: that the heaven that awaits heroes and pious sages is full of celestial maidens whose love is their reward; that the male deity resident in the icon of a temple, itself a reflection of heaven on earth, should be attended by a corps of female dancers, or hierodules; and so on ....

Eventually, the motif developed as one of the primary systems in Tantrism . . . Tantrism is an elusive term to define, and . . [it sometimes refers] to a specific group of teachings that emphasize the cosmic male-female polarity, or to those practices that use this polarity in ritual in order to bring a spiritual release from rebirth ... (Moon 227).

However Westerners or modern Indians may currently perceive these graphically erotic mithuna sculptures, does not mitigate the great likelihood that the old Hindu builders and worshipers saw within these erotic statues powerful religious symbols to be approached with reverence.

The Lovers mithuna (Image 3) is reflective of the ideas cited within the last three theories, given here as 6,7 and 8. With all three being jointly related, these theories-"The Symbol of Creation," "The Image of Supreme Bliss" and "Erotic Emblems and the Syllable AUM"-are all reflective of Jung's theory of the reconciliation and union of the anima-animus. The Lovers is likewise reflective of Jung's theory of the amalgamated male-female opposites.

I have found Georg Feuerstein's book titled Sacred Sexuality; to be one of the most comprehensive and superlative sources for upholding this particular premise that the Indian mithuna, such as the Lovers, is representative of the bliss and original wholeness that comes with the fusion of opposites. Feuerstein's Chapter 10, The Jewel in the Lotus: The Lessons of Tantrism, focuses particularly on the interpretation of the Tantric mithuna (copulation) ritual as a ceremony for imaginatively transcending polarity and temporality, and for realizing The Ultimate ("Ultimate" meaning God), in which everything-all polarities-are One.

Feuerstein discusses in depth the Tantric beliefs of the sacredness of sexuality. He distinguishes within Tantra the two differing outlooks of 'left-hand path' and 'right-hand path' ideologies. These two belief systems are similar but incompatible views. The 'left-hand path' and the 'right-hand path' are two contrasting interpretations for how sexuality is to be religiously viewed and ritualistically utilized. The right-hand path views sexual intercourse strictly as symbolic for imaginatively realizing the reconciliation of all opposites, while the left-hand path concerns itself more with the physiological sensations of sex. As 
Feucrstein cites, the (right-hand path) mithuna ritual is celebrated in one's own body-mind, which contains

both the masculine principle and the feminine principle:

We carefully distinguish between two fundamental forms of Tantrism- the ieft-hand path (vamamargal) and the right-hand path (dakshina-marga). On the left-hand path, which has attracted the greater attention in the West, the core ritual of sexual congress is taken literally. By contrast. on the right-hand path it is understood in purely symbolic or allegorical terms, as was the case with the love mystics of Europe and the Middle East, and no sexual contact [is] involved. Rather, the maithuna ritual is celebrated in one's own body-mind, which contains both the masculine cosmic principle, called Shiva, and the feminine cosmic principle, known as Shakti (136).

Feuerstein discusses how a central theme in Tantric ideology is the diametric relation between the male and female polarities and how these polarities symbolically represent the creation of time and space, and how the reintegration of male-female principles (androgyny) metaphorically represents the original, divine and ultimate non-temporal reality:

The divine is envisioned as being polarized into feminine and masculine, respectively called [in the Hindu variety of Tantrisml Shakti and Shiva . . . Together they form a transcendental/immanent continuum, which is inherently supra conscious and blissful .... On the ultimate level of existence, which we call divine, Shiva and Shakti exist in inseparable conjunction. There is no trace of otherness in this state of wholeness, or purna. Without forsaking this primordial wholeness, Shiva and Shakti together initiate the play (lila) that leads to the creation of the universe (140-41).

Psychiatrist Stanislav Grof has labeled the modern practice of Neo-Tantric ritualistic sex as "Oceanic sex: ... the aim is to experience the loss of one's own boundaries, a sense of fusion and melting with the partner into a state of blissful unity. The genital union and orgasmic discharge, although powerfully experienced, are here considered secondary to the ultimate goal, which is the reaching of a transcendental state of union of the male and female principles... (152)." It might here be noted that right-hand path Tantric sex is spiritually based, and therefore "... when the [right hand] Tantric practitioners become overly concerned with the generation of physiological effects, they risk vulgarizing what is essentially a spiritual discipline."

Sacred sexuality is not about energy play or sexual intercourse per se but about communing or identifying with the ultimate Reality, the Divine. This is a decisive distinction. For the spiritual practitioner, sexual intercourse is an opportunity to encounter the sacred dimension, which surpasses the individual man or woman just as it surpasses all other manifest forms. The bliss arising from the sexual union is not orgasmic pleasure but the innate delight of the primordial Androgyne, the ultimate Male/Female, the God/Goddess (198).

Some scholars suggest that the mithuna, as can be seen in the Lovers, is representative of right-hand path ritualistic sex and the transcendental effects. Following below is a description of a man and woman sharing in Tantric right-hand path ritual sex. They feel the distinction between male and female dissolve, and experience the sensation of being "as one." 
Just before the peak of orgasmic release, we stopped, relaxed, and became still once more. We repeated this pattern several times, and then something totally unexpected happened. Suddenly we both seemed to be floating in an unbounded space filled with warmth and light. The boundaries between our bodies dissolved and, along with them, the distinctions between man and woman. We were one. The experience became timeless, and we seemed to remain like this forever. There was no need to have an orgasm. There was no need even to "make love." There was nothing to do. nothing to achieve. We were in ecstasy (144).

Feuerstein discusses how the human mind or psyche is bisexual and how this psychic polarity allows the union of male-female opposites, via right-hand path ritualistic sex. to induce a spiritual reality or bliss. Right-hand Tantra is concerned with allowing the ritualistic sex practitioner to experience the original divine and androgynous wholeness as bliss, via the imaginative amalgamation of opposites. Because Jung believed that the soul or mind was fundamentally androgynous, and by understanding the psychological process he called individuation as striving for one's original mental wholeness, certain portions of the following material by Feuerstein sound Jungian.

It is this bisexuality of the psyche, understood as a multilevel system of energies, which underlies the Tantric path (sadhana). Without this psychic polarity, the approach of the Yoga, of the serpent power. . . would be impossible, for this type of Yoga understands the process leading to the ecstatic union between Shiva and Shakti in purely psychological terms.

Broadly speaking, the goal of Tantrism is to recapture in one's individual case the transcendental fusion between Shiva and Shakti [male and female]. Finite existence-which, in concrete terms, means human life-is characterized by fission. The Tantric practitioner seeks to achieve a state of bodily and mental harmony that mirrors and attunes him or her to the transcendental equilibrium (samarasa), or original wholeness, which is experienced as bliss . . . (142).

... [The Tantric practice of] Kundalini-Yoga[ $\left.{ }^{7}\right]$ is internalized sacred intercourse. Everything that happens in right-hand Tantrism between male and female occurs here in the subjective space of consciousness. This is thought possible because the divine masculine and feminine principles are not only macrocosmic but also microcosmic realities. In the language of modern psychology, our body-mind is androgynous (150).

This Tantric perception of the sacredness of sexuality can be found reflected in the mithuna, such as in the Lovers sculpture. The Tantric ideology of the reconciliation and integration of all opposites, especially male-female opposites, is similar to Jung's concept of the reconciliation and balance of all opposites within the psyche. Jung taught that a person reaches their ultimate psychological health, wholeness and happiness if they consciously embrace and synthesize all opposites within their psyche. Jung believed that one of the most influential and consequential set of opposites within the psyche is the anima and animus. Within the

\footnotetext{
7 'Kundali Yoga' studies and advocates the superlimation of sexual energy. This contemplative practice and ideology understands a long historical association between sex and spirituality, and propounds a body-and-sex-positive spirituality (Feuerstein 148).
} 
common genre of these erotic mithuna sculptures, the metaphor of uniting male-female opposites can be seen as a symbol for the coalescing of all polarities.

Like Jung, Tantrism taught that maleness and femaleness, when reconciled, leads to "the androgynous, original and ultimate reality of the psyche itself' (Feuerstein). Bliss is a natural outcome of male-female reconciliation, which is seen as representing the primordial and ultimate oneness with God that existed before the creation of time-space and the world of polarity. Feuerstein writes:

That primal state of wholeness or oneness, which the mystics claim to experience, is often depicted in Hindu iconography in the hermaphroditic $\left[{ }^{8}\right.$ ] figure of Ardhanarishvara [(see Image 30)]. The union between the male and the female principle, as the Tantric scriptures affirm, yields or is desire and bliss. It is desire when viewed from the level of manifestation, and bliss when realized on the level of absolute Being.

From an ontological perspective, the figure of Ardhanarishvara is a graphic depiction of the reconciliation of opposites aspired to by the mystics of all ages. It is a symbol of the perfect equilibrium that exists on the ultimate level, prior to all form and all space-time. From a psychological perspective, Ardhanarishvara embodies the androgynous reality of the psyche itself (142).

Within Tantric belief "the ritual of the mithuna, or sexual coupling, is the literal enactment of the fusion that exists on the transcendental plane between Shiva and Shakti. The man represents God; the woman, the Goddess. The purpose of their union is to realize the innate bliss and ultimate wholeness of the Divine (143)." This is realized through the contemplation of the return of all opposites to the original, harmonious and ultimate oneness of the divine.

As presented above, in India the medieval mithuna was a common genre of figurative temple art and is believed by many to represent the Tantric idea of realizing "The Absolute" ("The Absolute" meaning God). Lovers can be seen as a Tantric depiction of a sexual coupling. By understanding the Tantric righthand path ideology, it is easy to understand how this particular mithuna sculpture can reflect the Tantric view of the divine harmonization of Shiva and Shakti and male-female opposites. Lovers is metaphoric of the Tantric idea of achieving bliss, wholeness and oneness with God through the re-amalgamation of all opposites, which is represented simply by the re-integration of male-female or animus-anima opposites.

When erotic spirituality, or sacramental sexuality, is successful the gender distinctions on which it is based are suspended, for when there is ecstasy, all opposites coincide. There is no "I" and "Thou," no male and female. The original Reality is a symbiotic whole. The person who has

\footnotetext{
${ }^{8}$ The symbol of the hermaphrodite has different meanings within various cultures and contexts. As a symbol, some cultures have viewed the hermaphrodite as divine, while other traditions conversely have regarded it as diabolical.
} 
awakened to that Reality is thereby rendered whole. Sexual communion is a way of celebrating that wholeness (Feuerstein 199).

From which Khajuraho temple the Lovers bas-relief carving originated is unknown. Although some scholars might suggest that this sculpture was intended as an icon from Shaivism, ${ }^{9}$ both Tantrism and Shaivism have been mutually influenced by one another. As Benjamin Walker writes, " . . phallic or sisna worship, medieval Saivism and Tantrism, all centre around the worship of Siva and his consort, Sakti" (Hindu 407). As found in Tantric ideology, Jung's idea of the anima-animus also can be seen reflected in the nature of the Hindu god Shiva. Robert Zaehner writes:

In the full figure of Shiva . . . the male and female principles are united. and he himself is sometimes represented as half male and half female ... The significance of Shiva is that he is the reconciliation of all opposites: therefore he is both creator and destroyer, terrible and mild, good and evil .... Lingam [the phallus] and yoni [the female organ] together represent the totality of Nature and of all created existence (2367).

As found in Dogon mythology, a correlation to Jung's archetype of the anima-animus is found also within the Indian Tantric ideology of sacred sexuality. According to some Tantric teachings, the union of malefemale opposites exemplifies the idea that all opposites were originally integrated into an ultimate whole. Tantra suggests that for a person to be spiritually enlightened, they must understand, accept and embrace a reconciliation, reintegration and balance of opposites, especially male and femaleness. Tantra instructs that in God there is no differentiation, only a oneness, which incorporates all opposites. Feuerstein compares this Tantric theory of conciliated opposites to a Western source: According to the Gospel of Thomas, an early Gnostic text, Jesus is said to have taught that one enters the Kingdom of God "when you make the inner as the outer, and the outer as the inner, and the upper as the lower, and when you make male and female into a single one, so that the male shall not be male and the female [shall] not be female' (199).

The Chandella dynasty mithuna statue called Lovers, like the Dogon Seated Couple, represents an idea for transcendence via the contemplation of the reconciliation of the Jungian archetypal male-female or animus-anima opposites. Having origins in the Indian Tantric tradition, this sculpture is representative of an Eastern orientation. Similar to Dogon belief, the Tantric tradition has perceived the idea of the amalgamation of opposites as being symbolic of imaginatively surpassing the temporal world. Tantra ideology instructs that the sacred act of sex unites male-female opposites, nullifies temporality, and

\footnotetext{
${ }^{9}$ Shaivism is a belief that focuses on the worship of the Hindu god Shiva. 
symbolically facilitates the soul's transcendence into an experience of spiritual wholeness, harmony and bliss. In India, these figurative carvings, generally referred to as mithuna, are believed by some scholars to be metaphoric of this particular concept of exceeding temporality and realizing spiritual harmony via the contemplation of opposites. Tantric definitions of spiritual wholeness and bliss are similar to Jung's definitions of psychological health, wholeness and happiness. Just as in Tantric belief, Jung believed that the female principle-or anima, and the male principle-or animus, must be assimilated for achieving spiritual wholeness and happiness. 
In June 1999 I traveled to Boston. Massachusetts to visit the Boston Museum of Fine Arts to view an illustration titled Satan Watching the Endearments of Adam and Eve, by William Blake (see Image 4). This particular design, devised by Blake for an edition of John Milton's Paradise Lost, circa 1808, is one of a series of twelve different plates depicting scenes from Milton's poem. Very graciously, the museum's rare print room made this illustration available, along with other Blake watercolors, for my personal viewing. Upon seeing this artwork. I immediately began writing my first impressions. Within this section are excerpts from these notes.

This illustration is exquisite. Blake has paid great attention to detail; it looks as though a lot of time and thought has gone into this ink, and watercolor over pencil image. I believe that the overall exemplary composition and finish indicates that Blake meticulously conceived of the symbolism within this imagery.

The current colors appear to be problematic, however. They do not look saturated-all the colors in this composition look greatly faded. Relative to the other eleven illustrations within this series, the color in Satan Watching the Endearments of Adam and Eve appears faded, and the paper looks exceedingly yellowed. Within the color that can be seen in the roses, I can detect vestiges of mostly red. or the color rose, and also some blue. Yet, even after one hundred and ninety-one years this illustration. with its fading and decay, has a great impact of extraordinary beauty. It looks as if the blue and orange colors are least faded, while all the other colors seem to have faded exceedingly. The blue and orange colors could have been re-applied during the later nineteenth century. I can only imagine how much more striking this painting must have been when the colors were at their original saturation of 1808 . I should mention that details in coloring are obvious when viewing the original art, but unfortunately, the scanned image (Image 4) does not show, completely, these details of color.

Some of the leaves on the lilies at the bottom look like they had been colored red. Below them is a region of green. Purple is seen in Eve's bed of lilies, which almost looks like the mane of her hair. And the right section of this composition looks like it was once blue or purplish-blue. Interestingly, Adam's body 
has much more of the color red or orange in it than Eve's, which is likely due to Blake's use of color as symbolism. The 1949 museum catalogue suggests that Adam and Eve's bodies are gray and pink (Constable). Adam's body does look obviously much warmer (but pink?) than does Eve's. Perhaps their bodies each match the sky because the left side of the composition is charcoal gray, which would match the cool coloring of Eve's body, while the right side-with the sun-is orange, which would match the warm coloring in Adam's body. The 1949 museum catalogue states that the area of the sky with the sun is pink.

I would caution assuming that the current colors, as they appear, correspond exactly or even nearly to the original hues. The curator has suggested to me that some of the other illustrations from this 'Paradise Lost' series most likely were re-watercolored during the later $19^{\text {th }}$ century. Upon reviewing this illustration. I believe that Blake's use of color held a wide amount of symbolism. However, interpreting the use of color as symbolism would involve great research and perhaps assumptions and guesswork. I do not feel that this is necessary for this thesis. Without deeply researching Blake's use of color as symbolism I believe that I can successfully reveal, within this illustration, Blake's use of contour symbolism for representing the reconciliation of the male-female principles. The figures of Adam and Eve can be discussed directly because the ink contour lines have not faded.

A 1949 museum catalogue cites that Adam and Eve sit on nectarines! Clearly, this is not so. Certainly, what they sit on are not nectarines but most definitely roundly closed flowers. To my eye, they look like peonies, but there is much scholarship that has identified these flowers as stylized roses (Behrendt, Moment; Butlin \& Gott; Grant). They are likely Blake's conception of stylized tightly-closed roses. At first glance it looks as though Eve lies on her lengthy hair, but Eve does not lie on what appears to be her mane of hair. Consistently, throughout the other illustrations within this series, this same ornamentation appears, which is obviously a stylized mat of flowers-which I believe are stylized lilies. This same floral ornamentation is found to be consistent in the other illustrations, such as in Adam and Eve Asleep. Also, Christ stands on this same floral mat in another of the illustrations.

After inspecting all the other works in this series, I believe that Blake has greatly stylized the natural forms, such elements as the flowers and leaves. simply to help create greater compositional dynamism. It looks as though the rose leaves, with a zigzag contouring, have been stylized to better 
complement the rounded, curved form of the roses. This stylization of the leaves successfully creates a more dynamic composition. Perhaps Blake altered the natural contour of these leaves simply to create contrast and dynamism. It is plain to see that Adam wears a coronet of flowers and leaves around his head. This coronet appears to be made of a smaller version of the same type of flowers-supposedly roses-on which they lie. The leaves on Adam's coronet definitely appear to be the same as the leaves on the roses forming their bed.

Overall there is more detail in Adam and Eve than in Satan. This causes Adam and Eve to appear more beautiful than Satan does. Blake has rendered the serpent, which wraps around Satan. as a freakish thing. Satan's face and anatomy actually have an aspect of beauty, which is nearly as beautiful as Adam's, but the serpent-representative of Satan's inner pathologies—is rendered as his shortcoming-Satan's downfall into "ugliness." Those shadows that delineate Satan's musculature are placed incorrectly onto Satan's physique by Blake purposely, I believe. The gray watercolored contour shadows on Satan's body are anatomically incorrect. These faulty shadows make his otherwise beautiful, Neoplatonic-appearing musculature appear to be flawed, making Satan "incorrect." I believe this is symbolic of Satan's fall from psychological or spiritual "beauty" into "ugliness." Within Satan's anatomy one can distinguish that Satan has great potential for being beautiful, but because of Satan's pathologies, or evil, he falls short of perfect Neoplatonic and spiritual beauty. Satan is unaware that an aspect of himself, symbolized as his serpent, impedes his potential.

Most interestingly, there are detectable two lily buds wilting in the bottom center of the composition, below Adam and Eve; these lily stems are clearly in the center axis of the picture. They wilt onto Adam's hemisphere. In The Creation of Eve illustration, within the same series, there likewise seem to be lilies wilted and lying on the ground. (These details may be difficult to detect on the computer-scanned image (Image 4), but these details are clearly seen on the original art.)

My first impression is that this artwork conveys a theme of celestial engrossment and bliss. There is a theme of unity - or rather, near unity, but not absolute unity, because Eve's attention wanes as she glances out from the circuitous composition to notice Satan's presence. Theirs' is a psychic unity, whereby their consciousness and focus are assimilated into a unity. Her glance away from Adam's face ruins any 
idea of absolute unity. As can be obviously seen, there is an overall uniting symmetry to the structure of this composition, which creates balance and centeredness between the bodies of Adam and Eve. Adam and Eve are in their own paradisical reality. Except for Eve's glance outward to Satan, indicative of a break in Adam and Eve's celestial self-absorbed reality, the composition conveys a theme of focused eternal bliss. The pair is divinely locked into eternal and blissful ecstatic unison-both psychic and physical. I interpret the encompassing palm stalks and flowers-the bower-as a shield of protection for their innocence and blissful reality. They are experiencing a magnificently singular reality where boundless bliss is the eternal focus. If the area inside the bower represents wholeness and boundless bliss, then the area outside the bower would represent the opposite of wholeness and bliss, which would be disintegration and misery.

The bodies of Adam and Eve create a triangle, and the bower creates a circle encompassing all within. It looks to me that perhaps the original variance in the coloration of the bed of flowers could have formed an upside-down triangle, which when juxtaposed with the right-side up triangle created by the interlocking forms of Adam and Eve, would have formed a six sided star-a hexagram. There are what appear to be vestiges of a very strongly saturated area of blue watercolor directly behind the center stem of the bottom central lilies situated below Adam and Eve.' This strongly saturated area of blue paint further lends color-form to what could be the point of a possible inverted triangular structure. Considering how the form of the circular bower encompasses this seeming six pointed star, a hexagram within a circle seems to be employed as an esoteric symbol (see Image 10). The ancient emblem of the hexagram is routinely symbolic of wholeness, often with the name of God, placed within the center. This possible hexagram symbol would have been appropriate for Blake to use because Blake believed that before 'the Fall' humankind's spirit or psyche was whole, not fragmented. According to Blake this original humankind was androgynous, and upon the first 'Fall,' Eve was torn or created from the side of the original Adam. It was this first "Fall" that caused the fission of the sexes, and thus fractured the original androgynous wholeness of the original Adam, where within him everything-all opposites were fused into an ultimate whole.

Eve holds a "rose" in her right hand, while Adam holds a "lily" within his left hand. Adam holds what she seems to lie on-a bed of "lilies," while she holds what he lies on-a bed of "roses". Adam has

\footnotetext{
${ }^{1}$ Many details, such as this area of saturated blue, are clearly detectable when viewing the original, but do not show-up in the computer-scanned image (Image 4).
} 
"roses" in his hair, while it appears as though Eve's hair and the mat of seemingly stylized lilies that she lies on, structurally, have the same attribute. Her hair and these stylized lilies seem to flow together, and they may be symbolic of parity.

There is another interesting attribute, which seems to symbolize an integrated "oneness" of Adam and Eve. The near-profile view of their faces, together, forms an androgynous face. If one is to place a template, with a circle cutout about the size of a nickel, over the faces of Adam and Eve, their combined profiles create an androgynous face. This works beautifully. This theme of integration and oneness can be compared to the symbolically "shared arms" of the Lovers (see page 21) and the Seated Couple (see Flam's quote on page 14). Whether Blake intended this attribute, we probably never will know.

Perhaps the blue area detected below the bed of roses is symbolic of water and may be the "vast unknown." The blue seems to be a small pond and is certainly symbolic. In psychology Jung viewed water as symbolic of the unconscious, which is a vast unknown psychic expanse. Adam and Eve float above this small field of blue. Perhaps this is symbolic of the notion that our individualized souls are created out-of unconsciousness into consciousness. Perhaps this is symbolic of self-awareness and bliss as being above, beyond and opposite to the unconscious.

Consciousness arises from unconsciousness. As conscious-selfhood rises from the pond, Adam and Eve can see themselves-know themselves, and thus know consciousness and an amalgamated self as bliss. 


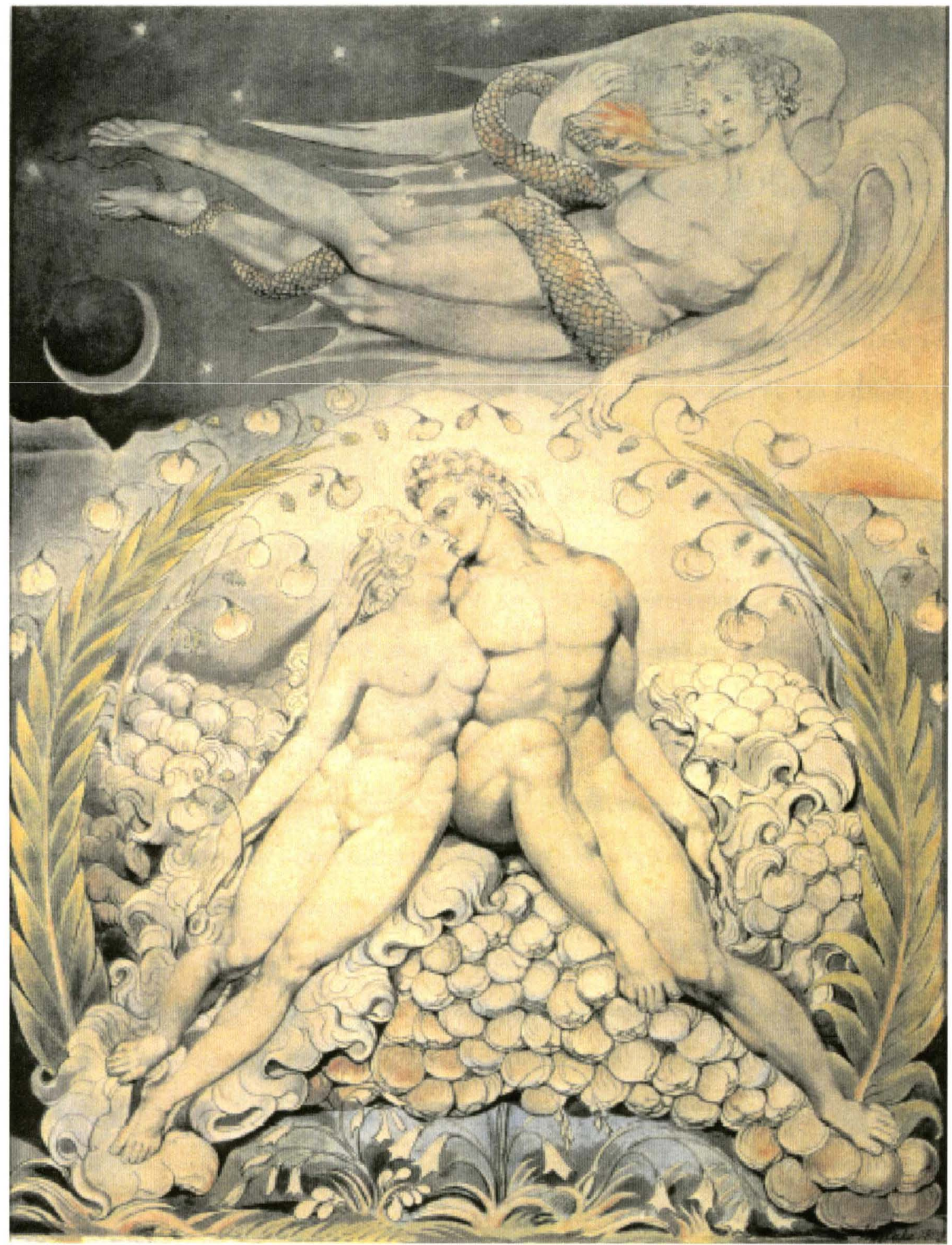

Image 4: Satan Watching the Endearments of Adam and Eve. 1808. William Blake illustration.

Source: (Butlin, plate 648) 


\section{CHAPTER III}

WILLIAM BLAKE'S DEPICTION OF ADAM AND EVE FOR PARADISE LOST

An ink, and watercolor over pencil illustration called Satan Watching the Endearments of Adam and Eve (Image 4, previous page) is in the collection of the Museum of Fine Arts, Boston. This work is one in a series of twelve illustrations created in 1808 for a circa 1808 edition of John Milton's well-known literary work Paradise Lost. These twelve illustrations depict various scenes from Milton's Paradise Lost. The artist responsible for these illustrations is the mystic, poet, painter and printer-the late $18^{\text {th }} /$ early $19^{\text {th }}$ century Englishman-William Blake.

This particular painting, in the rare print room of the museum, is one version of three known surviving similar designs for the theme of Satan watching the Endearments of Adam and Eve (this thesis contains two of the three designs—see Images $4 \&$ 9). There are also two surviving pencil sketches for this theme (see Image 6). Through the years 1806-08, Blake continuously re-conceived and made compositional changes to his design for Satan Watching the Endearments of Adam and Eve, and the final 1808 edition is his decisive design for this particular theme. Two of these designs are similar, while onethe earliest 1806 design-is quite different from the later two. This chapter focuses on Blake's final 1808

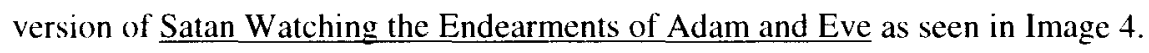

This mixed media illustration represents the Western tradition because Blake was English. As in the previous two works discussed in chapters 1 and 2, the imagery in this work represents an idea of transcendence through the contemplation of the amalgamated male and female principles. Like the Dogon and Tantric male-female figurative artworks, Blake's artistic imagery of 'Adam and Eve' symbolically signifies a contemplative path toward spiritual health, wholeness and ultimate happiness.

Blake believed that before 'the Fall' Adam was a complete image of God. including both male and female aspects. Blake understood Adam—-this original divine humankind-to be an integrated whole with both male and female principles united, integrated and balanced. Adam, Blake believed, was divinely androgynous. Blake understood the creation of Eve to symbolize the fission or splitting into opposites of 
this original and divine male-female spiritual or psychological whole. Jung and Blake's definitions of wholeness are essentially the same. Both Blake and Jung believed that the anima or female principle, and the animus or male principle, must be consciously reconciled, integrated and balanced for achieving spiritual and psychological health, wholeness and ultimate happiness. Blake's illustration titled $\underline{\text { Satan }}$ Watching the Endearments of Adam and Eve symbolizes this particular idea of transcendence and spiritual wholeness through the amalgamation of the Jungian archetypal anima-animus in Adam and Eve's loving embrace, which symbolically forms this original divine and assimilated psychological whole.

The following descriptions concern Blake's finalized 1808 edition illustration as exhibited in Image 4-titled, Satan Watching the Endearments of Adam and Eve.

The jeweled effect of sensuous richness here almost dominates the overall design. Although in Milton's poem this episode does not take place in Adam and Eve's bower, in Blake's design fronds of foliage meet over the heads of the lovers, creating an atmosphere of intimacy from which Satan is excluded. The placing of Adam and Eve in an almost circular frame with the sun rising on the right and the moon seen on the left creates a sense of universality. Eden, we are told by Milton, is in the centre of the earth and the focal point of Eden is Adam and Eve, our first parents. The scene is certainly one of universal significance. The endearments of Adam and Eve are watched by Satan, whose great fault is self-love. Blake therefore depicts Satan (in a pose reflecting that of Adam) caressing the serpent which is but an aspect of himself. Satan 's endearments of the serpent are thus a counterpoise to Adam's endearments of Eve. The image of the serpent coiled around the body recurs throughout Blake's art (Pointon 148).

Adam and Eve sit reclining on a 'soft downy bank damasked with tlow'rs, imparadised in one another's arms'. Milton lists a variety of flowers, although Blake seems to confine these to roses and lilies. Adam plucks a lily, Eve a rose. Satan, entwined by the serpent, a signilicant detail not in Milton's original text, hovers above them. He looks down upon Adam and Eve and her gaze seems to be directed at Satan rather than at Adam. The sun rises or sets (according to which interpreter one follows) on the right, while the waxing or waning moon is seen on the left ... (Butlin \& Gott 47).

Poet, painter, printer and mystic, William Blake was born in 1757 in England. Blake's art and theological ideology were considered crazy and nonsensical by all, but a small circle. The intellectuals of the day who knew of Blake were blind to his messages. Blake detested reason, and exalted the imagination as the actual path to spiritual truth and ultimate reality. He could never accept his isolation from the majority of society or understand why spiritual matters, that were for him clear, should seem incomprehensible to the general public. 
As a young man Blake was a member of the Swedenborgian New Church, ${ }^{2}$ which claimed to be a Christian humanism-a religion of "God as man." Blake was well read in Greek and Latin authors and also knew something of Indian (Hindu and Buddhist) religion. Blake revered the mystic Jacob Boehme and the physician and philosopher Paracelsus, and Blake seems to have read the publications of many alchemists. Blake seems to have read Heinrich Agrippa, Robert Fludd and perhaps Thomas Vaughan among others, and he almost certainly would have known the Platonist philosopher, Thomas Taylor. While living near the Strand, Blake was a neighbor of dramatist Frederic Reynolds and the painter and engraver William Hogarth. He visited the novelist Lady Caroline Lamb, where he met the poet and philosopher Samuel Coleridge (Raine, Man).

Because Blake lived both socially and geographically in the very heart of London (see map. Image 11), there were few aspects of London life, high or low, that were completely unknown to him. Blake was a poor Londoner and a man of the people. Yet, Blake was a friend of many of the important London-resident artists of the day, such as John Flaxman, Henry Fuseli. John Varley, Samuel Palmer and John Linnell. Blake was a foreseer not by visionary inspiration alone but by his knowledge of the most significant events in the social history of his country and century.

It is known that Blake was not only extremely intelligent, but also he was exposed to philosophical, theological and mystical literature not only of European and Mediterranean origins, but also from world cultures such as the Buddhist and Hindu cultures of India. Blake had an imaginative understanding of whatever works, domestic or foreign, that he read and studied. As Kathleen Raine suggests, there is nothing in Blake's writings that he could not have ascertained from his broad and in-depth reading of the Neoplatonic and alchemical texts that were available to him in English (242). Blake also knew a great deal about comparative world mythology. "As an apprentice, he worked on the engravings of Jacob Bryant's New System of Mythology:" Yet contrary to the perception of Blake's abilities as coming from study, William Blake himself tells us that his spiritual insights and cultural accomplishments came directly from spirits in eternity. According to Blake's own understanding of his insights, he merely acted as secretary as

\footnotetext{
2 The Swedenborg New Church was formed by Emanuel Swedenborg who--born in 1688-was the second son of the Lutheran Bishop of Skara, Sweden. In 1745 Swedenborg published Worship and the Love of God, and in 1747 his life became totally devoted to his religious work.
} 
those authors within eternity dictated their divine wisdom to him. The following quotations contain Raine's commentary on "the nature and source of Blake's knowledge."

There are two extreme views about the nature and source of Blake's knowledge. We must take him at his word when he says that his visions came to him spontaneously, and evidently with speed and energy which outran his powers of recording his impressions. He said that much of his poetry was 'dictated' and. on completing his Milton, he wrote in a letter, 'I may praise it, since I dare not pretend to be any other than the Secretary; the Authors are in Eternity' .... On the other hand, throughout his work there is evidence, not only of a powerful intellect, but of an extensive knowledge of English poetry and history, of contemporary political events and writings, and of that body of esoteric or occult knowledge which led Yeats to conclude that Blake had access to the secret oral tradition of the legendary Rosicrucians (241-2).

... but it is not necessary to assume that Blake was an initiate in any other sense than the only real initiation-insight into spiritual reality and an imaginative understanding of whatever works he read or studied. There is nothing in his writings which he could not have learned from his wide and deep reading in the Hermetic alchemical and Neoplatonic texts available to him in English ... . As an apprentice, he worked on the engravings of Jacob Bryant's New System of Myhology, which gave him an introduction to comparative mythology to which he continued to add, throughout his life, whatever knowledge was available. Blake also knew something of Indian religion... (242).

When it comes to questioning when or from where Blake may have developed his ideology concerning androgyny as divine. one can immediately turn to Jacob Boehme's earlier theory of androgyny. Boehme's theory of androgyny powerfully influenced Blake's ideology and writings on this subject, and Cavendish cites the account of creation in Genesis as a likely source for Western ideas of androgyny.

The two different creation stories in Genesis encouraged some Jewish and Gnostic writers to suggest that the first story describes the making of the ideal 'heavenly man, the image of God, a spiritual, non-material being who combined both sexes in himself: and that the second story describes the making of actual earthly man, a being who is part spirit and part matter (his body, made of earth) and who is divided into two sexes. Here again is the theme of the dual nature of man: material and spiritual, animal and divine.

The idea survived in Jacob Boehme's theory (which powerfully influenced William Blake) that there were two Falls. The original Adam was an angelic spiritual being. immortal, bisexual and virgin. He fell for the first time in acquiring a physical body and dividing into male and female. This was followed by the second Fall when the serpent successfully tempted Eve. bringing death and the necessity for reproduction of the species because man was no longer immortal (905).

This idea of the original "Adam" as divinely androgynous was not confined only to mystical or esoteric interpretations in Europe. The early Greek Church taught that death, suffering, and the polarity of the sexes were a result of a fall into sin. According to these Greek Fathers, Adam and Eve were originally "neither female or male."

The fathers of the Greek Church taught that Adam and Eve, while yet imparadised. led the chaste life of the angels. Had disobedience not intervened, they would have lived out their days in untroubled virginity, neither female nor male ... Therefore, sexual polarization, like death itself, must be the outcome of $\sin$, and procreation a makeshift remedy against dying. It was a device instituted by divine justice to perpetuate the race in perpetual subjection to death. But in Paradise, where death was not, and no philoprogenitive drive was required, neither would there have been 
differentiation of sex .... Thus according to the Greek Fathers, Adam and Eve before succumbing to $\sin$ were genderless creatures. They may even have lacked the organs of reproduction ... (Steinberg 230-1).

The idea of the rapprochement of all polarities as ultimate "perfection" has long been symbolized among European occultists by the metaphor of male-female unity. Throughout European history the notion of divine androgyny has been a concept that reappears within Western culture. Just as in other cultures, the Western tradition could never completely rid itself of the archetypal idea of the androgyne. As with any archetype, divine androgyny always has been hiding or residing in European and Western thought, and at times has been detectable whether implicitly or explicitly.

As the institutionalized theology of the Catholic Church dominated European thought, mystics and artists kept alive this "heretical" idea of God as male-female and possessing all opposites within One. Richard Cavendish and Elemire Zolla discuss the European occultist maintenance of this idea of androgyny as divine.

The union of the sexes is the stock European occultist's example of a reconciliation of opposites, which is physically fruitful (in the conception of a child) and also spiritually and magically fruitful. The magical idea is 'the whole man, the man who unites all human characteristics and potentialities in harmony, the man who is all that a human being could possibly be, and so, in effect. the man who has become the One, or God. To do this, he must bring all the opposite forces of his nature into balance (Cavendish 1925).

Mystics and theologians such as the ninth-century Scotus Erigena who soared beyond the limits of a personal and male concept of the godhead, and felt and restated the presence of the archetype of androgyny, risked the ban of the Church. Their ideas went underground, and the paraltel Jewish esoteric culture became the store-house into which daring, searching souls dipped for knowledge through the centuries. Along with Jewish esotericism. there was also the Hermetic tradition, whose doctrine of androgyny was summed up in a famous passage of Asclepius: "Then you say, Trismegistus, that God is both sexes?"--"Yes. and not only God, Asclepius, but all things animate and inanimate, for both sexes teem with reproductive power. and their binding power. or rather unity, which you call Venus or Cupid or both is beyond understanding-highest charity, joy, mirth, desire, and divine love are innate in it" (Zolla 26).

Bcing a tireless scholar, Blake would have discovered very easily the esoteric philosophies and symbolism within Western culture that would have fueled his imaginative thoughts and writings. He would have been actively on the lookout for ideologies to feed his powerful imagination. As Ann Simmons writes, "the earlier Renaissance painters also used symbols of androgyny to portray a perfected human personality whose external traits stemmed from inner characteristics" (397). Blake would have had access to a profusion of culturated ideas from which to formulate his own ideologies. "In seventeenth-century Germany a new kind of Protestant mysticism flourished, which was based on the cult of the androgyne 
Adam." In this Protestant mysticism, "Jacob Behmen enjoyed visions of Adam, and his disciples went back to the primitive Christian notions of androgyny." This mysticism espoused that men "suffer for the loss of all the female qualities in us." (Zolla 30). Zolla comments on how "the Reformation opened the way for a revival of this whole hidden strain in Christian thought."

With the stamping out of Catholicism in England, people started dreaming of the repressed androgyne. The spirit of the Reformation opened the way for a revival of this whole hidden strain in Christian thought. The Catholic Church practiced androgyny in its politics. but refrained from acknowledging it theologically, whereas Protestants. who were purely male-minded politicians, opened up to androgyny in a spiritual way.

Spenser, who forged his epic poem. The Faerie Queen, in the service of an ideal of Protestant chivalry, used the image of the hermaphrodite to convey the idea of a complete blending of two [male-female] souls .... With the new atmosphere of Protestant mysticism the archetype [of androgyny] started becoming apparent to many ... (29).

Considering how European heritage, whether implicitly or explicitly, continued the idea of divine androgyny, it becomes understandable how Blake would have had a broad source of ideas and symbols with which to spark and fuel his supreme imagination towards the idea of divine androgyny. As Zolla observes, regarding Blake, the motif of androgyny helped lead him toward a new mythology.

In William Blake's mind the archetype acted so strongly that a brand new mythology developed, in which the remaining Christian terms were charged with fresh meaning. God, or Eternal Man, he taught. was originally androgyne beyond female space and male time, but he fell from that perfection, expelling from his completeness a series of projections. starting with Albion, 'a Shadow from his weary intellect' $(30)$.

In Blake's three varying designs for the theme of Satan Watching the Endearments of Adam and Eve (of which two are contained in this thesis-see Images $4,6, \&$ 9) Blake strives to create an image of paradise on earth. Although the first Fall had caused the fission of Adam-Eve or man-woman, nevertheless, a harmonized amalgamated relationship between the sexes was maintained on earth within the "Garden of Eden.' In conceiving the three different designs for Satan Watching the Endearments of Adam and Eve Blake was striving to represent this Garden of Eden or "State of Beulah." This harmonized state is represented while "Adam and Eve embrace embowered by flowers in the night of Beulah, that earthly paradise in which, for a time, contraries are equally true" (Paley 63). Stephan Behrendt writes about this Blakean primordial State of Beulah as the earthly Garden of Eden, which is an earthly equivalent to the original non-temporal psychic heavenly state of divine androgynous harmony before the spiritual fall. In addition to discussing this State of Beulah, Behrendt also mentions that in the three differing designs for 
Blake's theme of Satan Watching the Endearments of Adam and Eve all three contain differentiated symbolic conceptions. It seems clear that as Blake's ideas developed within his "powerful intellect," so did the symbolism and compositions within his artwork:

In their unfallen state Adam and Eve are united and unified, their correct love manifested outwardly in their mental contentment and physical pleasure. Their relationship comes as near the androgynous state Blake described to Crabb Robinson as possible in the physical world.

As a mental construct, this design for Satan Watching the Endearments of Adam and Evel alludes to the Eden of Blake's mythology, the state of the fully integrated personality [see Image 32]. In terms of the physical metaphor of Eden, the design represents the state of Beulah, in which even though man is divided from his emanation they still exist in perfect marriage . . . . Blake's design points toward the Fall, citing its origins in the division of identities that grows increasingly pronounced as the drama [of the Fall] unfolds .... But as subsequent designs-and indeed the second version of this design-make clear, the Fall has already begun, as Eve's thrusting left foot in both versions suggests by its contrast to Adam's right, and as is further indicated in both versions by the facts that Adam wears a wreath of roses (foreshadowing the Son's crown of thorns) and that both Adam and Eve are seen to pluck iconographically significant flowers--he a lily, she a rose (Behrendt, Moment 145).

As Blake worked, it seems as though his developing ideas were encoded into his designs so that the imagery in his illustrations likewise evolved. This certainly seems to be true of the two sketches and three designs for Blake's theme of Satan Watching the Endearments of Adam and Eve. "Above them flies Satan, his human self in an almost masturbatory relationship with his serpent self. This brilliant contrast did not occur to Blake immediately. There is in the Fogg Museum a drawing of this subject in which Satan merely holds his hands to his head in jealous dismay and the serpent slithers under the feet if the human lovers" (Paley 63). The changing attributes found in Blake's three versions of Satan Watching the Endearments of Adam and Eve (such as the serpent first being drawn on the ground, then later wrapped around Satan-see Images 4, 6 \& 9) suggests that Blake's ideas-of the paradisical condition and Eve's temptation-were themes that Blake tirelessly perfected as he contemplated and formulated his ideas and designs: "Note that this [theme of Satan Watching Adam and Eve] is a composition on which Blake exercised some thought, as it is an alteration of the 1806 version in which the serpent lies at Adam's feet" (Tayler 67). Furthermore, as Pamela Dunbar observes, in the first (1806) version for Blake's idea of Satan Watching the Endearments of Adam and Eve, "the conception of Satan as Adam's Spectre and the Serpent as a projection of the Spectre's evil has not yet emerged" (Dunbar 60). With regards to the progression and importance of Blake's thought process concerning his theme of Satan Watching the Endearments of Adam and Eve, Darrell Figgis and Bette Werner have the following to say: 
The connected thought in all this is patent. Blake was not working at random. His symbols were carefully chosen. As a separate design Blake expressed in this [1806] drawing all he desired ... But now observe the development of his thought. The following year, 1807, he made his first series of designs for Paradise Lost. Not satisfied with these, in 1808, he made another series. The second series is incomparably finer than the first. The first is indifferently done; the second is in the highest rank of his work. In both, he used his design of 1806; but he introduced changes that are of extraordinary significance ... . Note the changes by which this is accomplished. In both the Paradise Lost series the Serpent is no longer seen under Adam's foot . . . . It is found [coiled] about a winged Satan in the air . . . That is a significant change; but there are others also. In the design of 1806 the entire scene had been enclosed in a happy garden . . . In the two Paradise Lost series, on one side in the distance the sun sets beneath a sea of waters. while on the other a crescent moon rises to throw a pale reflected light ... The only difference in Blake's use of this design in the two series is that Satan's position, and the positions of the sun and the moon, are reversed. But there are other changes in the two series, for as he worked Blake's thought developed ... (Figgis 68).

the design [of Satan Watching the Endearments of Adam and Eve] was important and successful enough for Blake so that it became one of those scenes of which he produced a third tinished version

Blake's portrayal of Satan differs significantly in his various treatments of this scene. There is an early version of the design in an unfinished painting, dated 1806. which is presently in the Fogg Art Museum of Harvard University [Image 9] . . . Blake's later. finished versions of the design [Image 4] develop a richer perspective upon Satan's character. He [Satan] is depicted with the serpent coiled about his body ... a appears troubled and hesitant, reluctant to disturb the happiness [of Adam and Eve] that he points out to the serpent. The serpent casts his guileful glance towards Eve, and, in premonition of future developments, appears in the Boston and Melbourne versions to have succeeded in catching her eye ... (Werner 72).

Blake's conception of the Fall as being, in part, a cause for the fission of the original androgynous "Adam" into the sexed Adam and Eve is cited abundantly in scholarship concerning Blake's lifework (Damon). Blake understands this Fall from original androgyny as a mental or psychological process of diminution. When humankind begins to embrace errors in thought or imaginative perception, then the divine, ultimate, and original reality becomes a fallen reality. Blake's dream-like world of poetry is comprised of his message of restoration to the original divine reality, which in part can only be realized when the polarized sexes reconcile and reintegrate into the third psychic possibility where male and female no longer exist as differentiated. Furthermore, Bindman points out that ". . . the process [of 'the Fall'] may be said to have begun with the Creation of Eve, for in Blake's ideology the sexes were in a state of androgyny before the Fall. It is Adam's divided part, that is Eve, which is susceptible to Satan's wiles, for it is in Adam's divided state that Eve is seduced by his [Satan's] serpentine form ..." (191). Bette Werner observes, “. . Blake understands the creation of the sexes as a fall from a state of original androgyny in Eternity ..." (73). In the following quotations, Diane Hoeveler and Stephen Behrendt also cite Blake's ideal of divine androgyny as pivotal to his belief system. 
In considering Blake's treatment of the Fall in his illustrations to Paradise Lost . . we need to begin by recognizing that the Fall is for Blake first and foremost an act of disintegration, of separation, division and diminution. It destroys the imaginative wholeness represented in the prelapsarian unity of Adam and Eve. Furthermore, the Fall is a private mental event that occurs whenever man subscribes to Error, when he contracts his imaginative vision, denies his mortal body as sinful flesh. and represses or perverts his Energy" (Behrendt. Trivium 39).

Blake's poetry, then, is dominated by the image of the androgyne, which he envisions as a paradisal state of consciousness that has resolved all dichotomies so the "man" possesses that complete harmony in which "he" is Albion-Jerusalem, both God and all external, "feminine" reality. For Blake the androgynous is a consciousness that is neither masculine nor feminine; rather, it is a distinct third psychic possibility in which neither sex predominates . . . Blake emphasized that sexual divisions must be annihilated psychically, because both sexes are cqually fallen from the original divinity of the androgyne: 'In Eternity they neither marry nor are given in marriage'....

.. Blake's poetry contrasts the fallen physical body, constricted to the limitations inherent in the divided sexes and represented by the hermaphrodite, the human-divine, [and] the androgynous "body." In his poetic versions of the Fall, an original androgynous union of masculine and feminine is destroyed, thereby giving rise to the fallen world of nature. This fallen physical world incorporates qualities that Blake depicts as feminine. while the other, and even greater, evil in his system is the conception of the self, which is embodied in the male. These two separated [male-female] principles cause the ensuing sexual warfare . . . This state of divisive warfare between the sexes is at the root of the fallen state in Blake's poetic world . . (Hoeveler 29).

Blake distinguishes a dichotomy between the androgyne and the hermaphrodite by contrasting their mental attitudes. For Blake, the genuine male-female amalgamated attitude of the androgyne is in sharp contrast to the insincere and thus profane attempt of the hermaphrodite to forcibly and manipulatively "yoke" the fissioned sexes. The sincere reconciliation of the sexes was symbolized by the divine androgyne, while the insincere, self-serving, manipulative attempt of the sexes mutually to exploit one-another through halfhearted union was symbolized by the "monstrous" hermaphrodite. ". . . a Shadowy hermaphrodite, black \& opake ... a Vast Hermaphroditic form heav'd like an Earthquake, lab'ring with convulsive groans intolerable; at length an awful wonder burst from the Hermaphroditic bosom, Satan he was nam'd ...." (Damon 181-2). The androgyne represents harmony, while the hermaphrodite represents a half-hearted and thus hypocritical attitude and consequently a lack of reconciliation. Hoeveler suggests that Blake got this idea from the "longstanding tradition in theological speculation" of the androgyne as being a symbol of genuine reconciliation contrasted to the hermaphrodite being a symbol of insincerity and coercion of the sexes, and thus scorn. According to Blake, it is this continued generational, artificial and forced merger of the fallen form of the sexes which continues to perpetuate the profane and diseased aspect of history, which is symbolized so appropriately by the visually grotesque hermaphrodite. Blake suggests that the farther one continues to reject their male or female psychic counterpart, the more deeply they fall into a spiritual or 
psychological malformed condition, which eventually leads to the same pathological and spiritually bankrupt condition of Satan. Foster Damon and Diane Hoeveler cite this distinction between androgyny contrasted to hermaphroditism:

\begin{abstract}
A hermaphrodite is a being with the organs of both sexes. To Blake it symbolized a sterile state of unreconciled and warring opposites .... The opposite of the hermaphrodite is the androgyne, in which man's bisexual nature is perfectly harmonized. This was his [humankind's] original state [before the Fall]. Blake found the theory in Ovid (CR 263), in Plato's Symposium, in Spenser's Faerie Queene, and also in Genesis I: 27 and v: 2: "So God created man in his own image, in the image of God created he him; male and female created he them." Later, Eve was divided from Adam; this was a stage in the Fall, which brought death into the world (Damon 181-2).
\end{abstract}

Blake, then, describes the androgynous condition chiefly by depicting what it is not. He contrasts the sacred image of redeemed sexuality to the profane image, the hermaphrodite. The contrast of the hermaphrodite and the androgyne as opposites is a long-standing tradition in theological speculation.' Blake follows in this tradition hy viewing the hermaphrodite as a sterile fusion of the physical male and female, while the androgyne transcends sexual division to become a spiritual and psychic ideal $^{2} \ldots$

History for Blake, then, can be viewed as a cycle of hermaphroditic unions between the fallen female and male as they struggle for dominance . . . Blake . . states that the only escape from history as a panorama of sexual conflict and religious perversion lies in transforming the sexual altogether . . . . For Blake, then, the hermaphrodite is a sterile monstrosity not because it is asexual, but because it is multi-sexual; it yokes together by force two sexes in their fallen forms (Hoeveler 30).

Blake believed that final ultimate reality could only be achieved by way of the creative imagination. His idea of androgyny as divine has little concern with the biology of a man and woman but is concerned with the harmonizing of mind. A whole, and therefore ultimate reality, is attained through the cultivation of a mindful creative attitude of perceiving all polarity as fissioned components to be reintegrated into a divine whole. The androgyne is symbolic of a "spiritual state [of perfection] that symbolizes [all aspects of] the mind's reintegration." Hoeveler cites Blake's idea for ultimate reality as attainable through the imaginative realization of androgyny as metaphoric of the reintegration of all countenances of the mind.

Throughout his life. Blake believed, as he declared in "All Religions are One," that "the Poetic Genius is the true Man, and the . . body or outward form of Man is derived from the Poetic Genius" (E. 2; K, 98). The Poetic Genius. humanity's divine imaginative power, is "the source" of the "true Man." These statements support the view that androgyny as an ideal in Blake's poetry is an imaginative construct and a spiritual state that symbolizes the mind"s reintegration. The androgyne is an image based on sexual identities and polarities, yet it repudiates both and becomes the most paradoxical state the human mind can imagine. The androgyne is an oxymoron, a concept that combines contradictions and attempts to grasp the ideal as imaginative reality. For, as Blake pointed out in his Annotations to Berkeley's Sirius, every object's "Reality is its Imaginative Form" (E, 653; K, 213). "Reality" is not what is perceived by the fallen senses, but what can be imagined. If humanity can imagine itself as androgynously and harmoniously unified. then Blake posits that imaginative vision as humanity's ultimate form (40). 
William Blake may have influenced Carl Jung's scholarship because Jung was familiar with some of Blake's work. As Barbara Frieling notes, “. . . [Jung] did know selected portions of Blake's . . work, mentioning him seven times in his Collected Works. However, it appears that he [Jung] is familiar only with The Marriage of Heaven and Hell, which he quotes in his essay 'On the Relation of Analytical Psychology to Poetry' ... J Jung also uses two of Blake's watercolors as illustrations for Individual Dream Symbolism in Relation to Alchemy... " (Frieling 212).

Blake's mixed media illustration titled Satan Watching the Endearments of Adam and Eve represents the same idea of transcendence via the Jungian archetypal reconciliation of male-female opposites as is seen reflected in the Dogon and mithuna sculptures. As in the two artworks discussed previously in chapters 1 and 2. it is believed that Blake's art likewise instructs the viewer on how to achieve spiritual health, wholeness and harmony. Blake's illustration of Adam and Eve is representative of a Western tradition, not only because Blake was English, but also because his mystical ideology drew from the tradition of European mysticism-which can be observed, in part, in alchemy. Blake believed that before the first Fall, "Adam" was a complete image of God, including both male and female aspects. Blake understood "Adam"- this original divine humankind - to be an amalgamated whole with both male and female elements integrated and balanced. Blake understood the creation of Eve to symbolize the splitting into opposites of this original and divine male-female spiritual or psychological whole. Blake and Jung's definitions of wholeness are practically identical. Both Blake and Jung believed that the anima-or female principle, and the animus-or male principle must be integrated and balanced for achieving ultimate psychological or spiritual health, wholeness and happiness. Blake's mixed media illustration of $\underline{\text { Satan }}$ Watching the Endearments of Adam and Eve symbolizes an idea of transcendence and spiritual wholeness because Adam and Eve's loving embrace symbolically forms this original, divine and consolidated psychological whole. 


\section{CONCLUSION}

At the time I was choosing my topic, I was under the assumption that the discipline of art history had marginalized Jungian psychoanalytic perspectives towards art and art history. When starting my research, I was presupposing that Jungian-based art history scholarship would be scarce. Indeed, my research has confirmed this original assumption and has validated the importance of my topic. It is under this premise that I have enthusiastically researched and written my thesis.

Art history scholarship reflecting a Jungian psychoanalytic approach certainly can be found either addressing or embracing a Jungian viewpoint (Neumann Archetypal, and Art; Parker; Spector; Lammers). But nevertheless, the proportion of Jungian-based art historical scholarship is minute relative to the overall basis of traditional art historical scholarship.

By focusing on a Jungian psychoanalytic methodology as an approach in art history, I am not arguing that a Jungian perspective is a better methodology. Nor am I arguing that a Jungian perspective is a more creative way for the production of art, or its perception or appreciation. Rather. I believe that each person, whether specialist or non-specialist, has a right to have been exposed-at the very least-to the general tenets of a Jungian psychoanalytic viewpoint applied towards art and art history. Currently, this exposure is difficult with so little art history having been written from a Jungian perspective. A basic understanding of the Jungian approach towards art could enrich the potentials of art and art history.

This thesis focuses on one of Jung's most compelling, well-known and most important archetypes. I have examined three figurative works to demonstrate how they reflect Jung's universal archetype of the reconciled 'anima' and 'animus.' Such coalesced male-female principles can be conceived as 'divine androgyny.' Jung taught that the consoluation of the anima-animus brings psychological wholeness, health and happiness.

Each artwork and its corresponding tradition represent one of three world cultures. As this thesis has revealed, in each of these cultures, there can be shown to exist a tradition that has embraced the theme of divine androgyny as having transcendental power. 
A correlation to Jung's archetypal idea of the anima-animus is found clearly in Dogon tribal mythology. According to this mythology, every human spirit is composed of an ideal balance between male and female components. Dogon mythology teaches that for a person to be spiritually healthy and to maximize survival, men and women must consciously accept and embrace a mental balance and integration of male and female principles. Dogon cosmology instructs that the very first human-like being, created by 'Amma' (God) before the creation of earth, was androgynous and thus perfect, complete and divine.

The Dogon carving (Images $1 \& 2$ ) exemplifies Jung's notion of the timeless and universal archetype of the anima-animus within an indigenous culture. A fundamental belief of the Dogon is that opposites are temporal, and thus are spiritually (or we might now say, psychologically) incomplete, and that by contemplating their coalescence, the temporal world and psychological incompleteness are symbolically transcended. These definitions of spiritual health found within Dogon mythology, and reflected in certain Dogon figurative sculpture, are similar to Jung's definition of psychological wholeness acquired through the reconciliation of anima-animus.

Another correlation to Jung's archetype of the reconciled anima and animus is found within the Indian Tantric ideology of 'sacred sexuality.' According to some Tantric teachings, the union of malefemale opposites exemplifies the ideal that all opposites ultimately must be integrated into an absolute whole for experiencing God. Tantra suggests that for a person to be spiritually enlightened, they must understand and embrace an amalgamation of opposites, especially male-and-femaleness. Tantra instructs that in God there is no differentiation, only the Oneness, which incorporates all opposites.

The Hindu Chandella dynasty erotic sculpture (Image 3), like the Dogon Seated Couple, represents an ideal of transcendence via the archetypal integration of male-female opposites. Such mithuna sculptures depict a male and female either in various stages of uniting through a loving embrace, or in united copulation. Tantra instructed that the sacred act of sex and copulation unites male-female opposites, thus symbolically canceling temporality, and imaginatively facilitating the soul's transcendence toward an experience of spiritual harmony and bliss. Tantric definitions of spiritual health and bliss are similar to Jung's definitions of psychological wholeness. 
A further correlation to Jung's archetype of the reconciled anima-animus is found in William Blake's conception of the androgynous condition of the original "Adam." Blake conceived that for a person to be spiritually healthy they must understand and embrace the soul's intrinsic androgynous nature. which existed before the original 'Fall.' Blake believed that when humanity finally comes to experience "heaven," it is then that people will finally understand and accept their true androgynous spiritual nature.

Blake's Satan Watching the Endearments of Adam and Eve-as do the Dogon and mithuna carvings-represents transcendence and divine androgyny. Blake's mystical ideology drew from the Western tradition of European mysticism-which in part can be observed in alchemy. Blake believed that before 'the Fall' Adam was a complete image of God, including coalesced male and female aspects. Blake understood the first Adam - this original divine humankind-to be an integrated whole with both male and female elements integrated and balanced. Blake understood the creation of Eve to symbolize the splitting into opposites of this original and divine male-female psychoiogical whole.

Jung and Blake's definitions of wholeness are practically identical. Both Jung and Blake believed that the female principle and the male principle must be joined and balanced for achieving mental wholeness and harmony. Blake's painting of Adam and Eve symbolizes an ideal for transcendence and psychological wholeness because Adam and Eve's loving embrace symbolically forms this original celestial wholeness and bliss.

Some Jungians have suggested that Jung's theory of the consolidated anima-animus should not be interpreted as a hetero-centric view (Jackson). Homosexual relationships can also partake in the divine bliss of integrated male-female opposites. Since every person's psyche (not his or her biology) harbors the anima-animus, and is thus androgynous or bisexual, then same sex couples can also experience-as do heterosexuals-the bliss of a psychological coniunctio of the anima-animus psychic opposites.

I have examined the occurrence of archetypal art in principal world cultures because a broad crosscultural study of archetypal art would more nearly support Jung's theory for the universality of the collective unconscious and the archetype. (I also have chosen to focus on art that metaphorically utilizes the human figure because I, as a figurative artist, have had great interest in the human figure and its worldwide depiction in art, as stated in my preface.) 
Archetypes_or "patterned themes of thought"-are universal and "timeless." They are found in all cultures throughout history. They are expressed within mythology, religion and the arts. According to Jung, the archetype of the reconciled anima and animus is paramount to spiritual perfection and bliss. Moreover, the union, integration and balancing of all opposites-but particularly of these anima-animus opposites-is a momentous attribute within the psychological process that Jung called 'individuation.' Jung taught that such a coniunctio of opposites led to psychological and spiritual health. Often, an archetype such as the coalesced anima-animus is found commonly among differing cultures that have developed over the centuries unaccustomed to one another. The broader implication is that these archetypes, often portrayed within art, are inherent to all cultures (see Images $33 \& 34$ ) because they emanate from humankind's collective unconscious. In this thesis I have identified, within the visual arts, the universal archetype of divine androgyny by showing how the three artworks examined in chapters 1,2 and 3 reflect Jung's ideal of the archetypal amalgamated anima-animus.

Since Jungian viewpoints towards art history have been marginalized, I believe this thesis is a valuable introduction for contemplating the relevance of Jungian perspectives on art and art history. Mere acknowledgement of any possible applicability of Jungian perspectives towards art and art history can only enrich the fields. Since art history has not readily applied a Jungian viewpoint towards the interpretation of the visual arts, it is my hope that this thesis will encourage more thought in this area. 
IMAGES 
IMAGE 5:

Window on Eternity

This mandala is what Jung considered to be one of his most significant, which he called Window on Eternity, and dedicated in memory of his friend. He gave it a legend in Latin, which reads, "On January 1927, Hermann Sigg my friend, died in the fifty-second year of his life." Jung acquired the idea for this mandala from one of his dreams. Jung interpreted this ancient symbol of the mandala as an expression of the original wholeness of the psyche, or in particular, the self. As is also true of the great mandalas of cross-religious traditions, Jung likewise believed that the mandala could express a potential for individual wholeness or represent cosmic wholeness. Often, people who are feeling emotionally, spiritually and psychologically fragmented will encounter mandalas in their dreams, thus Jung believed that the mandala could function defensively for people who are psychologically fragmented, by helping hold together or unify their sense of self.

Source: (Jaffe 90-1) 


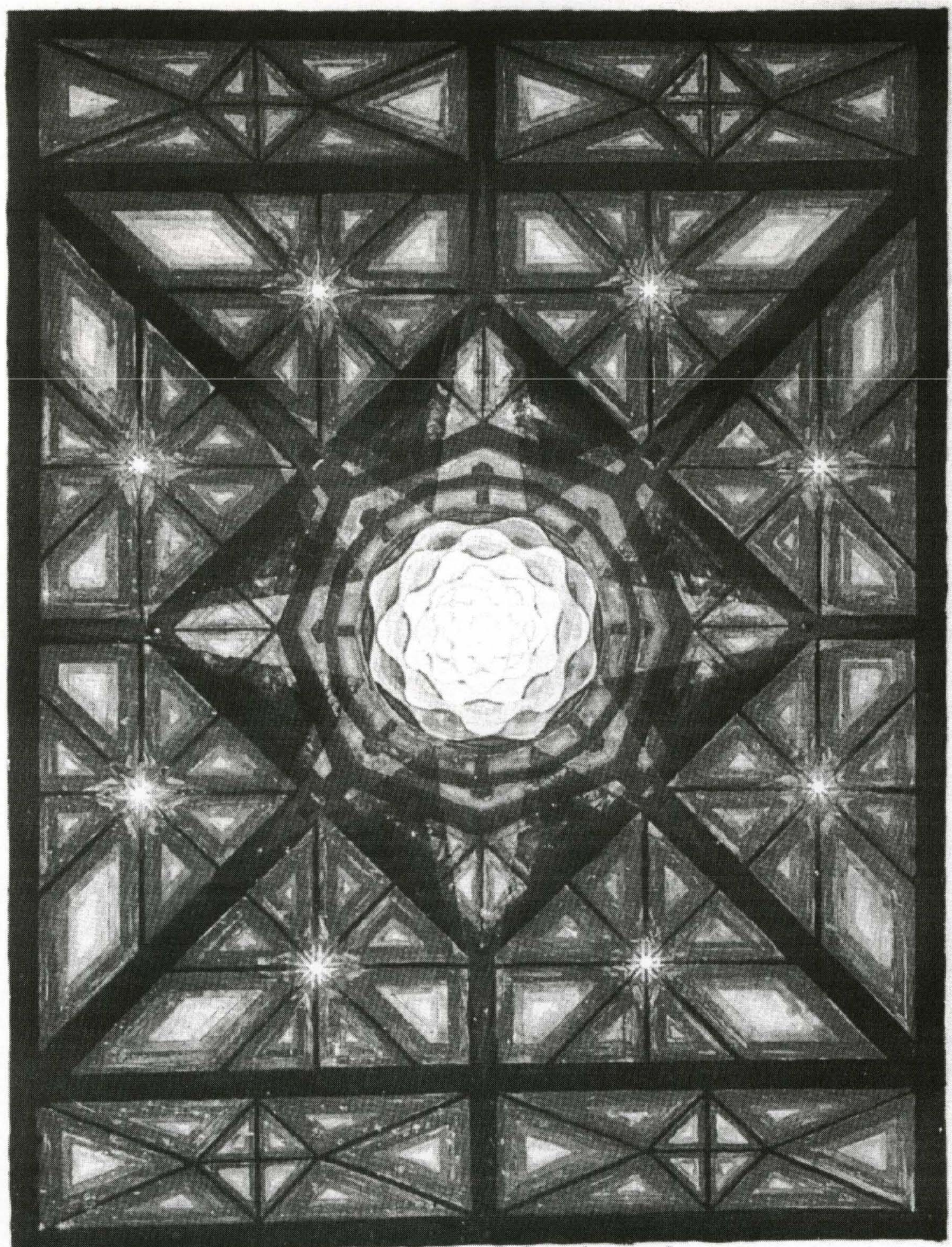

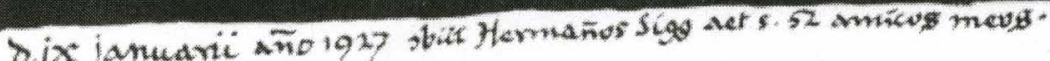




\section{IMAGE 6: Pencil Sketches for Satan Watching the Endearments of Adam and Eve}

Comparable to Blake's earliest 1806 Satan Watching the Endearments of Adam and Eve watercolor, this tiny pencil sketch similarly shows no developed idea for Satan, but only shows Adam and Eve in their bower. It is drawn on the back of a portion of a letter in an unknown hand. This tiny sketch is inscribed by Blake "Adam and Eve." The other larger 1806-7 version sketch has elements of all Blake's developing design stages, which finally resulted in the finished and last watercolor design for Satan Watching the Endearments of Adam and Eve. This 1806-7 larger pencil draft was probably sketched in-between the productions of the two 1806 and 1807 version watercolors.

Sources: (Butlin, William 644; Keyes, Pencil) 


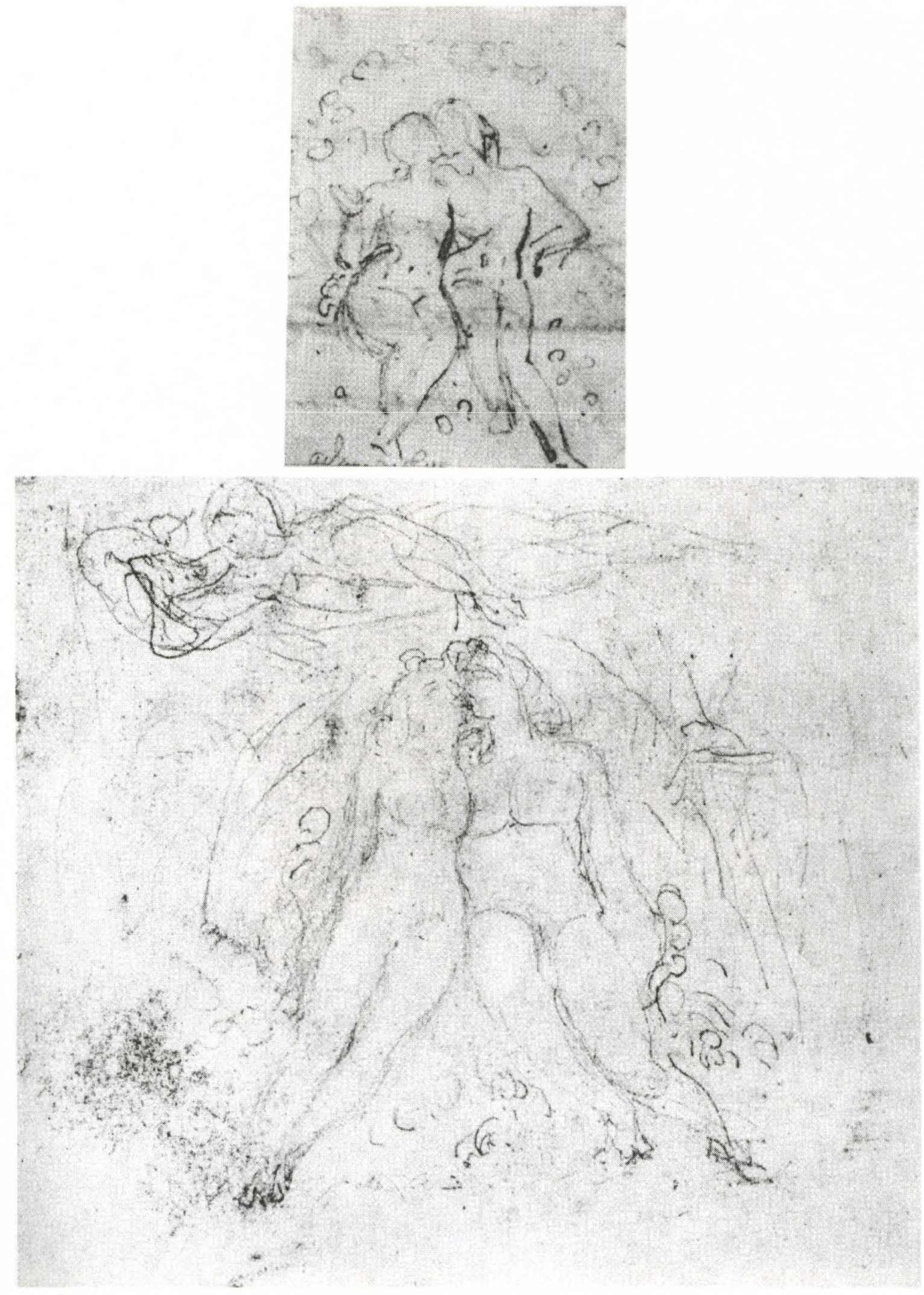




\section{IMAGE 7:}

\section{Stephan Rigaud's Adam and Eve in their Bower}

It is suggested that Blake got his idea for the positioning of the bodies of Adam and Eve from the artist Stephan Rigaud's engraving called, Adam and Eve in their Bower. Behrendt writes, "Blake must have known of Rigaud's design for this scene, published in 1801, for already in the [two] sketches [of 1806-7] the postures of Adam and Eve are remarkably like those of the Rigaud illustration though Rigaud treats the bower in a more representational fashion and handles Satan much differently."

Source: (Behrendt, Moment 146-7) 


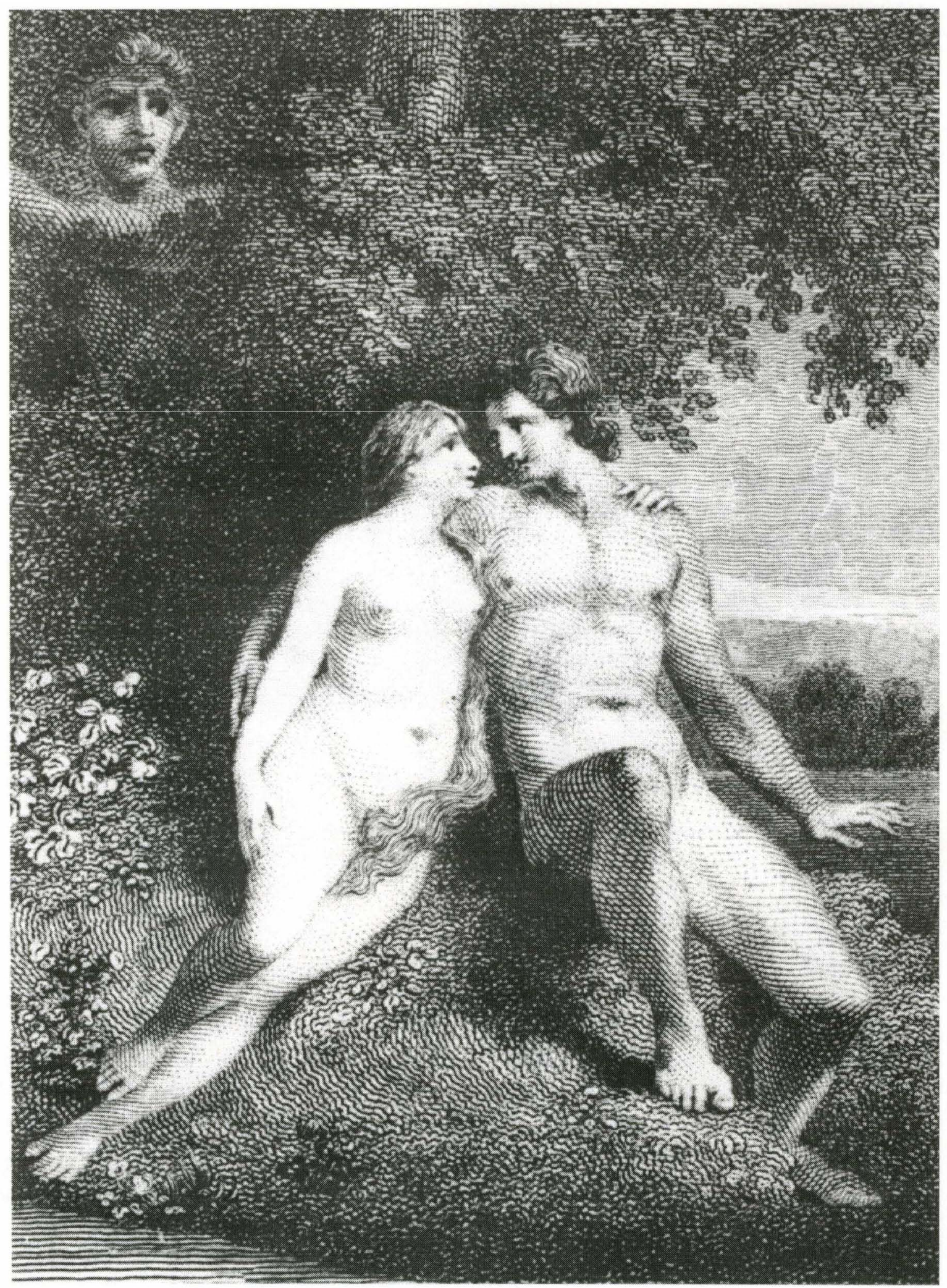


In 1762 James Basire engraved this Greek tower with these allegorical figures of The Winds for inclusion in the publication of The Antiquities of Athens by James Stuart and Nicholas Revett. In the 1770's James Basire was Blake's master. It is believed because these Winds are in positions resembling Blake's Satan in Satan Watching the Endearments of Adam and Eve, that Blake got his idea for Satan's floating appearance from Basire-his master's engraving of these allegorical Winds. Blake himself engraved four plates for the third volume of The Antiquities of Athens by Stuart and Revett, published in 1794.

Sources: (Stuart 26-31 \& plate IX; Paley, Blake 178) 


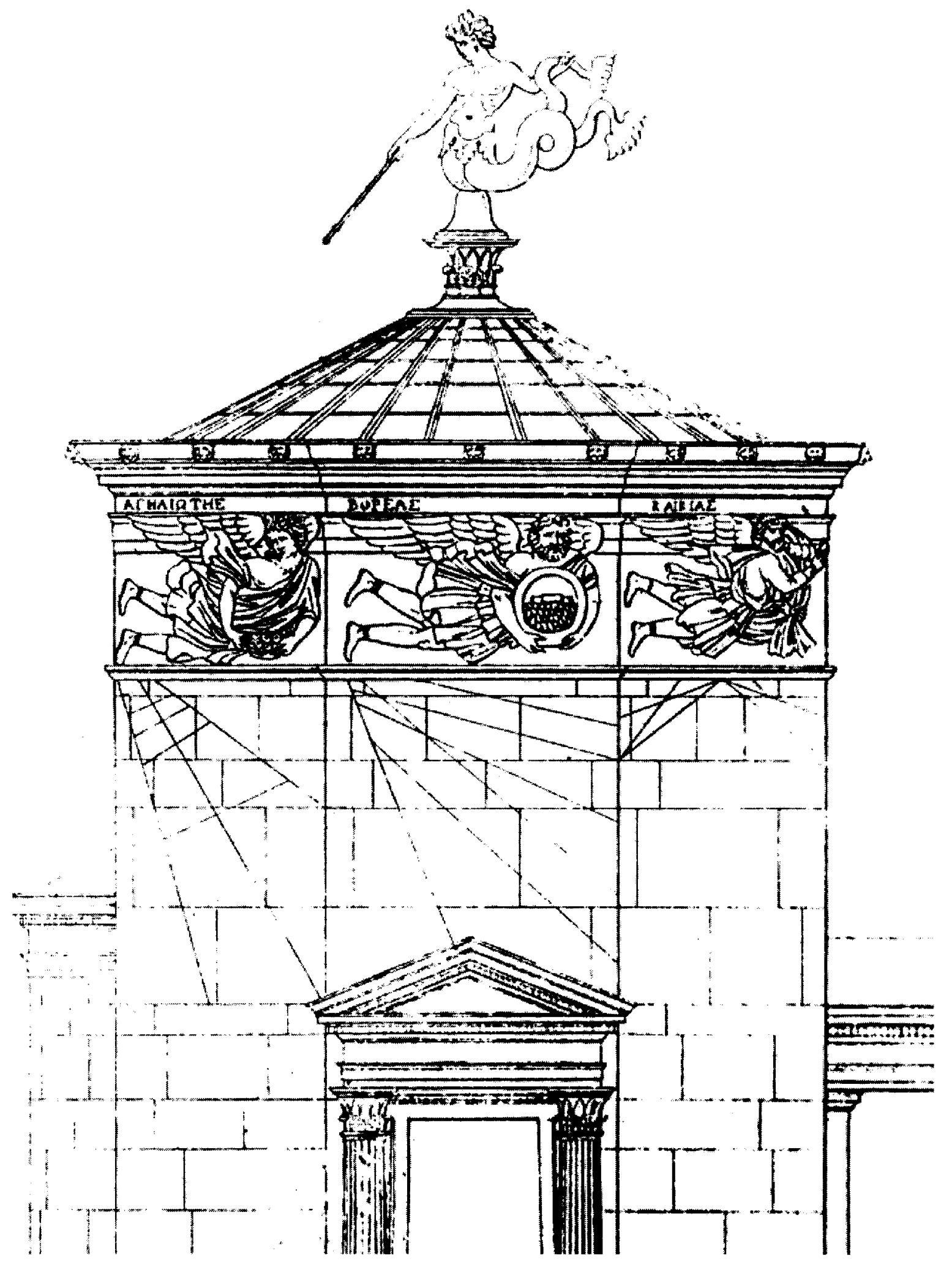




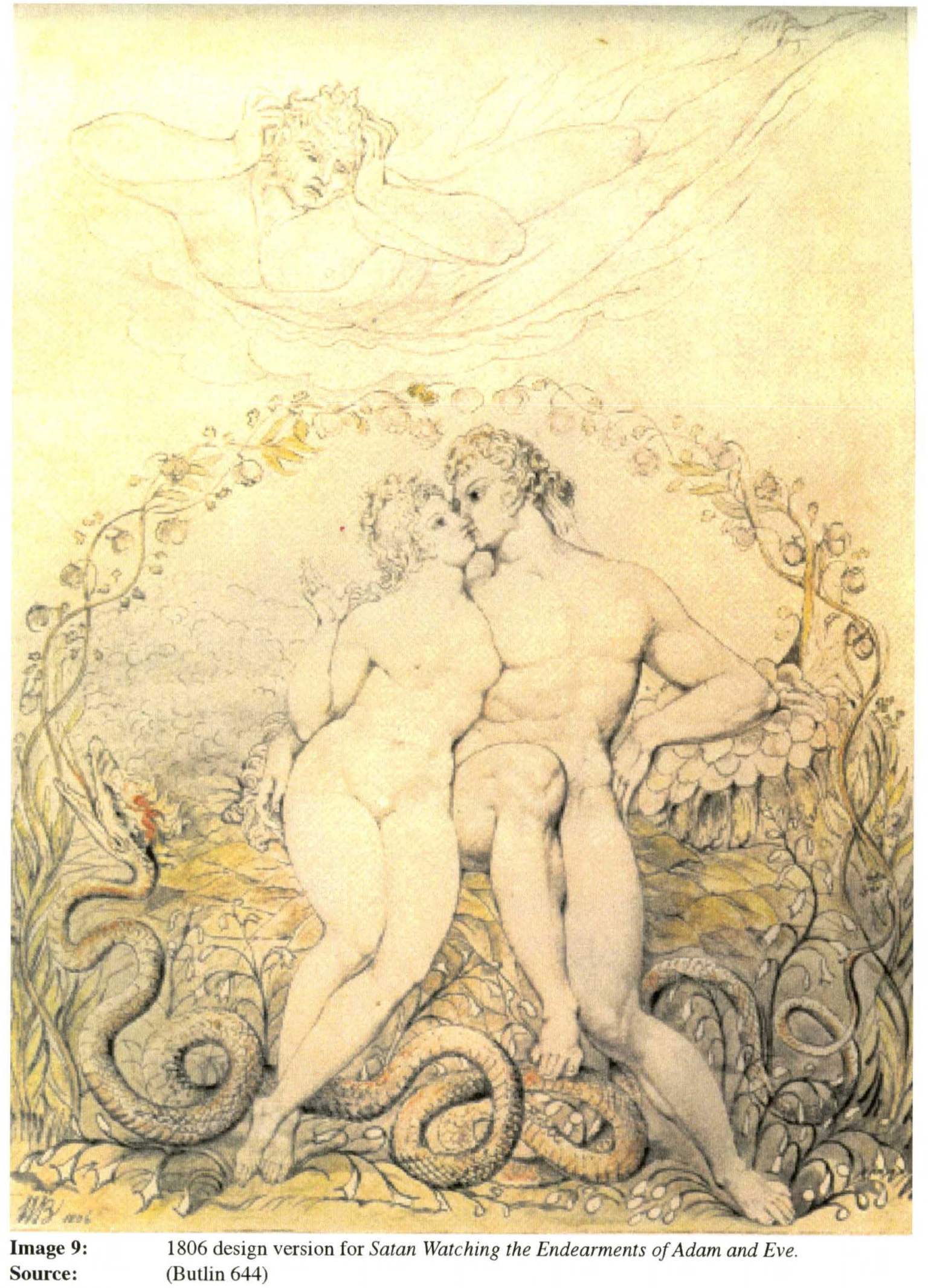


IMAGE 10:

\section{The Hexagram}

In Satan Watching the Endearments of Adam and Eve, the bodies of Adam and Eve create a triangle, and the bower creates a circle encompassing all within. In addition to these forms, it seems to me that perhaps the original variance in the coloration of the bed of flowers could have shaped an upside-down triangle, which when juxtaposed with the right-side up triangle created by the interlocking figures of Adam and Eve, would have formed a six sided star-a hexagram. Furthermore, there are what appear to be vestiges of a very strongly saturated blob of blue watercolor directly behind the center stem of the bottom central lilies situated below Adam and Eve. This strongly saturated blob of blue paint further lends a triangular shape. via color, to what could be the point of a possible inverted triangular structure. Considering how the form of the circular bower encompasses this seeming six pointed star, a hexagram within a circle seems to be formed and thus exhibited as an esoteric symbol. The ancient emblem of the hexagram has been routinely symbolic of wholeness, often with the name of God, being placed within the center. This possible hexagram symbolism would have been appropriate for Blake to use because Blake believed that before "the Fall' humankind's spirit or psyche was whole, not fragmented. According to Blake this original divine wholeness was, in part, resultant of the androgynous nature of "Adam" before the first fall. Eve was torn or created from the side of this original Adam, resultant of this first fall. It was this first fall that caused the fission of the sexes, and thus fractured the original androgynous and psychological wholeness of the original Adam, where within him, everything-all opposites-had been fused into an ultimate.

Sources: (Butlin, William 648; Briderman 173-4) 


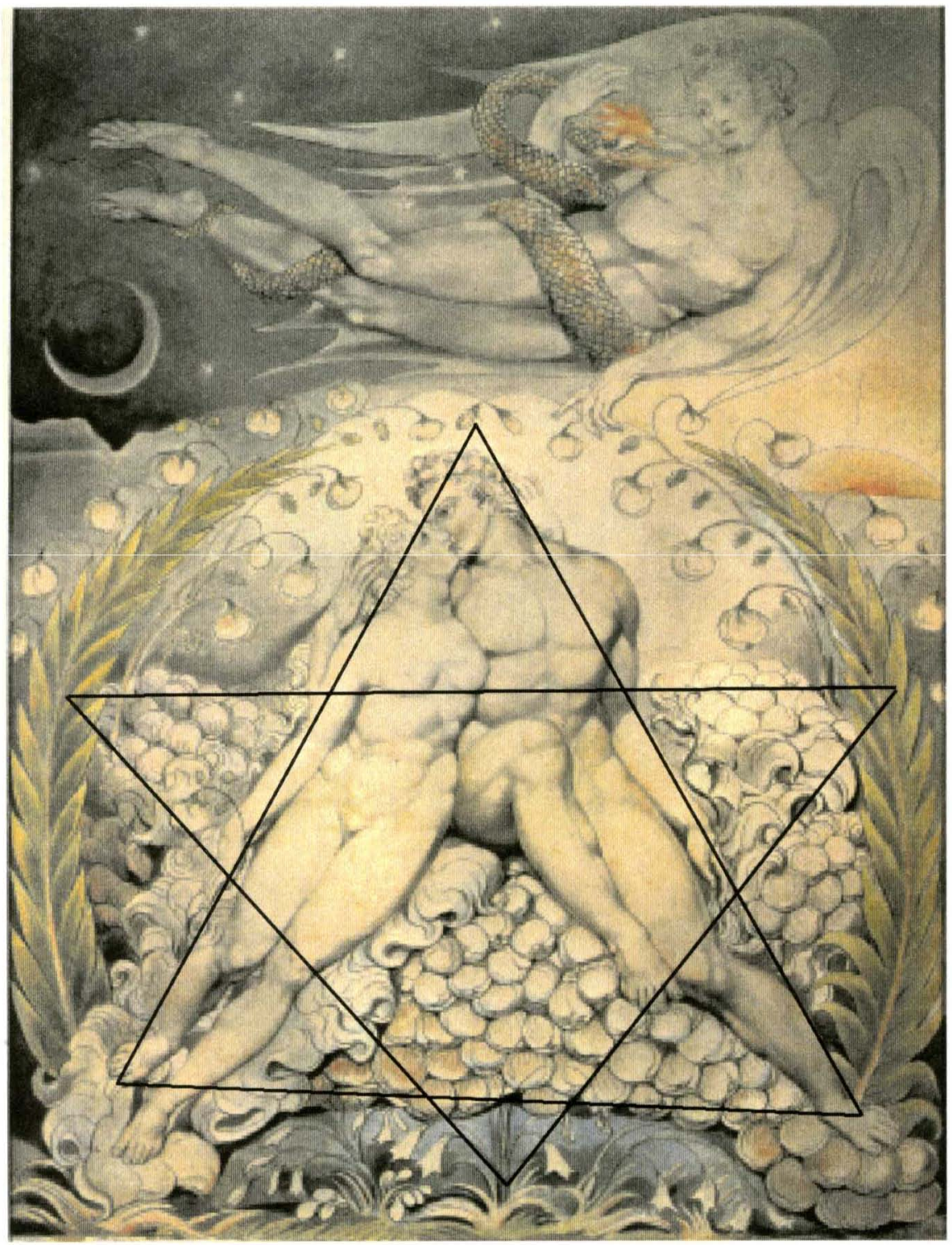

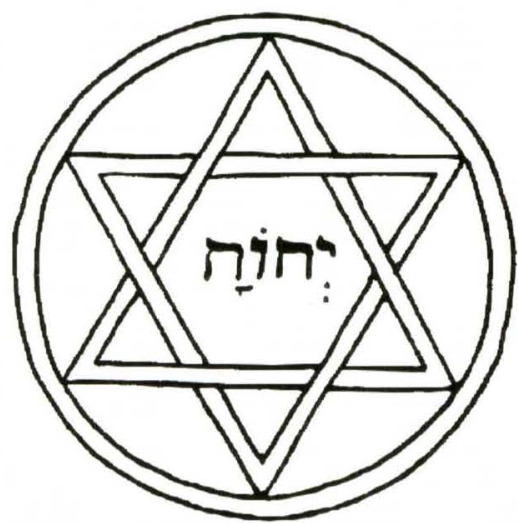

Hexagram: Masonic emblem with the name of God at its center. Ca. 1800

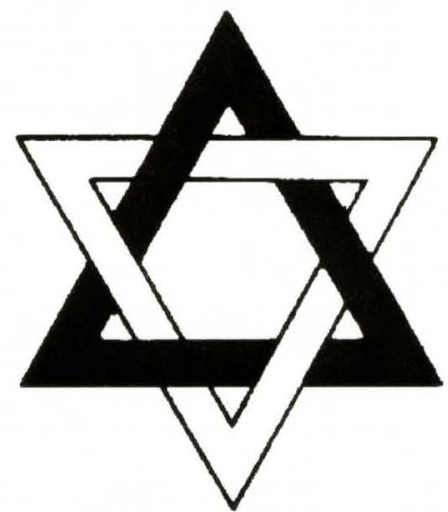

Hexagram constructed from interlocking triangles 


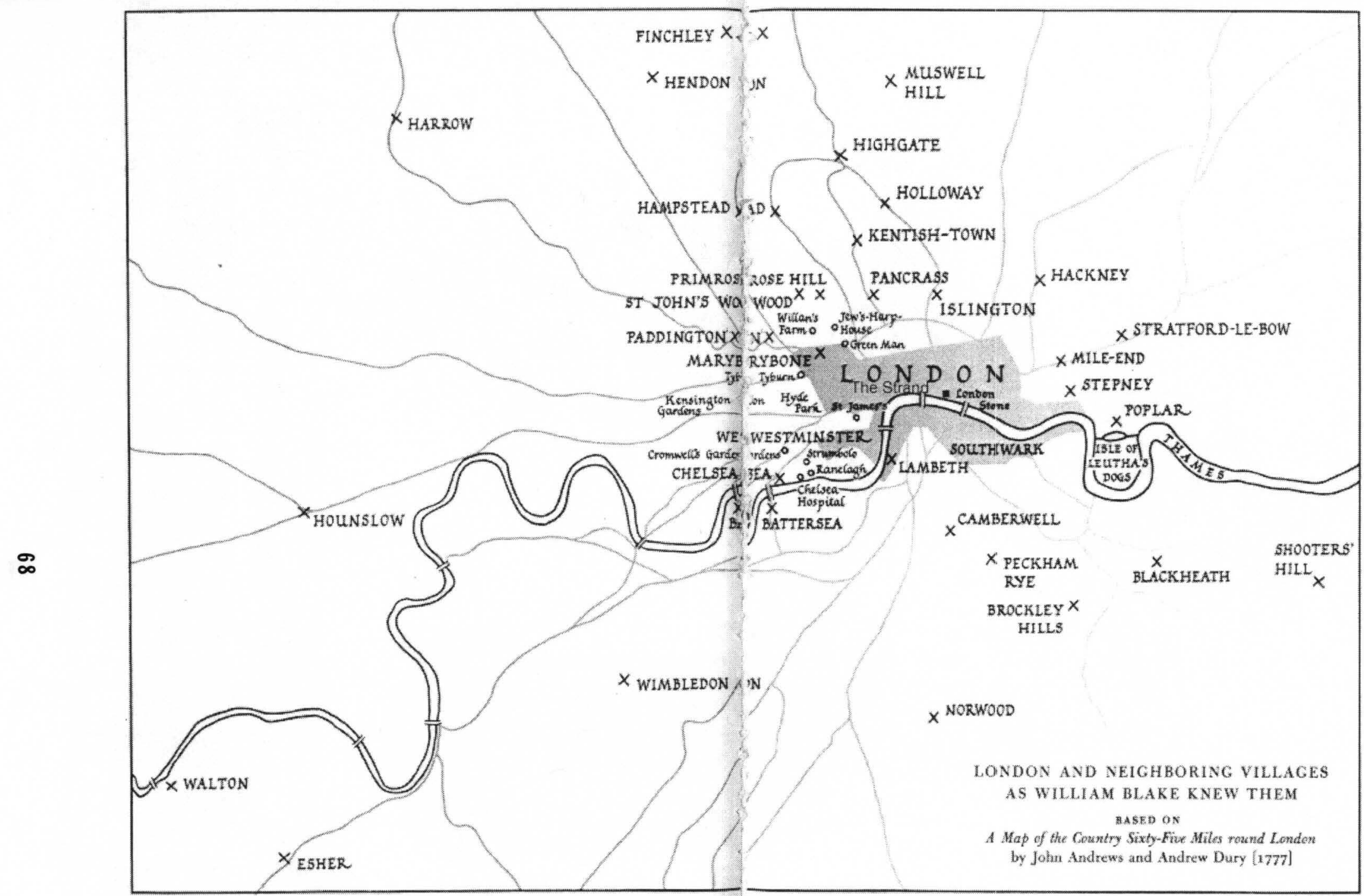

Image 11:

Map of "London and neighboring villages as William Blake knew them," 1777.

Source:

(Damon VII) 
IMAGE 12:

Alchemical Image

This is a page from a well-known treatise on Alchemy called the Rosarium Philosophorum (Rosary of the Philosophers) printed in 1550 in Frankfurt. Jung saw the alchemical symbols of the sun-moon and kingqueen as images symbolically equivalent to the male-female principles and the psychological concepts of the animus-anima.

Source: (Jaffe 126) 

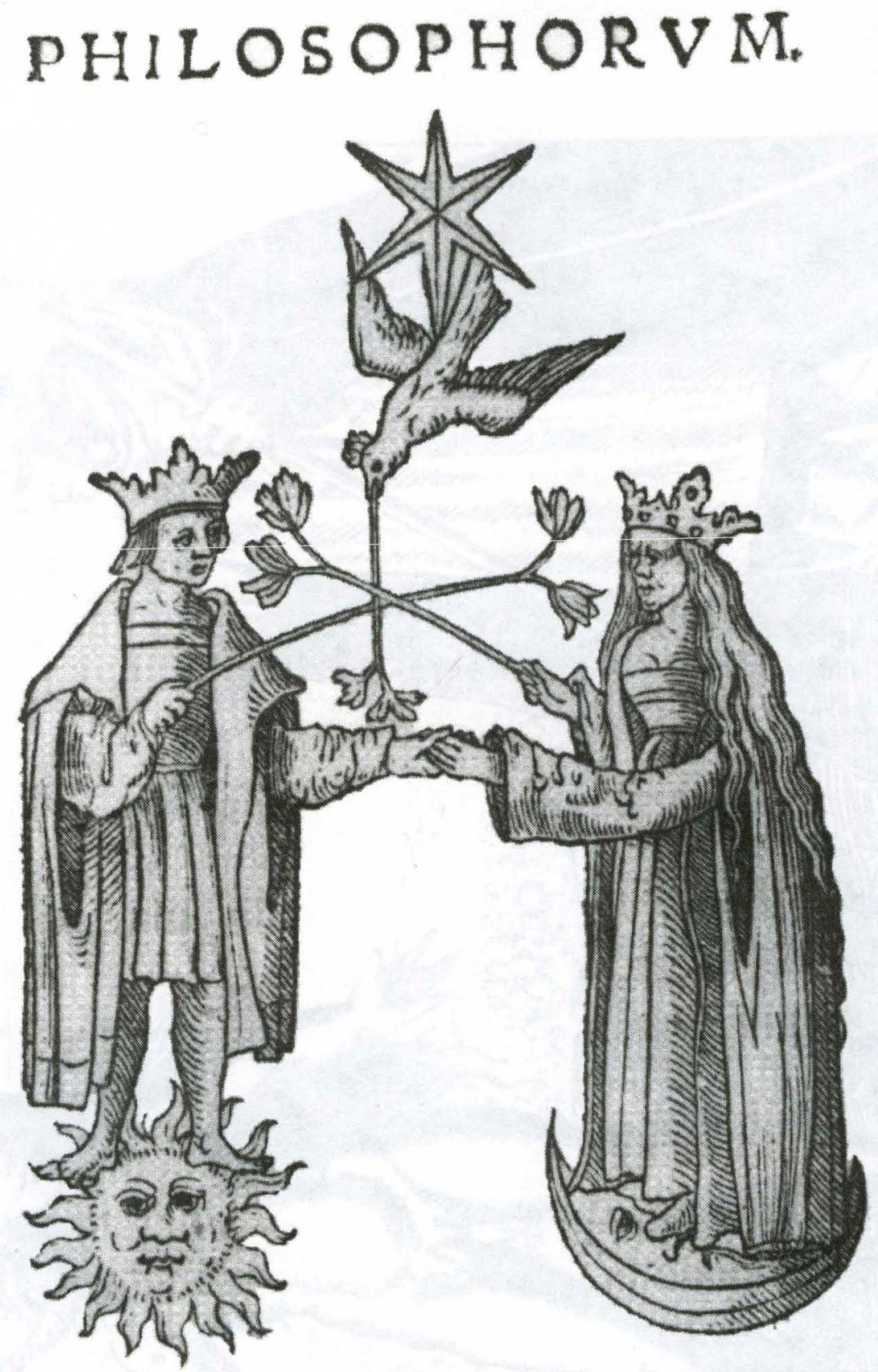

Nota bene: In arte noftri magifterij nihil eft secretum celatũ à Philofophis excepto fecreto artis, quod artis non licet cuiquam reuelare, quod fi fieret ille ma lediceretur, \& indignationem domini incur" reret, \&apoplexia moreretur. Quare om" nis etror in arte exiftit, ex eo, quod debitam. 


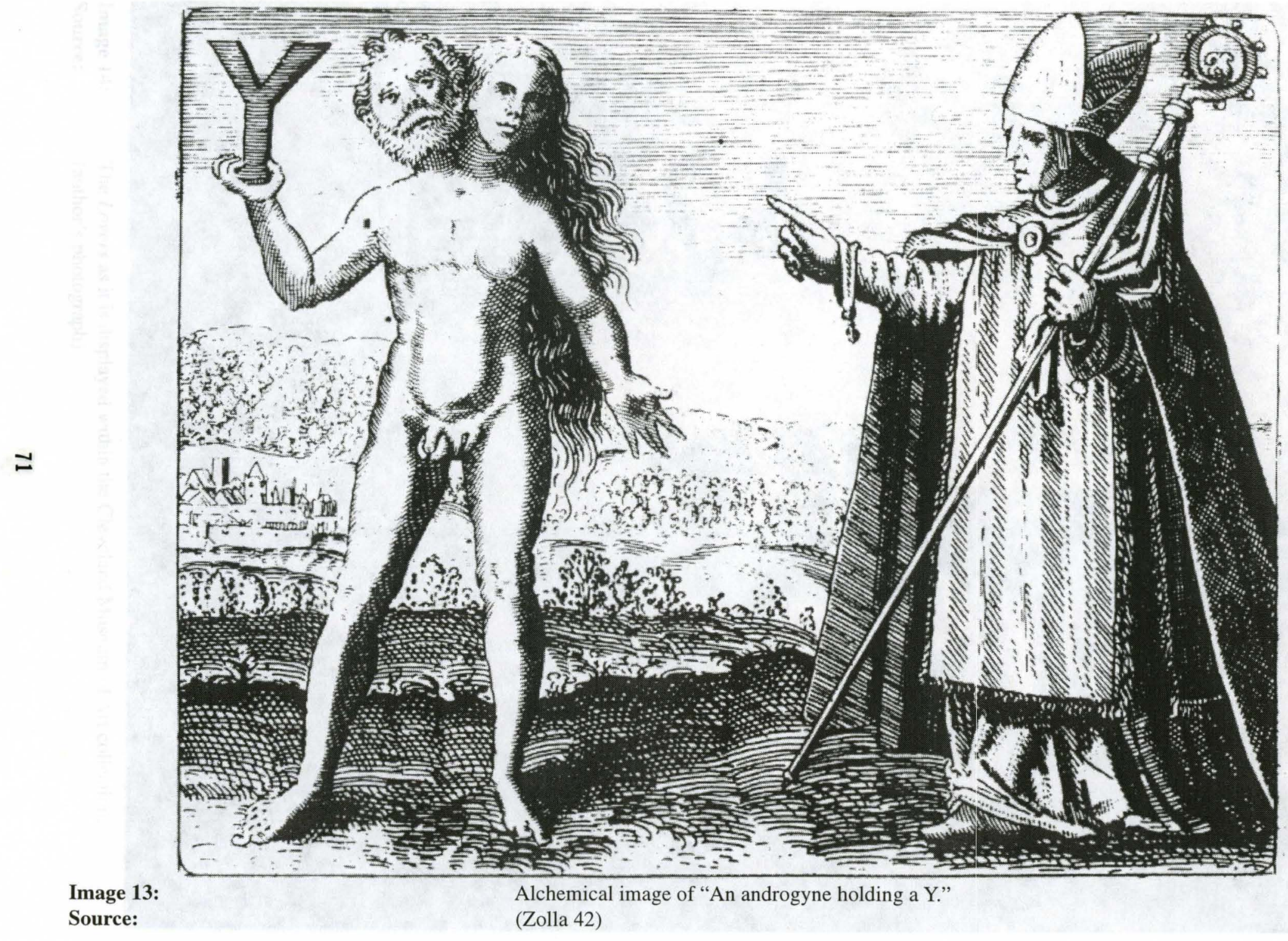




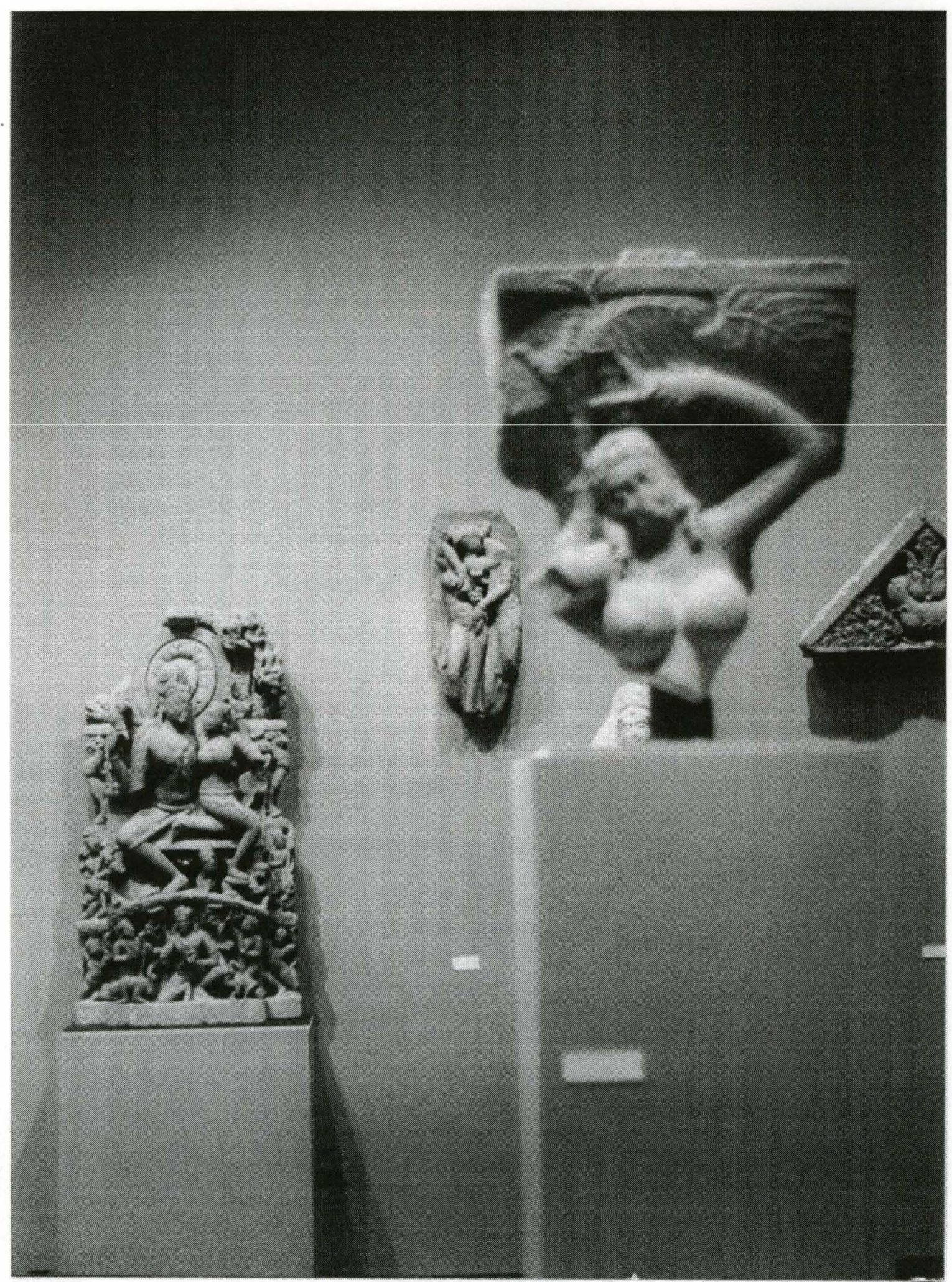

Image 14: The Lovers as it is displayed within the Cleveland Museum of Art collection. Source: (author's photograph) 


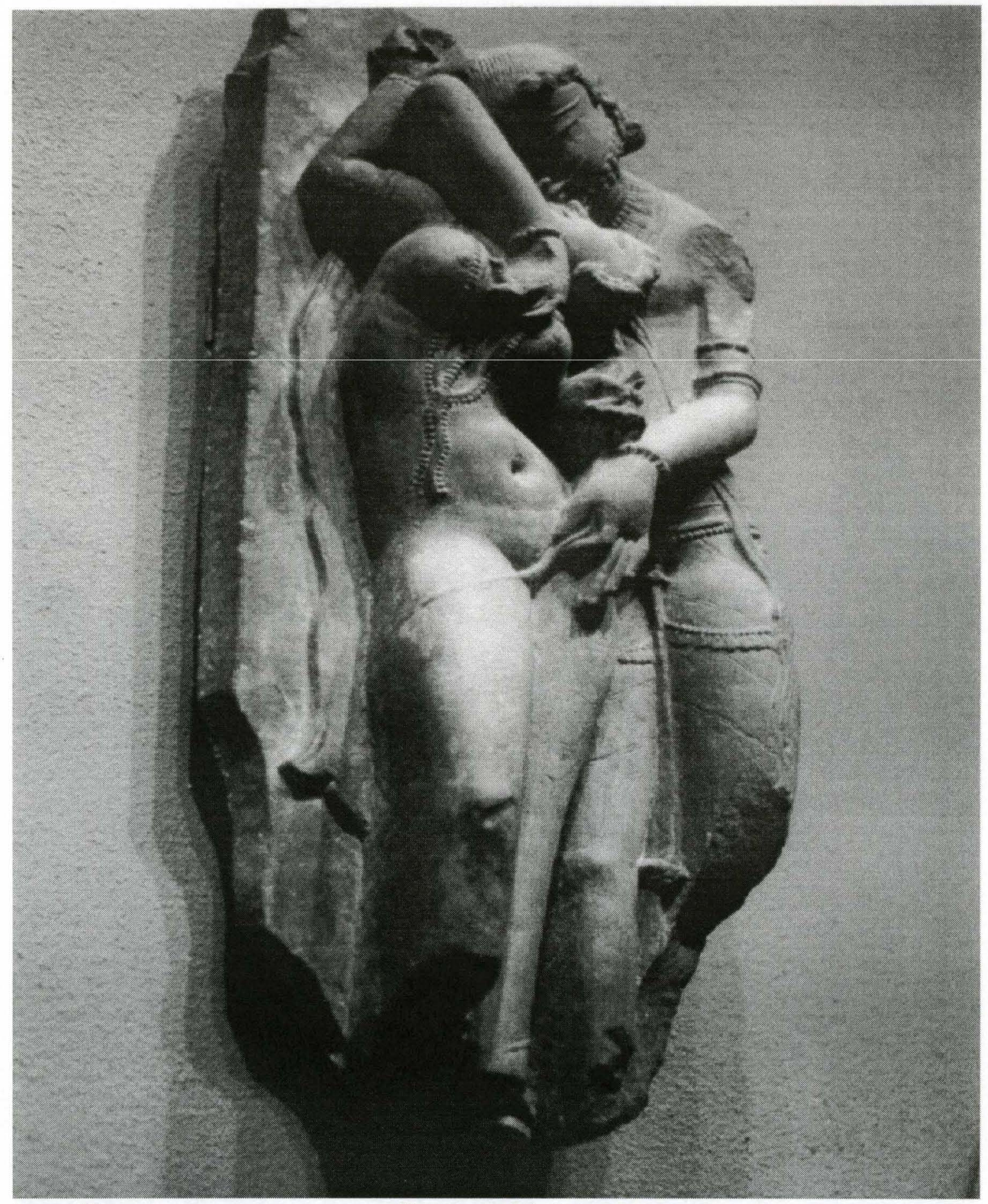

Image 15:

The Lovers. 3/4 view.

Source:

(author's photograph) 


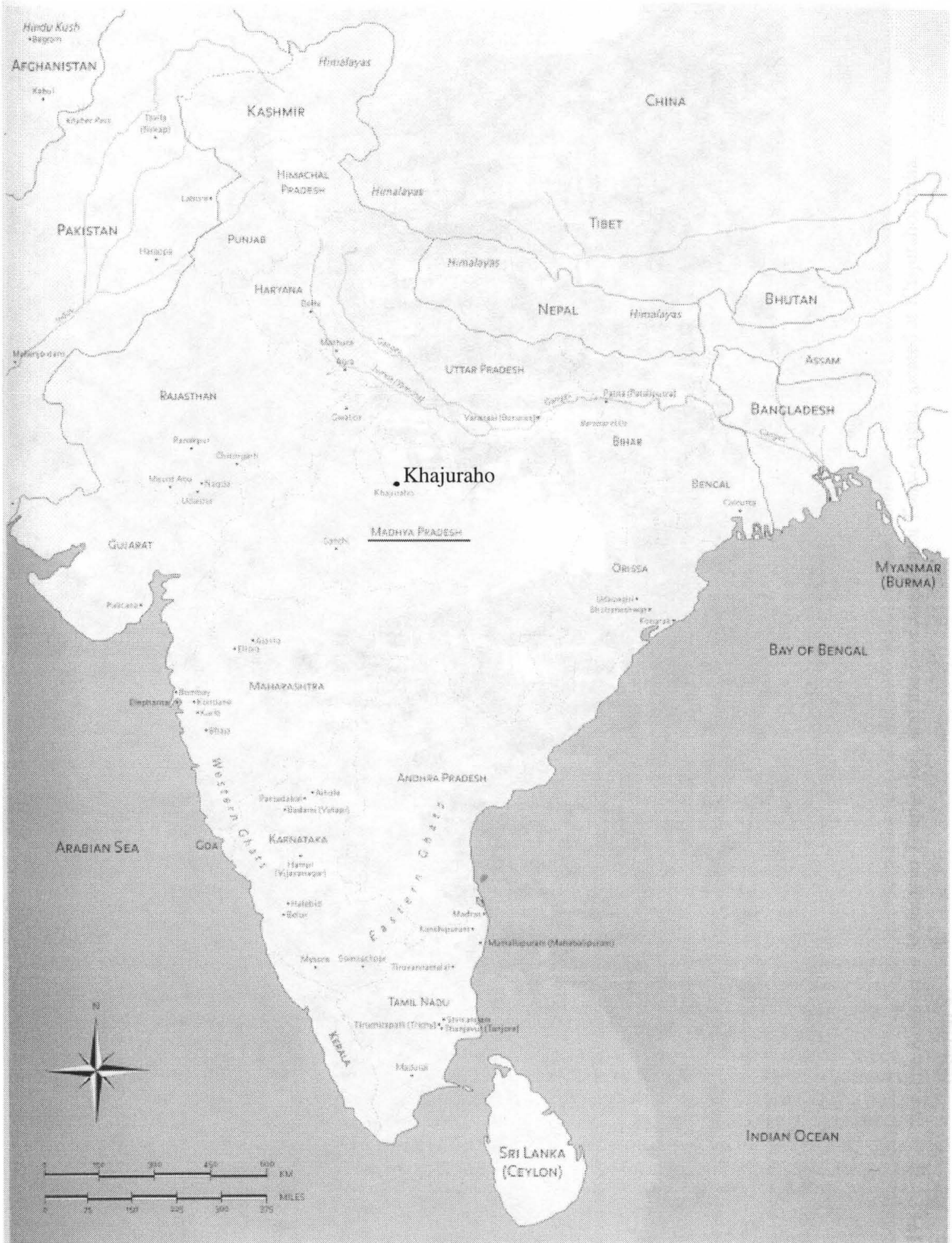

Image 16:

Source:

Map of Medieval India.

(Stierlin 9) 


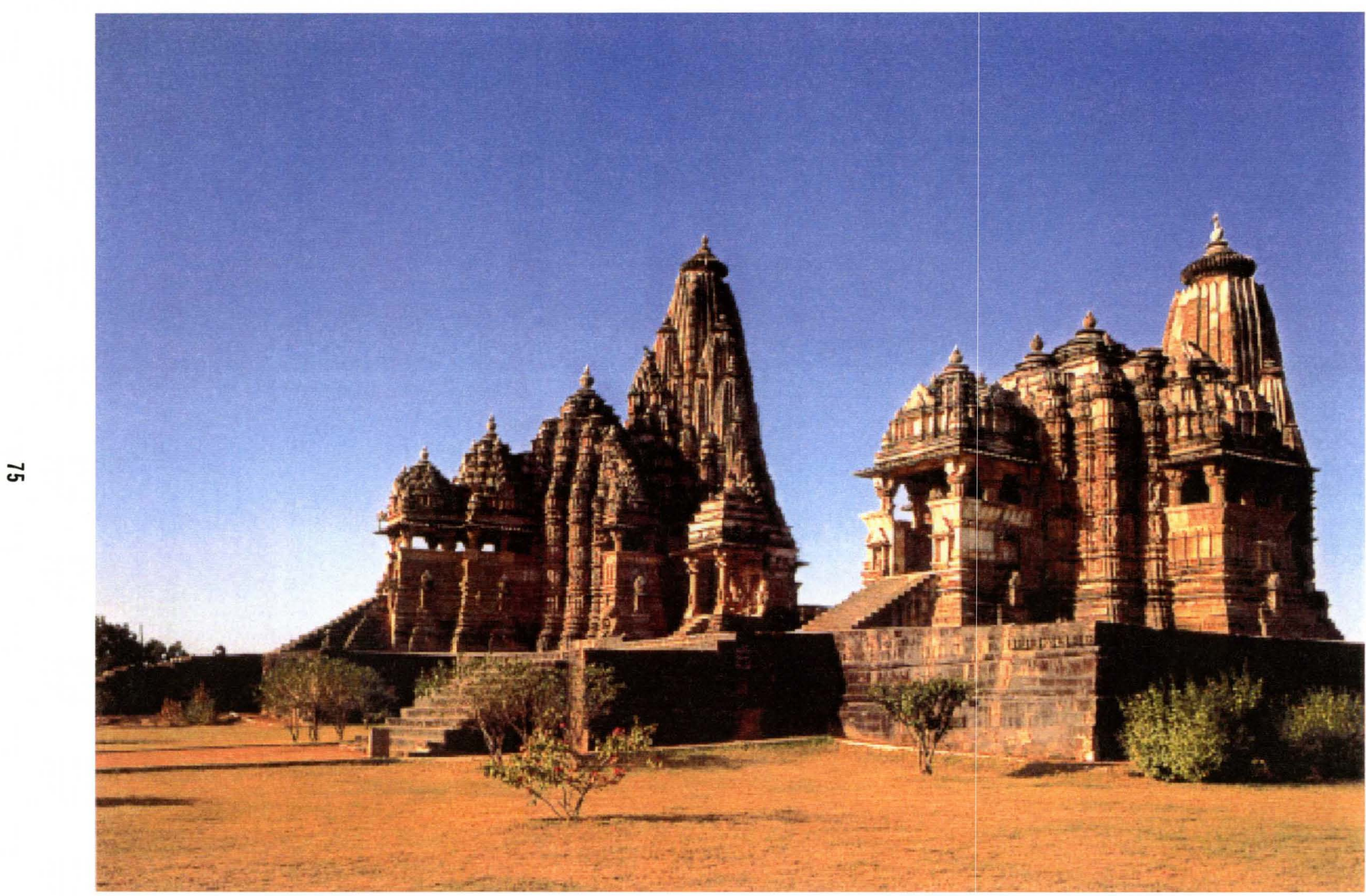

Image 17:

Source:

The Kandariya Mahadeva Temple, left, and the Devi Jagadambi Temple, right, located at Khajuraho, India. (Stierlin 8) 


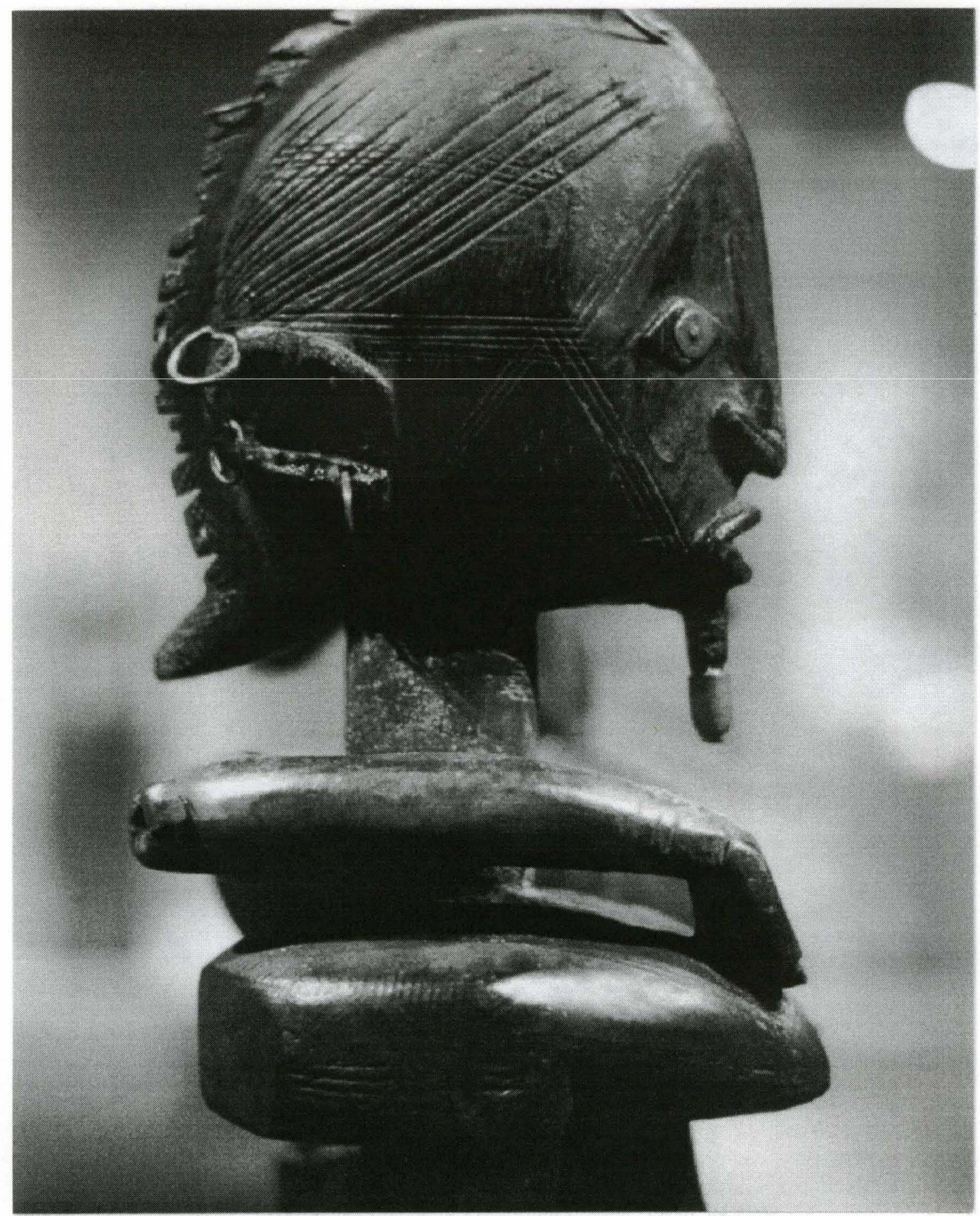

Image 18:

Source:
The Seated Couple or Primordial Couple. Profile of female's bust. (author's photograph) 


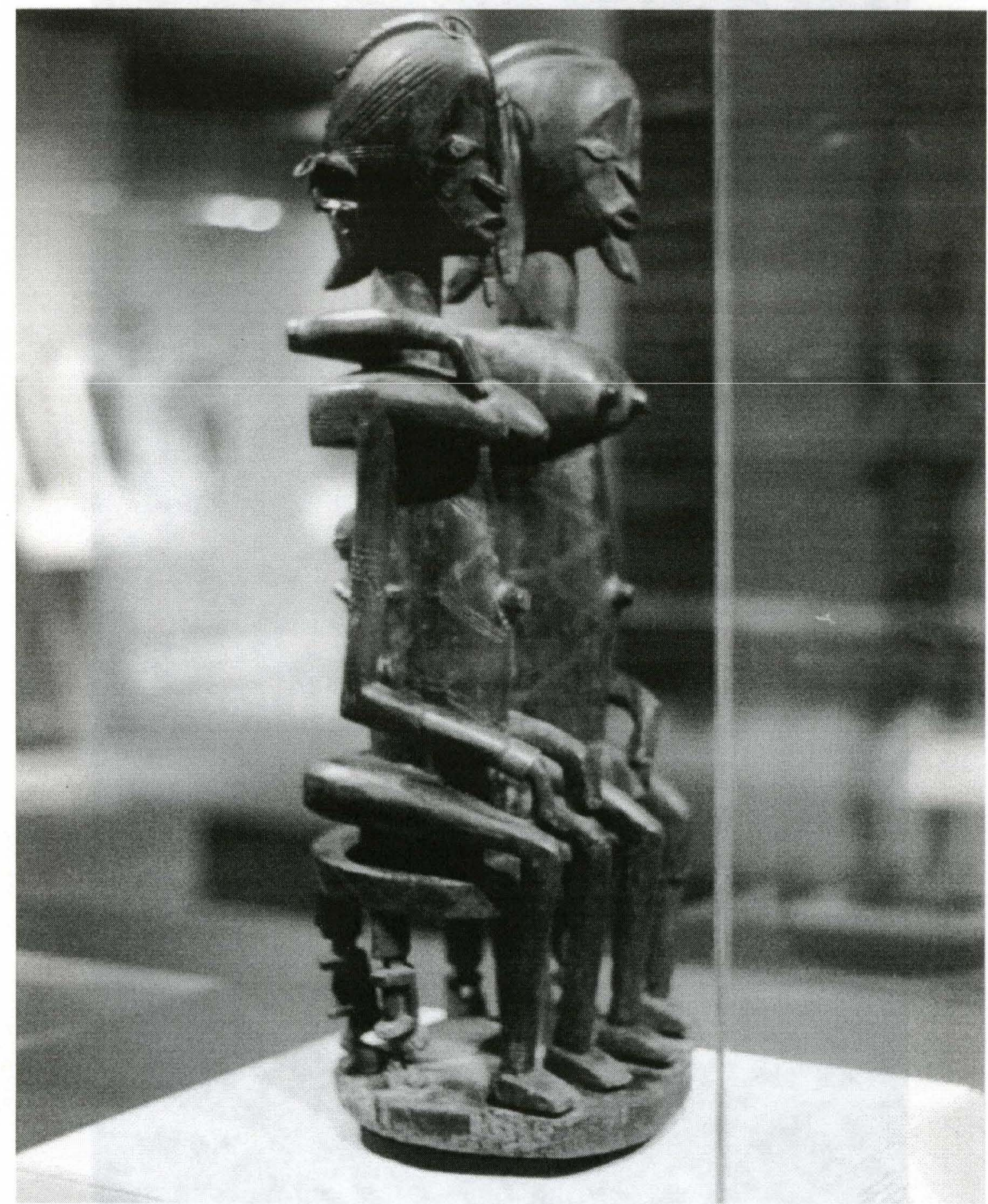

Image 19:

Source:

The Seated Couple or Primordial Couple. Front 3/4 view. (author's photograph) 


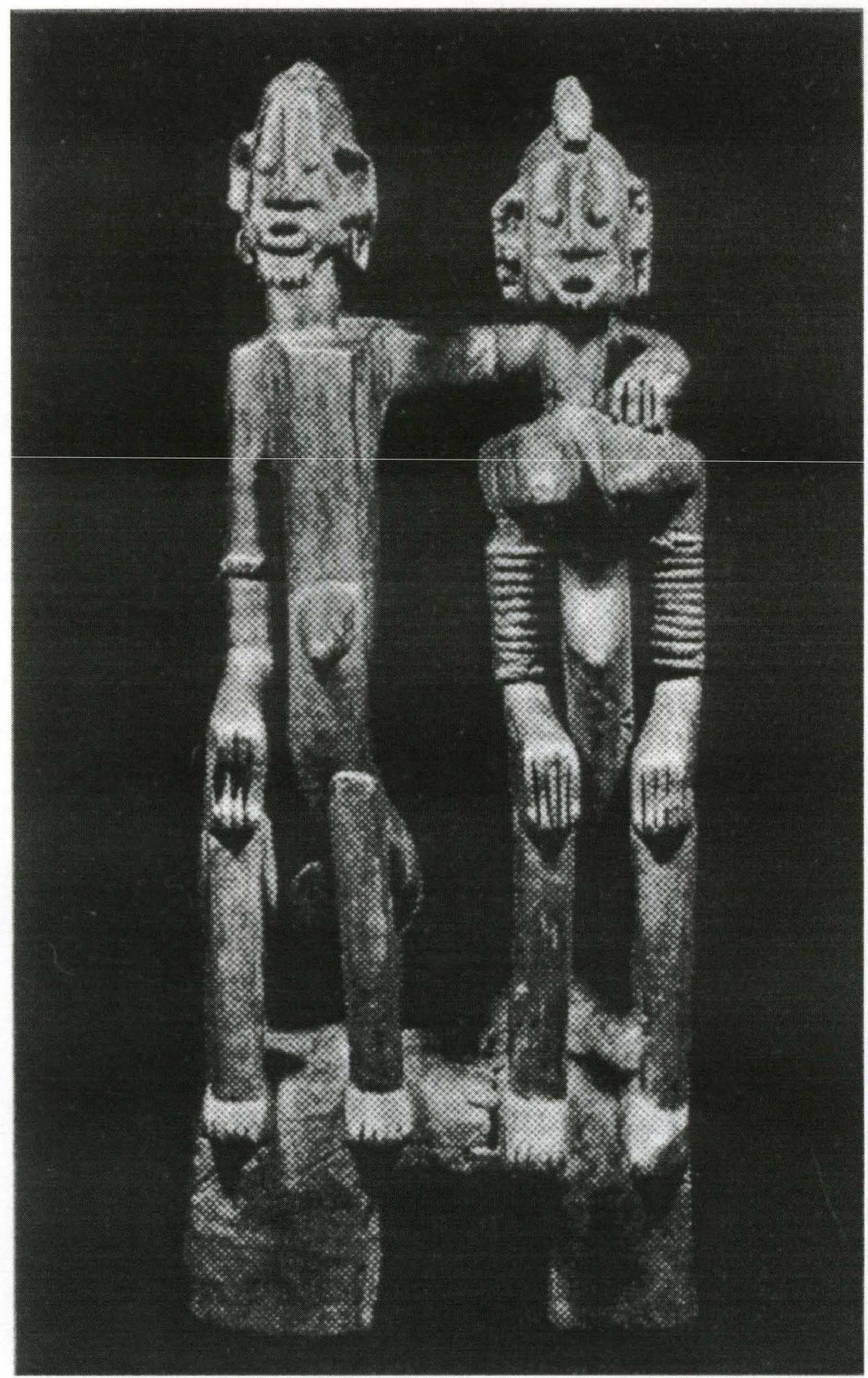

Image 20:

Source:

La Couple Originel, (The Original Couple) or Dogon Primordial Couple. (Leuzinger, Art 37; Paudrat 114-23) 


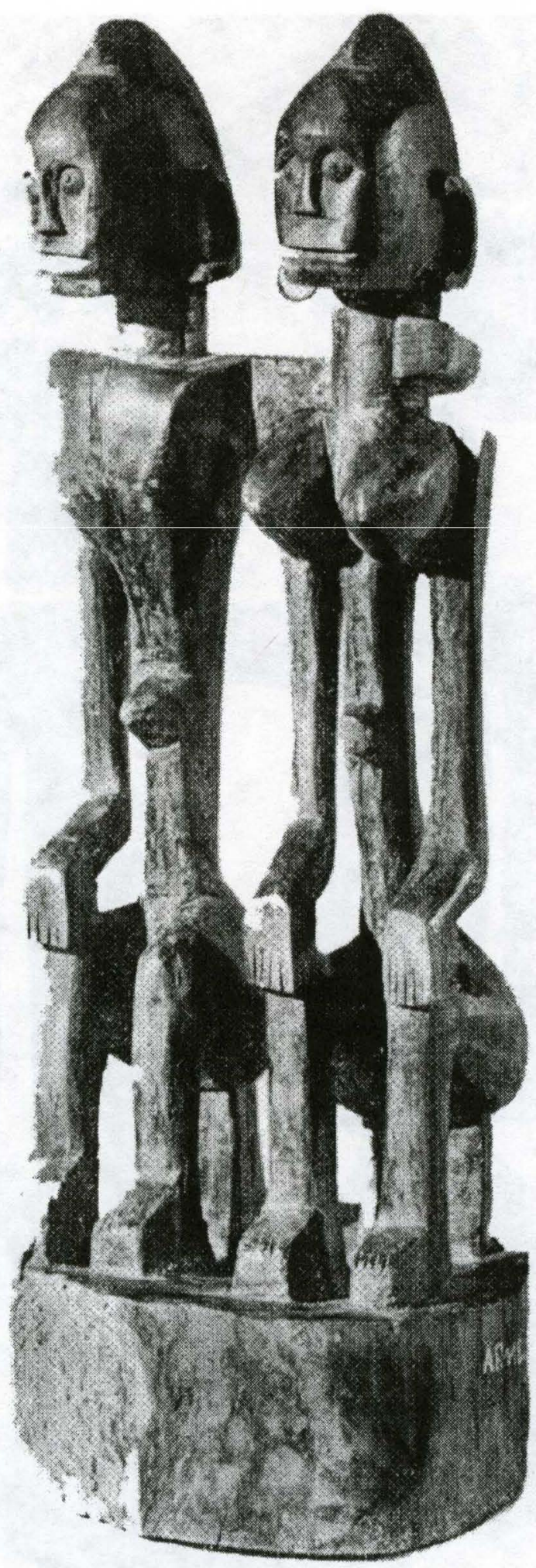

Image 21:

Source:

Dogon Ancestor Pair, or Primordial Couple. (Leuzinger, Art 36) 


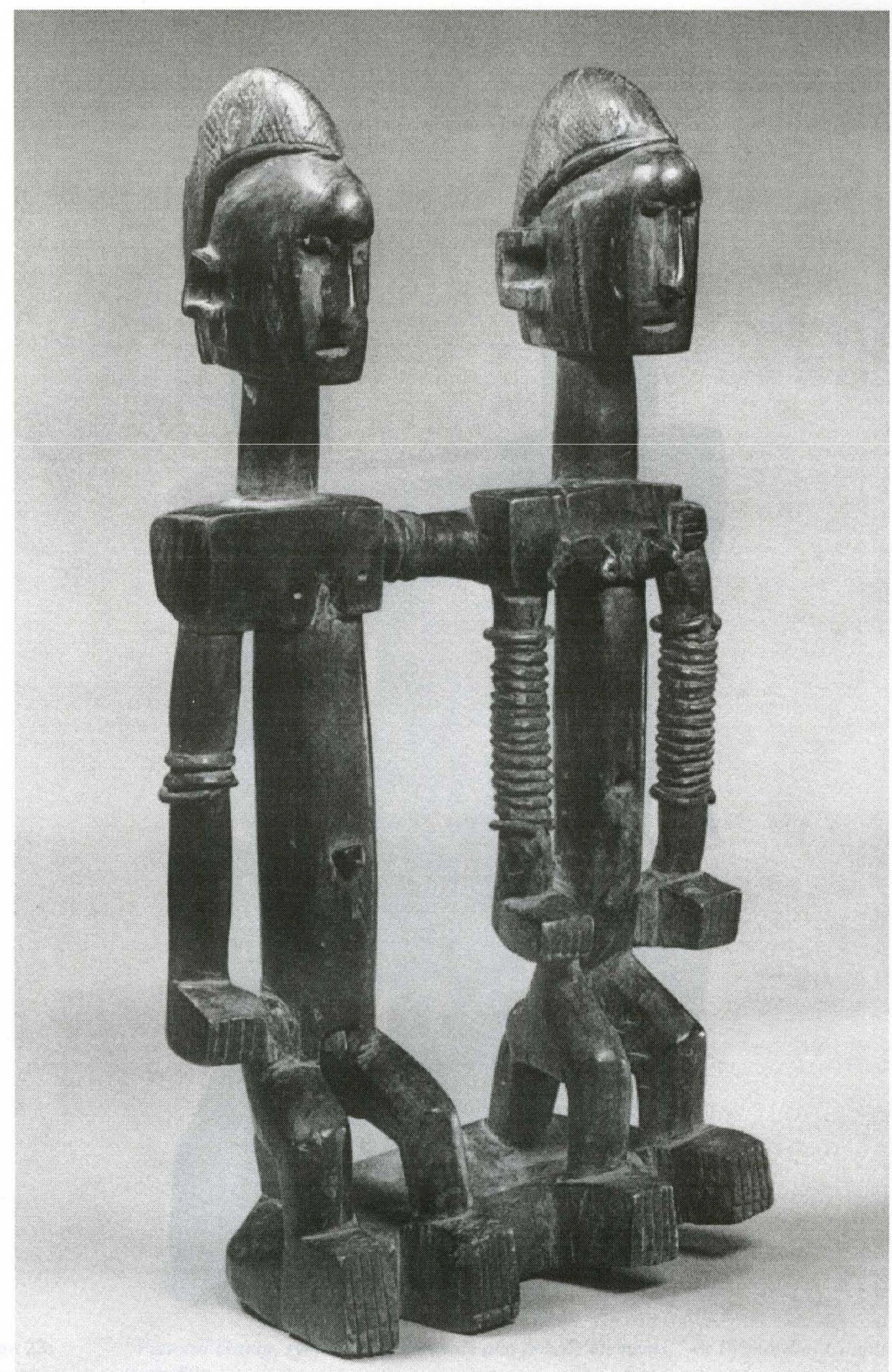

Image 22:

Source:
Dogon Seated Couple or Primordial Couple.

(Ezra, Art 66) 


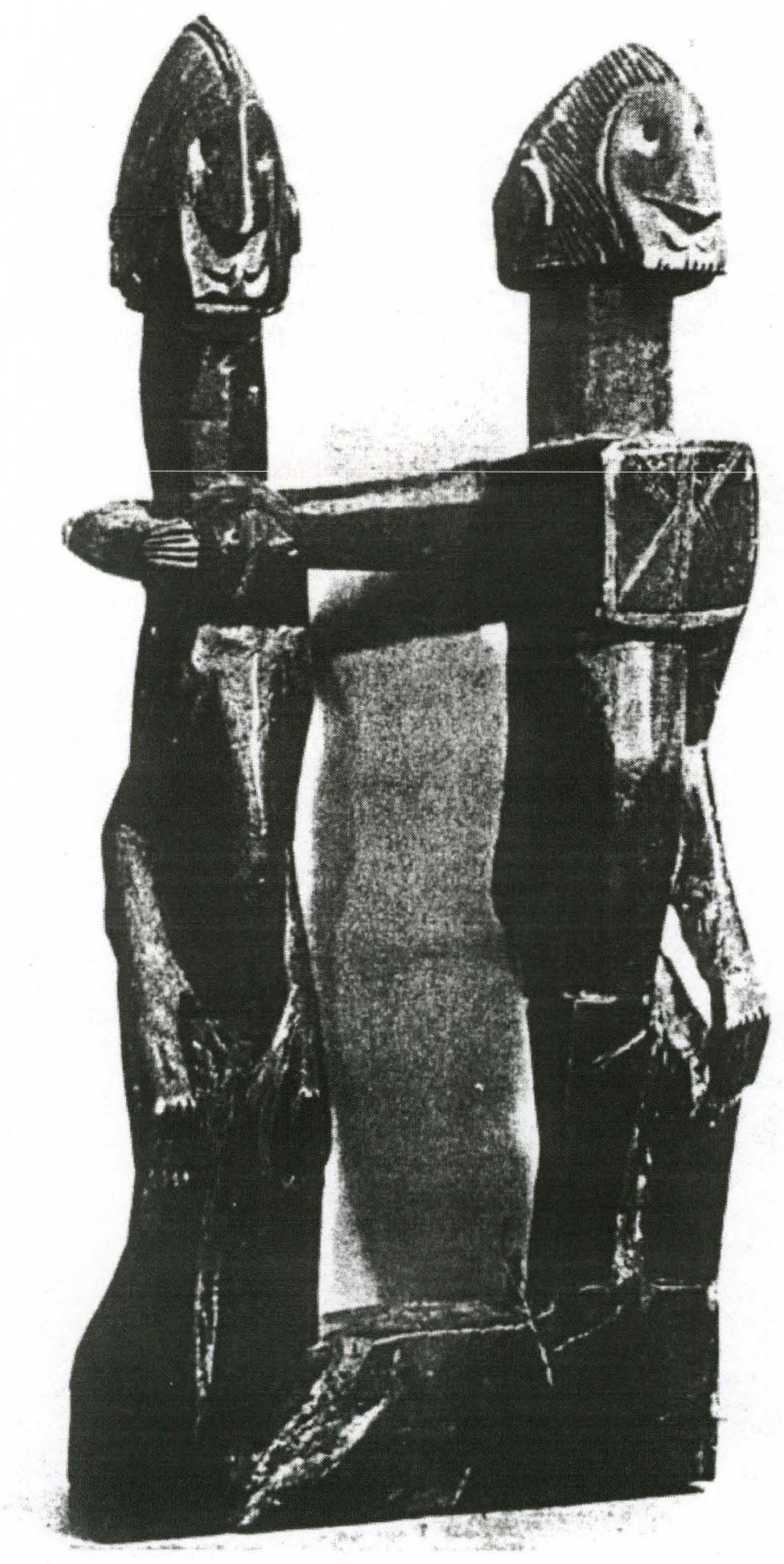

Image 23: "Funeral Group, symbolizing the male and female elements," or Primordial Couple. Source: (Lem 52) 
This figure represents one of the androgynous and serpent-like Nommo water spirit divinities who serve as mythic culture heroes and ancestors to the Dogon people of West Africa. These Nommo divinities, being masters of water, fertility, speech and weaving, are the essential mythic foundation from which Dogon theology is shaped. "The wooden androgyne is seen from the side. It has a long and undulating body and arms beneath small high breasts. The legs have been merged into one serpentine tail, and the head is small above a long cylindrical neck .... The Nommo were flexible and fluid, human from the waist up and serpentine from the waist down (hence their traditional depiction as one-legged creatures). Their bodies were green and sleek all over, gleaming like the surface of water, and covered with fine green hair, a sign of vegetation and generation."

Source: (Moon 362-5) 


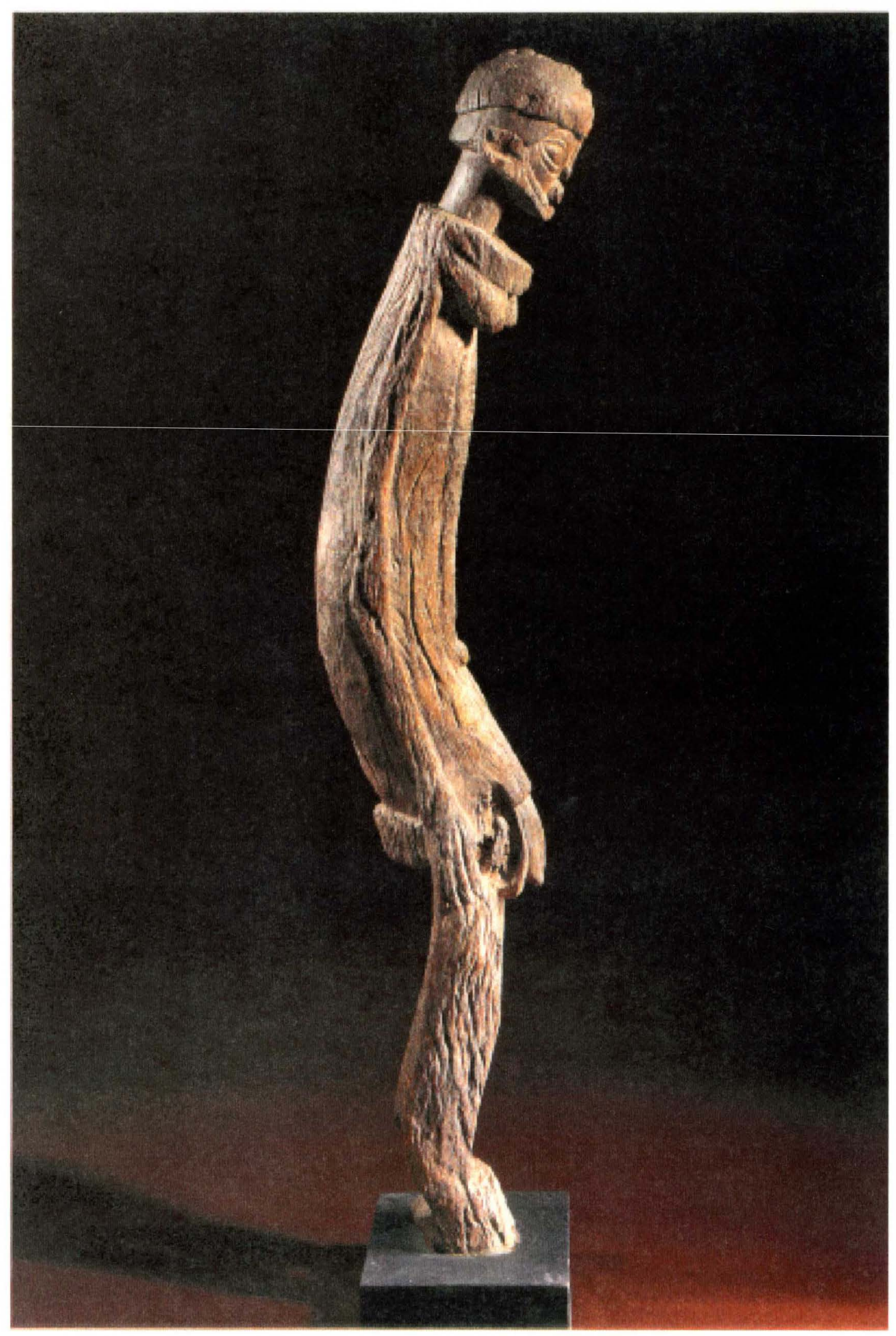




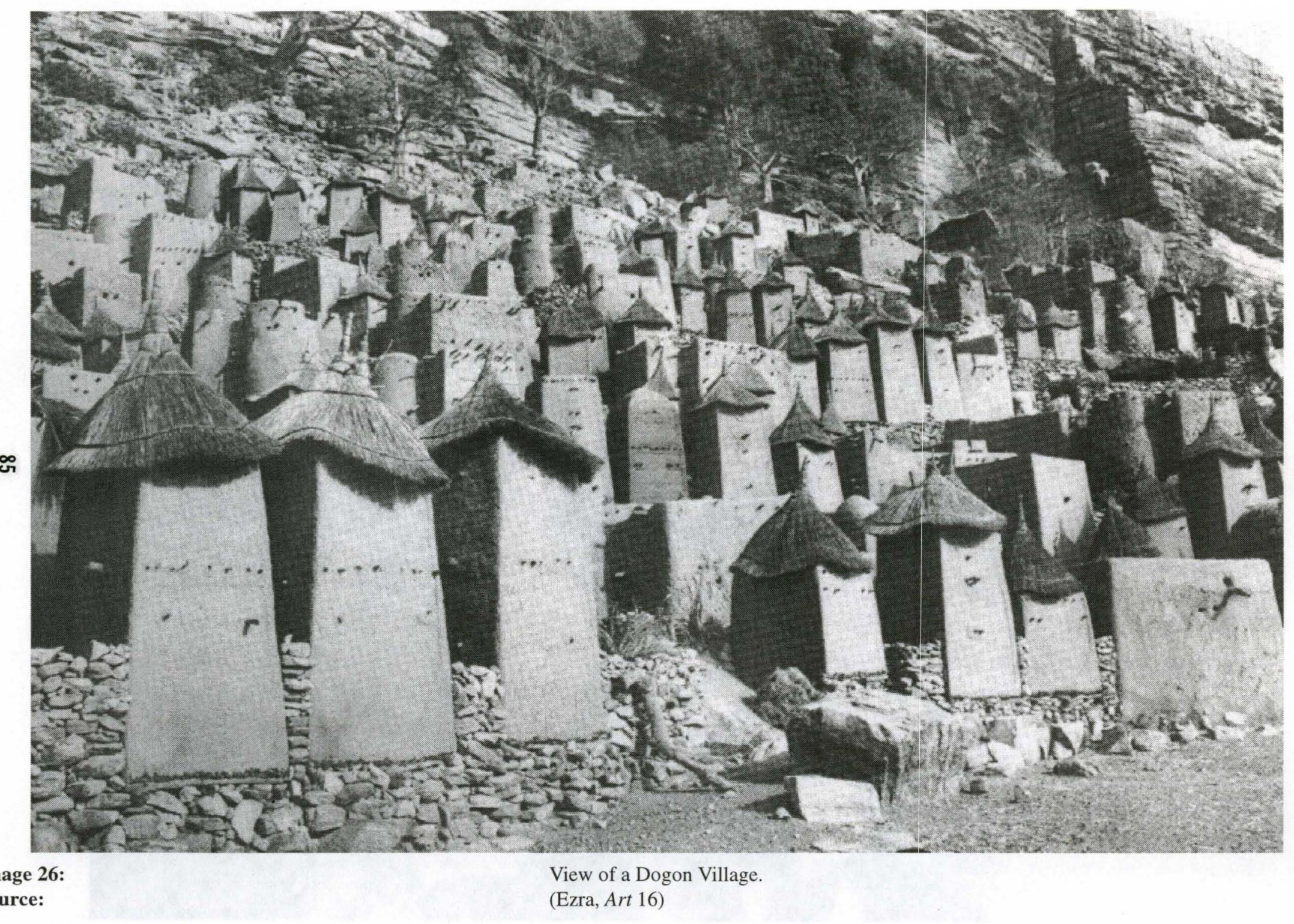




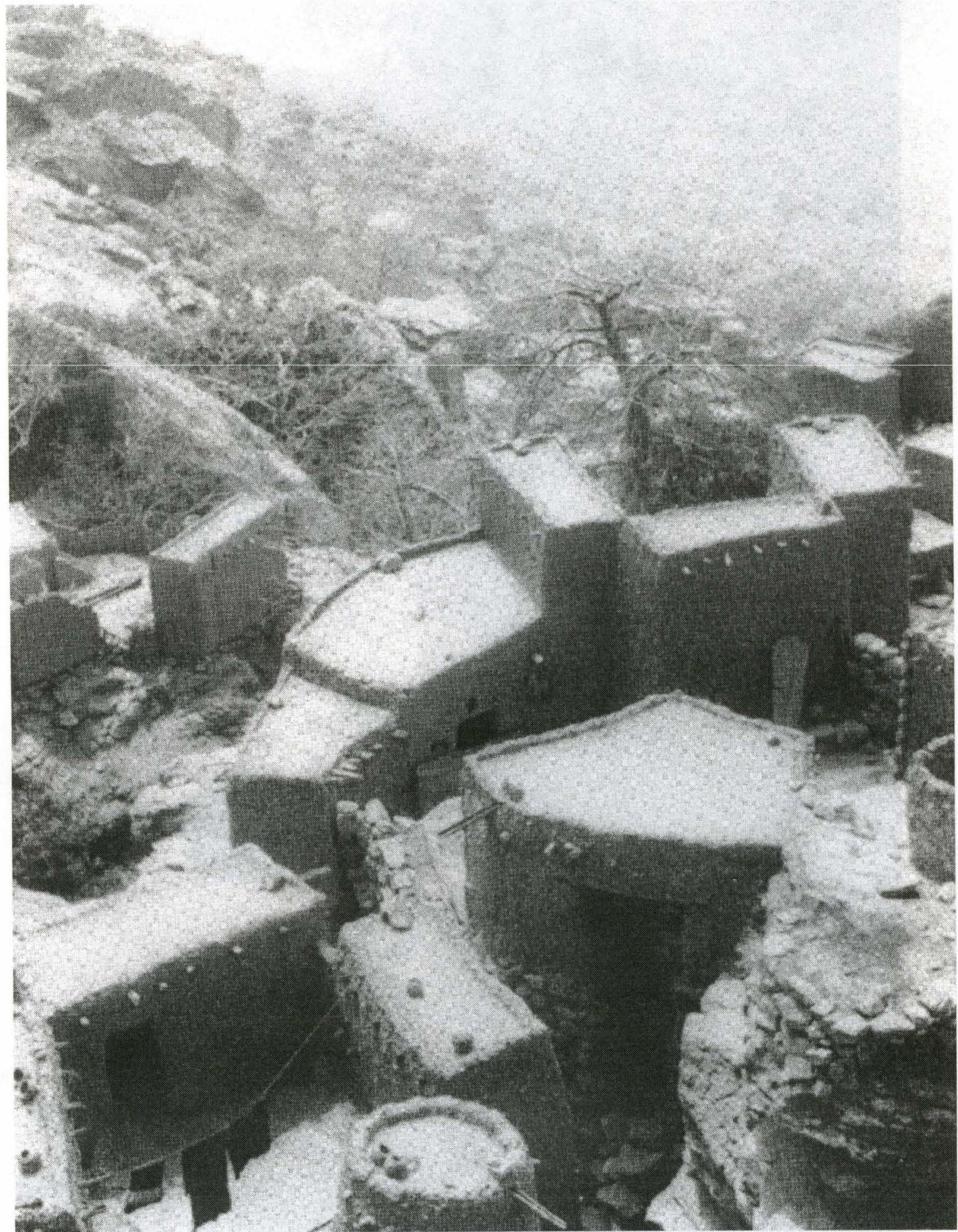

Image 27:

Looking down onto Dogon houses.

Source:

(Ezra, Art 17) 


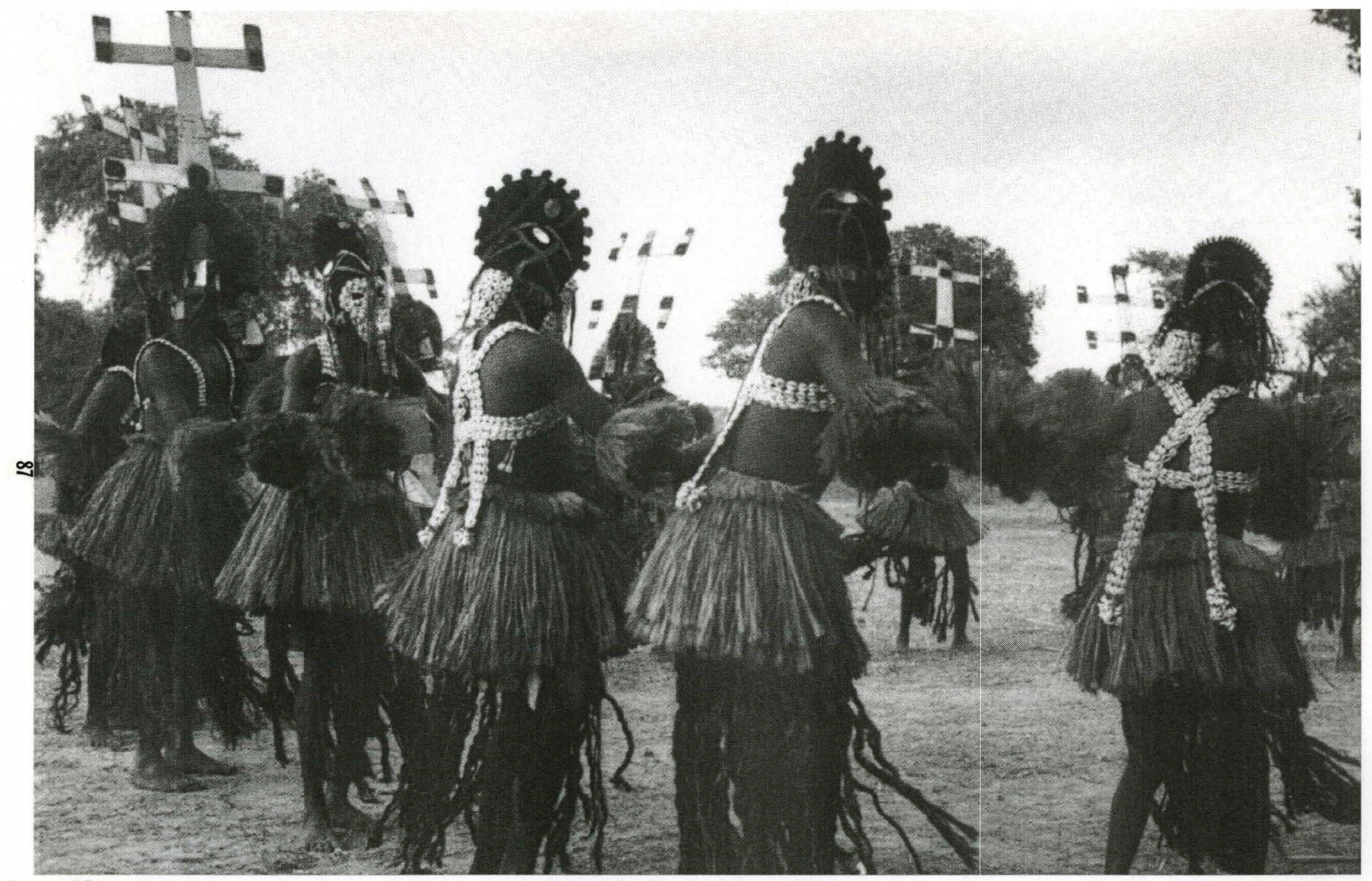


IMAGE 29:

The Ancient Androgyne

The Ancient Androgyne is a Dogon religious icon which is representative of the completeness and perfection of the primordial and first human-like beings created by Amma (God) in the "dream time," before the existence of time-space. Although hermaphroditism is within some traditions considered to be a sign of freakishness, conversely among the Dogon, this "hermaphrodite" clearly carries connotations of divinity and perfection. According to Dogon religious belief, "The androgyny of the Nommo is a primordial form of androgyny, that is [to say], it is not the result of fusion but ontologically present from the start ... . The original Nommo ... were born ... in accordance with the divine order. They had both male and female characteristics as a sign of their completeness."

Sources: (Paudrat 23; Moon 363). 


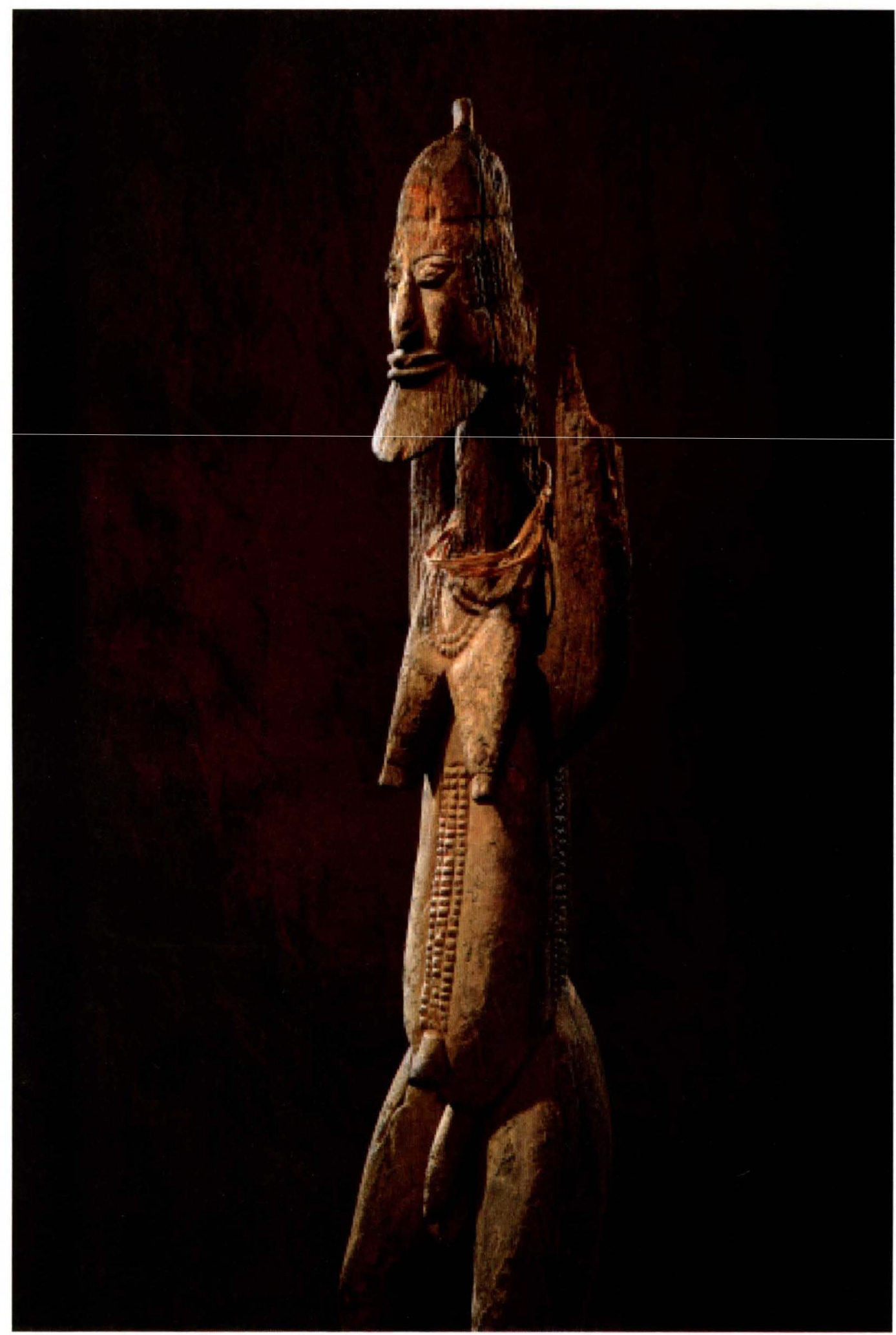

Image 29: Le Vieillard Androgyne (The Ancient Androgyne) or Dogon hermaphrodite Nummo. Source: (Paudrat 23) 
"In India Siva is essentially androgyne even when his aspect is male. In the hymn devoted to him at the opening of the Tamil Sangha Anthology, it is said that 'Half his body enfolds the opposite sex, / His form sucks it in and hides it up". When his dual nature is displayed, he is called Ardhanarisvara, male-female Lord ... and to Tantric practitioners symbolizes the state of samarasa, the 'flavor of sameness', in which breathing and thinking cease and semen is stayed." Robert Zaehner writes: In the full figure of Shiva . . the male and female principles are united, and he himself is sometimes represented as half male and half female .... The significance of Shiva is that he is the reconciliation of all opposites: therefore he is both creator and destroyer, terrible and mild, good and evil ... . Lingam [or phallus] and yoni (the female organ) together represent the totality of Nature and of all created existence (2367).

Source: (Zolla 74; Zaehner 2367). 


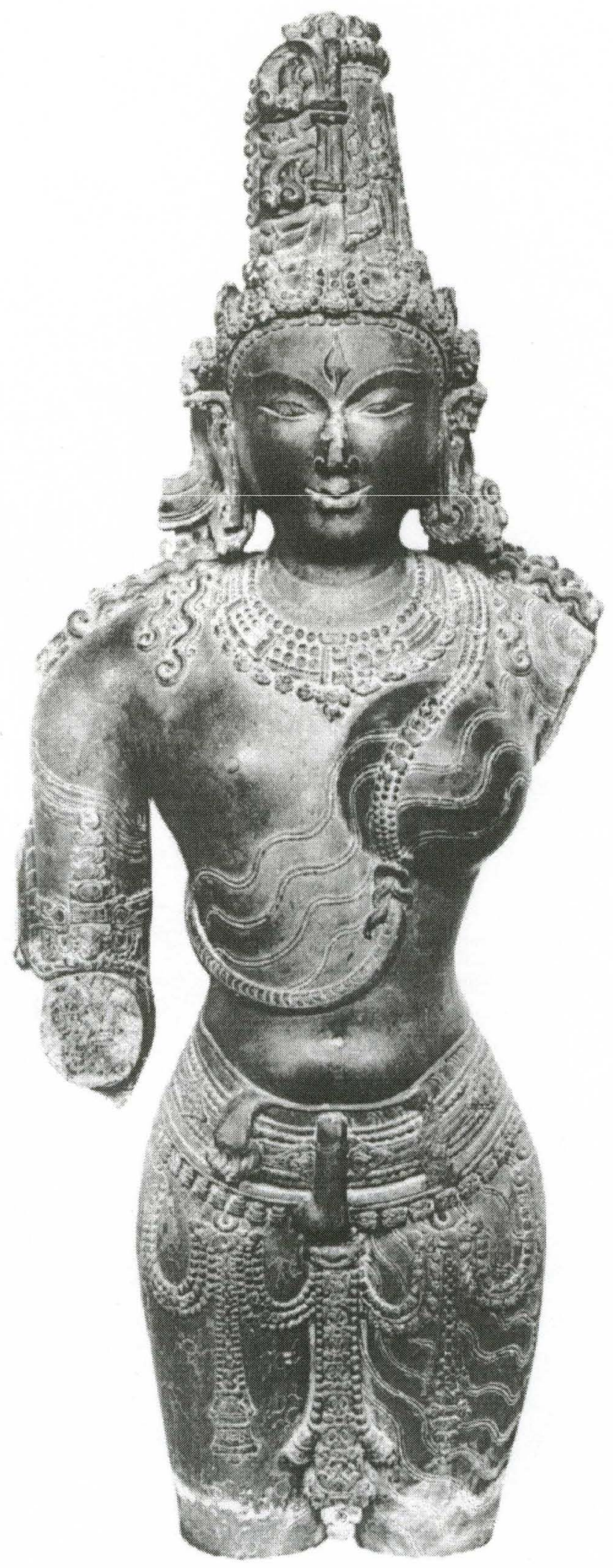




\section{IMAGE 31:}

\section{Egyptian Androgyne}

"Most of the gods in Egypt were androgynous .... The statue [on the right] has been identified with the Nile, in which case its bisexuality would also stress the Nile's character as world axis and unifier of the country. A particular striking feature of this androgyne (among many in Egyptian art), is its quiet assurance and the sweeping, easy gait, which convey the sense of a peculiar kind of power, emanating from the inner balance of androgyny."

Source: (Zolla 58-9). 


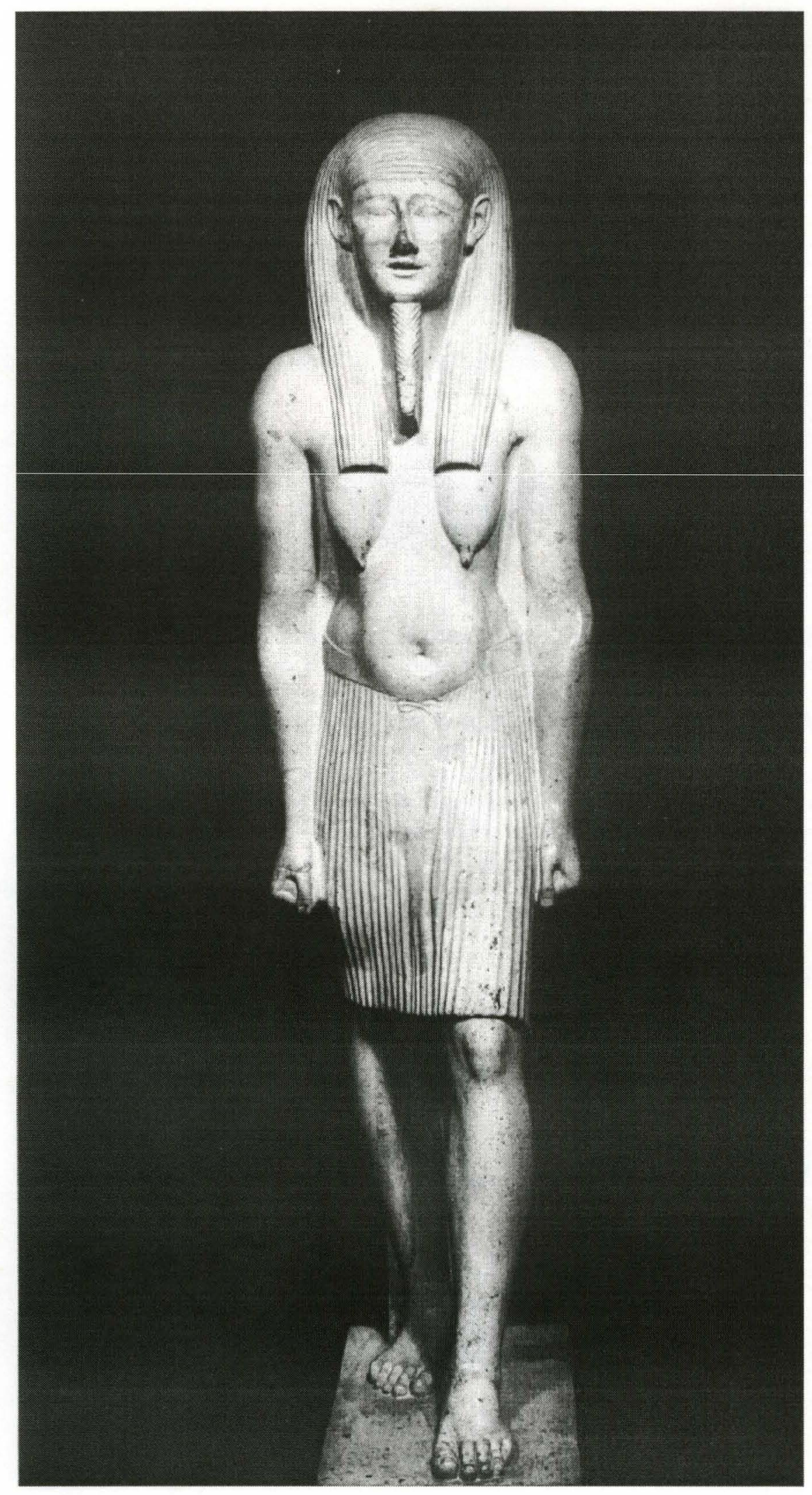


IMAGE 32:

Jung's Compass

This compass of the psyche shows the interrelational, interdependent and complementary four zones of thinking, feeling, sensation and intuition. Jung (and Blake) espoused that the healthiest area on this compass was in the central area, were all four psychological inclinations were integrated and balanced. Jung believed that the inclinations of thinking (reason), feeling (emotions), sensation (body) and intuition (spirit) must be consciously controllable and integrated for a person to have psychological wholeness. Similarly, Blake believed that original divine humankind had possessed before 'the fall,' in addition to androgyny, a spiritually or psychically integrated wholeness by having the four elements of reason (thinking), emotion (feeling), body (sensation) and spirit (intuition) united and balanced. For a "thinking" type personality, the "feeling" side would be least developed. In a "sensation" type personality, the thinking or the feeling side could be almost as strong. Of course, these zones can be overlapping in each individual.

Source: (Jung, Man 60; Damon) 

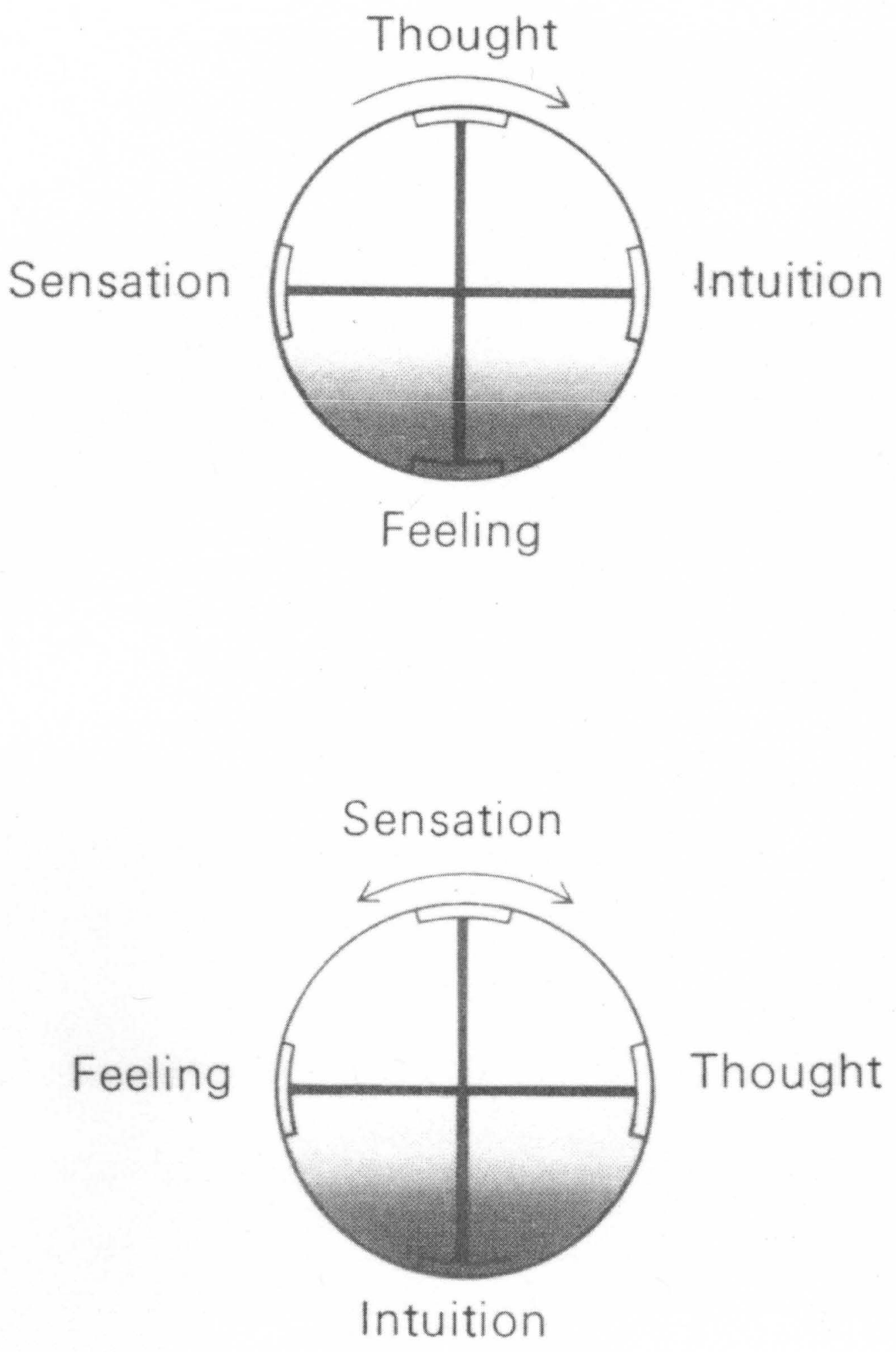
Created for a native American Navajo "Shootingway chant" and depicted in sand painting circa 1940 CE is "Father Sky. Mother Earth, and Rainbow." Father Sky and Mother Earth are common mythological figures. They broadly "represent the two great symbol systems of the heavens. and the earth. transcendence and life ... . The natural world is [seen as] a unified system depending on the light, rain, and air of the heavens in conjunction with the soil of the earth for the world of vegetation and animal life ... This unity is symbolized in the marriage of [male and female as] Heaven and Earth. The rainbow often represents this union, providing a bridge between the two realms."

Source: (Moon 202-5) 


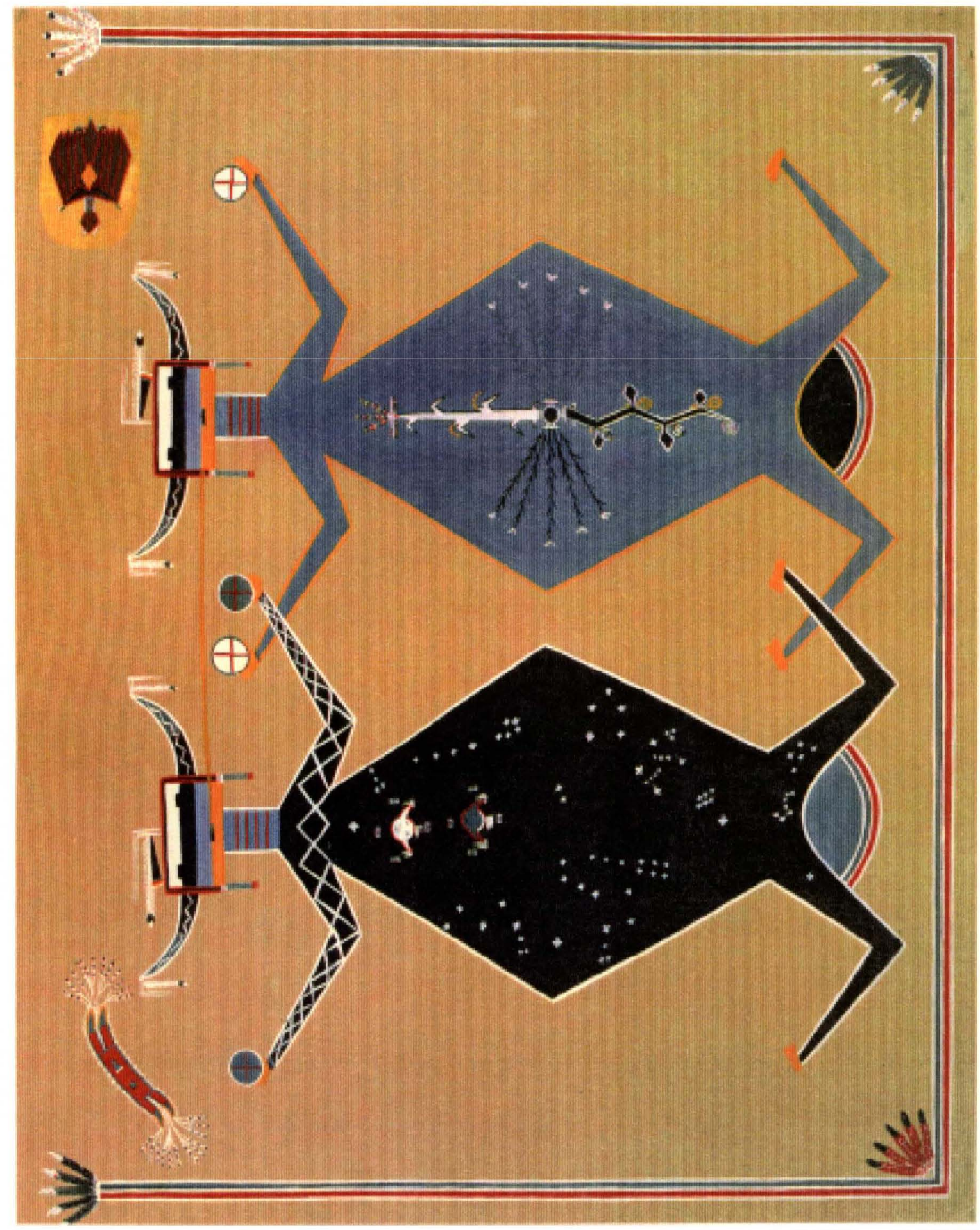


IMAGE 34:

Mythical Horned and Double-Sexed Creature

The belief in a Mythical Horned and Double-Sexed Creature ". . . dates back to the very first Inative American] settlers, at least in the Colorado region." The hermaphroditic figure, pictured on the right, is from a 1st century AD painted pottery bowl from Colorado. This horned hermaphroditic configuration has also been discovered drawn on the wall of a Colorado cave. "The tradition [of this mythical bisexual creature] is carried on even today among esoteric native [American] societies. [such] as in the case of Maria Sabina, one of the very few fairly well documented cases of shamanic androgynization .... 'Santosanta, santo-santa' [(Spanish for: male-saint, female-saint)] becomes an incantation. Feeling her/himself to be both a male and a female saint helps the shaman rise above human, limited existence."

Source: (Zolla 12, 82-3)

The broad implication of this thesis is that the anima-animus, often portrayed within 'the arts,' is inherent to all cultures because this motif emanates from humankind's collective unconscious. This coalesced anima-animus is found to be common among differing cultures that have developed over the centuries unaccustomed to one another. Although this thesis has focused on only three world traditions, a much broader research should document the presence of this archetype among many varying cultures, such as native American, Australasian and Oceanic. 


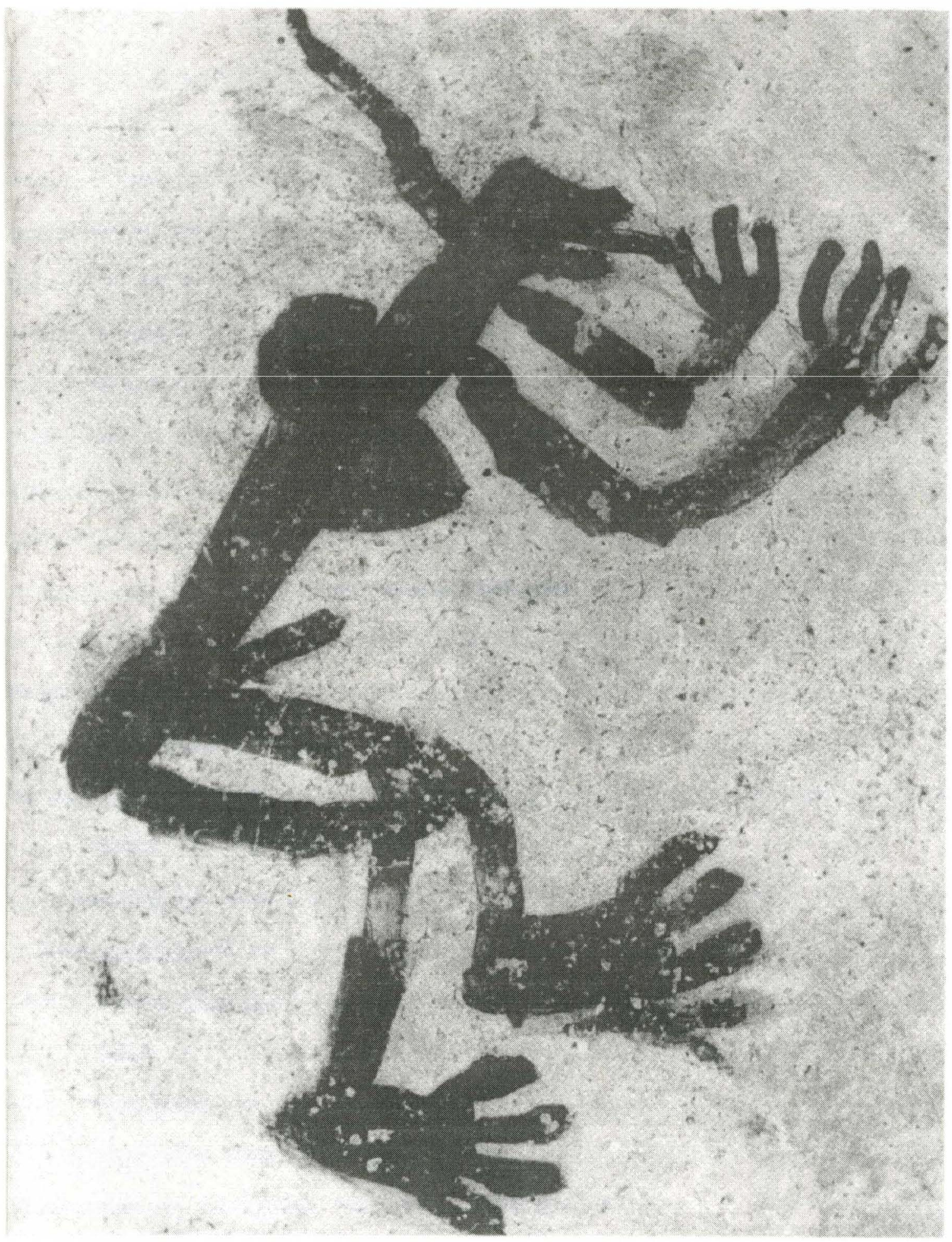


SELECTED BIBLIOGRAPHY 


\section{SELECTED BIBLIOGRAPHY}

Ackroyd, Peter. Blake. New York: Knopf, 1996.

Agarwal, Urmila. “Mithunas: Why Obscene Sculptures?” Oriental Art. XIV (1968): 260.

Armstrong, Karen. A History of God. New York: Knopf, 1993.

Avalon, Arthur (Woodroffe, Sir John). Shakti and Shakta. New York: Dover, 1978.

Baker, C. H. Collins. Enlarged and revised by R.R. Wark. Catalogue of William Blake's Drawings and Paintings in the Huntington Library. San Marino, CA: Huntington Library, 1957.

Bascom. William. African Art. New York: Norton, 1973.

Beardsworth, Patricia. Larousse World Mythology. New York: Putnam, 1965.

Beer, John. Blake's Humanism. Manchester, NY: Manchester UP and Barnes, 1968.

Behrendt, Stephen C. ' 'Paradise Lost' and Blake's View of the Fall.” Trivium. 18 (1983): 39-48.

---. The Moment of Explosion: Blake and the Illustration of Milton. Lincoln, NE: U of Nebraska P, 1983.

Bhattacharya, T.P. "Mithuna Figures in Indian Art." Lalit Kala. XIII (1967): 47-50.

Bianchi, Ugo. "Twins." The Encyclopedia of Religion. Ed. Mircea Eliade, et al. 16 vols. New York: Macmillan, 1987.

Bindman, David. "William Blake and Popular Religious Imagery." The Burlington Magazine. 128 (1986): $712-8$.

--- William Blake, His Art and Times. New Haven, CT: Yale Center for British Art, 1982.

--. Blake as an Artist. Oxford: Phaidon, 1977.

Binyon, Laurence. Catalogue of Drawings by British Artists and Artists of Foreign Birth.... Vol. I. London, 1898.

Blake, William. Milton. New York: Random, 1978.

-.-. William. Jerusalem. Princeton: Princeton UP, 1991.

Blunt, Anthony. The Art of William Blake. New York: Columbia UP, 1959.

Bly, Robert, and Marion Woodman. The Maiden King. New York: Holt, 1998.

Bolle, Kees W. "Hieros Gamos." The Encyclopedia of Religion. 
Boundaries of the Soul: Explorations in Jungian Analysis. Prod. Jeffrey Mishlove, and Arthur Bloch. Videocassette. Thinking Allowed Productions, 1988.

Briderman, Hans. Dictionary of Symbolism. Trans. James Hulbert. New York: Facts on File, 1992.

Brooks, Harold F. "Blake and Jung: Blake's Myth of the Four Zoas and Jung's Picture of the Psyche." The Aligarh Critical Miscellany. (Aligarh, India) 1.1 (1988): 47-74. [Aligarh. India]

---. "Blake and Jung III: Reintegration." The Aligarh Critical Miscellany. 5.1 (1992): 41-89.

Burn, Barbara, ed. Masterpieces of the Metropolitan Museum of Art. New York: Metropolitan Museum of Art, 1993.

Butlin, Martin. William Blake. 1 \& 2 vols. London: Tate Gallery, 1978.

---. The Paintings and Drawings of William Blake. New Haven, CT: Yale UP, 1981.

Butlin, Martin and Ted Gott. William Blake in the Collection of the National Gallery of Victoria. Melbourne: National Gallery of Victoria, 1989.

Calame-Griaule, Genevieve. Ethnologie et Language: La Parole Chez Les Dogon. Paris: Gallimard, 1965.

---. Words and the Dogon World. Trans. Deidre LaPin. Philadelpia: Inst. for Study of Human Issues. 1986.

Campbell, Joseph, ed. The Portable Jung. Trans. R.F.C. Hull. New York: Viking, 1971.

Carl Gustav Jung, Artist of the Soul. Prod. Werner Weick. Videocassette. Mystic Fire Video, 1991.

Cavendish, Richard. "First Man." The Encyclopedia of Man, Myth, and Magic. Ed. Richard Cavendish, et al. 21 vols. New York: Cavendish, 1997.

Chakrauarty, Kalyan Kumar. The Art of India Khajuraho. New Delhi, India: Gulat Vazirani, 1985.

Constable, W.G., ed. Museum of Fine Arts, Boston: Catalogue of Paintings and Drawings in Watercolor. Boston: MFA, 1949.

Coomaraswamy, Ananda K. "An Indian Temple: The Kandarya Mahadeo.” Art in America. 35 (1947): 285 92.

Cramer, Patricia. "The Role of Ahania's Lament in Blake's Book of Ahania: A Psychoanalytical Study." Journal of English and Germanic Philology. 83.4 (1984): 522-33.

Cunningham, Michael R. Masterworks of Asian Art. New York: Thame/CMA. 1998.

Damon, S. Foster. A Blake Dictionary. Hanover, NH: UP of New England, 1988. 
Danielou, Alain. "An Approach to Hindu Erotic Sculpture." Marg. II (1948): 78-89.

Davidson, J. LeRoy. "Mannerism and Neurosis in the Erotic Art of India." Oriental Art. VI (1960): 88-9

Davies. John Gordon. The Theology of William Blake. Oxford: Clarendon P. 1948.

De Grunne, Bernard. "Ancient Sculpture of the Inland Niger Delta and Its Influence on Dogon Art." African Arts. 21.4 (1988): 50-5.

Dehejia, Vidya. "Reading Love Imagery on The Indian Temple." Asian Art \& Culture. (1998): 97-113.

DeMott, Barbara. Dogon Masks. Ann Arbor, MI: UMI Research P, 1982.

Desai, Devangana. Erotic Sculpture of India. New Delhi, India: Tata McGraw, 1975.

---. The Religious Imagery of Khajuraho. Mumbai, India: Franco-Indian Research Pvt, 1996.

Deva, Krishna. Khajuraho. New Delhi, India: Archaeological Survey of India, 1987.

Dieterlen, Germaine. "Masks and Mythology Among the Dogon." African Arts. 22.3 (1989): 34-43.

Digby, George Wingfield. Symbol and Image in William Blake. Ox ford: Claredon, 1957.

Donaldson, Thomas. "Propitious-Apotropaic Eroticism in the Art of Orissa." Artibus Asiae. 1.2 (1975): 75100.

Dunbar, Pamela. William Blake's Illustrations of the Poetry of Milton. Oxford: Claredon. 1980.

Dyer, Donald R. Cross Currents of Jungian Thought. Boston: Shambhala, 1991.

Elder, George R. "God Removes Adam's Rib.” An Encyclopedia Of Archetypal Symbolism: The Body. Ed.

George E. Elder. 2 vols. Boston: Shambhala, 1996.

Eliade, Mircea. Myth and Reality. Trans. Willard R. Tusk. New York: Harper, 1975.

--. "Opposites." Man, Myth, And Magic.

---. Yoga: Immortality and Freedom. Trans. Willard R. Tusk. Princeton: Princeton UP, 1969.

--- The Two and the One. Trans. J.M. Cohen. New York: Harper, 1965.

--- Patterns in Comparative Religion. Trans. Rosemary Sheed. New York: World, 1963.

--.. The Sacred \& the Profane: The Nature of Religion. Trans. Willard R. Tusk. New York: Harcourt, 1958.

Ellis, Edwin J. The Real Blake. New York: McClure, 1907.

Ezra, Kate. Art of the Dogon. New York: Metropolitan Museum of Art, 1988.

---. "The Art of the Dogon." African Arts. 21.4 (1988): 30-3. 
--. Rev. of Villages Perche's Des Dogon Du Mali, By Jean-Christophe Huet. African Arts. Spring. 1997: $14-6 ; 84-5$.

--- "Dogon Seated Couple." The Pacific Islands, Africa, and the Americas. Ed. Metropolitan Museum of Art. New York: Metropolitan Museum of Art, 1987. 64.

Fabian, Mira. "Recent Exhibitions." African Arts. 7.1 (1973): 72-7.

Feuerstein, Georg. Sacred Sexuality. Los Angeles: Tarcher, 1992.

Fiedler, Leslie, trans. "Archetype and Signature." Literature In Critical Perspectives, an Anthology. Comp. Walter K. Gordon. New York: Appleton, 1968. 515-26.

Figgis, Darrell. The Paintings of William Blake. New York: Scribner's, 1925.

Flam, Jack D. "Some Aspects of Style Symbolism in Sudanese Sculpture." Journal de la Societe Des Africanistes. XL.2 (1970): 137-150.

Fraser, Douglas. ed. African Art as Philosophy. New York: Interbook, 1974.

Frieling, Barbara. "Blake at the Rim of the World: A Jungian Consideration of Jerusalem." Journal of Evolutionary Psychology. 8.3-4 (1987): 211-8.

Gangoly, O.C. "The Mithuna in Indian Art.” Rupam. 22 (1925): 54-61. [Calcutta, India]

Garimella, Annapurna. "Lovers." Rings: Five Passions in World Art. Ed. J. Carter Brown. New York: Abrams, 1996.

Godard, Jerry Caris. Mental Forms Creating. Lanham, MD: UP of America, 1985.

Grant, John E. "Two Flowers in the Garden of Experience." William Blake: essays for S. Foster Damon. Ed. Alvin H. Rosenfeld. Providence: Brown UP, 1969.

Griaule, Marcel. Dogon Masks. Trans Jean H. Winchell. New Haven, CT: Smithsonian, 1986.

---. "Nouvelles Recherches sur la Notion de Personne Chez Les Dogons." Journal de Psychologie Normale et Pathologieque. 40.4 (1947): 425-31.

--. Folk Art by Black Africa. Trans. Michael Heron. New York: Tudor, 1950.

Griaule, Marcel, and Germaine Dieterlen. "The Dogon of the French Sudan." African Worlds. Ed. Cyril Daryll Forde. London: Oxford UP, 1954. 83-110.

--- The Pale Fox. Trans. Stephen C. Infantino. Chino Valley, AZ: Continuum, 1986. 
Guillaume, Paul, and Thomas Munro. Primitive Negro Sculpture. New York: Hacker, 1968.

Harle. James C. The Art and Architecture of the Indian Subcontinent. New York: Penguin, 1986.

Harper, George Mills. The Neoplatonism of William Blake. Chapel Hill, NC: U of North Carolina P. 1961.

Hart, Vaughan. "Carl Jung’s Alchemical Tower at Bollingen." Res. 25. (1994): 36-50.

Hill, Gareth S. Masculine and Feminine. Boston: Shambhala, 1992.

Hillman, James. Re-Visioning Psychology. New York: Harper, 1975.

Hoeveler, Diane Long. "Blake's Erotic Apocalypse: The Androgynous Ideal in Jerusalem." Essays in Literature. 6 (1979): 29-41.

Jackson, Graham. The Secret Lore of Gardening: Patterns of Male Intimacy. Toronto: Inner City, 1991.

Jaffe, Aniela, ed. C.G. Jung Word and Image. Trans. Krishna Winston. Bollingen Series XCUII: 2. Princeton: Princeton UP, 1979.

Jolly, Penny Howell. Made in God's Image?: Eve and Adam in the Genesis Mosaics at San Marco, Venice. Berkeley: U of California P, 1997.

Joseph Campbell Understanding Mythology. Prod. Arthur Bloch. Videocassette. Thinking Allowed Video, 1988.

Jung. Carl G. "The Collective Unconscious, Myth, and the Archetype." Literature In Critical Perspectives, an Anthology. Trans. Walter K. Gordon. New York: Appleton. 1968. 510-4.

---. Symbols of Transformation. London: Routledge, 1967.

--. Man and His Symbols. Garden City, NY: Doubleday, 1964.

---. Mysterium Coniunctionis: An Inquiry into the Separation and Synthesis of Psychic Opposites in Alchemy. Trans R.F.C. Hull. Princeton: Princeton UP, 1977.

--- "The Concept of the Collective Unconscious." Literature In Critical Perspectives, an Anthology. Trans. Walter K. Gordon. New York: Appleton, 1968. 504-9.

--- Carl G. "The Transcendent Function." The Collected Works of C.G. Jung: the Structure and Dynamics of the Psyche. Trans. R.F.C. Hull. Ed. Herbert Read, Michael Fordham, and Gerhard Adler. Vol. 8. Princeton: Princeton UP, 1966. 131-93. 
--. Carl G. The Collected Works of C.G. Jung: Aion. Trans. R.F.C. Hull. Ed. Herbert Read. Michael Fordham, and Gerhard Adler. Vol. 9. Princeton: Princeton UP, 1966.

Kan, Michael. "Dogon Sculpture and the Understanding of African Art." Artnews. 72. (1973): 76-9.

Karaban, Roslyn A. "Jung's Concept of the Anima/Animus: Enlightening or Frightening?" Pastoral Psychology. 41.1 (1992): 39-44.

Keynes, Geoffrey. Bibliotheca Bibliographica. London: Trianon, 1964.

--- Pencil Drawings by William Blake, $2^{\text {nd }}$ Series. Neth: Nonesuch. 1956.

--. Blake Studies. London: Rupert, 1949.

--- Drawings of William Blake, 92 Pencil Studies. New York: Dover, 1970.

Klobe, Marguerite A. “A Dogon Figure of a Koro Player.” African Arts. 10.4 (1997): 32-5.

Krishan, Y. "The Erotic Sculpture of India." Artibus Asiae. 34. (1972): 331-43.

Lammers, Laurel Beth. Kaethe Kollwitz: Her Art and Her Soul, A Jungian Interpretation of Her Work. Thesis. U of Louisville, 1996.

Laude, Jean. African Art of the Dogon: The Myths of the Cliff Dwellers. Trans. Joachim Neugroschel. New York: Brooklyn Museum and Viking, 1973.

---. "Seated Couple." The Metropolitan Museum of Art Guide. Ed. John P. O'Neill. New York: Metropolitan Museum of Art, 1994.

Lee, Sherman E. A History of Far Eastern Art. New York: Prentice and Abrams, 1982.

Leeming, David, and Margaret Leeming. "Dogon Creation." Encyclopedia of Creation Myths. Santa Barbara. CA: ABC-CLIO, 1994.

Leiris, Michael. and Jacqueline Delange. African Art. Trans. Michael Ross. New York: Golden, 1968.

Leloup, Helene. "Dogon Figure Styles." African Arts. 22.1 (1988 Nov): 44-51.

Lem, F.H. Sudanese Sculpture. Paris: Arts et Metiers, 1949.

Leuzinger, Elsy. Africa: The Art of the Negro Peoples. Trans. Ann E. Keep. New York: Crown, 1967.

--- The Art of Black Africa. Trans. R.A. Wilson. New York: New York Graphic Society, 1972.

Lincoln, Andrew. "Blake and the Natural History of Creation." Essays and Studies. 39. (1986): 94-103. MacClancy, Jeremy. “Dogon.” Man, Myth, and Magic. 
MacKenzie, Lynn. Non-Western Art. Englewood Cliffs, NJ: Prentice, 1995.

Mahony, William K. "Upanisads." Encyclopedia Religion.

Majupurias, T.C. Glories of Khajuraho. Lashkar [Gwalior], India: Gupta, Lalitpur Colony, 1990.

Maple, Eric. "Evil Eye." Man, Myth. and Magic.

Maquet, Jacques. The Aesthetic Experience: An Anthropologist Looks at the Visual Arts. New Haven, CT: Yale UP, 1986.

Matter of Heart: The Extraordinary Journey of C.G. Jung into the Soul of Man. Videocassette. Prod. Michael Whitney. Videocassette. Kino on Video, 1985.

Meeks, Wayne A. "The Image of the Androgyne: Some Uses of a Symbol in Earliest Christianity." History of Religions. 13.3 (1974): 165-208.

Meister, Michael W. "Juncture and Conjunction: Punning and Temple Architecture." Artibus Asiae. 2.3 (1979): 226-34.

Mellor, Anne Kostelanetz. Blake's Human Form Divine. Berkeley: U of California, 1974.

Milton, John. Paradise Lost. Liverpool: Liverpool Bookseller’s, 1906.

---. Poems in English. 2 Vol. London: Nonesuch, 1926.

Miner, Paul. "Visionary Astronomy." Bulletin of Research in the Humanities. 84.3 (1981): 305-36.

Minor, Vernon Hyde. Art History’s History. Edgewood Cliffs, NJ: Prentice, 1994.

Mookerjee, Ajit. The Arts of India from Prehistoric to Modern Times. Rutland, VT: Tuttle, 1966.

Mookerjee, Ajit. and Madhu Khanna. The Tantric Way. Boston: New York Graphic Soc., 1977.

Moon, Beverly Ann. ed. "Eleven-Headed Female Figure," "Khandariya Mahadeva Temple," "Father Sky, Mother Earth and Rainbow," "Loving Couple," "A Pair of Intertwined Serpents," "Ardhanarisvara," "Androgynous Water Spirit," and "The Goddess Chinnamasta." An Encyclopedia of Archetypal Symbolism. Ed. Beverly Ann Moon, and George Elder, et al. 2 vols. Boston: Shambahala, 1991.

Moore, Robert and Douglas Gillette. "The Lover.” King, Warrior, Magician, Lover. San Francisco: Harper, 1991.

Munsterberg, Hugo. Art of India and Southeast Asia. New York: Ahrams, 1970. 
Murry, John Middleton. Adam and Eve. London: Andrew, 1944.

Mythos. Prod. William Free. Videocassettes. 2 vols. Inner Dimension, 1997. [Joseph Campbell on myth]

Narain, L.A. Khajuraho: Ecstasy in Indian Sculpture. New Delhi, India: Roli, 1982.

Nath, R. The Art of Khajuraho. New Delhi, India: Shakti Malik Ahhinav, 1980.

Nesmith, Fisher H., Jr. "Dogon Bronzes." African Arts. 12.2 (1979): 21 -6.

---. "Dogon Bronzes." African Arts. 13.3 (1980): 89-90.

Neumann, Erich. The Archetypal World of Henry Moore. Trans. R.F.C. Hull. New York: Pantheon, 1959.

---. Art and the Creative Unconscious. New York: Pantheon, 1959

O'Flaherty, Wendy. Women, Androgynes, and Other Mythical Beasts. Chicago: U of Chicago P, 1980.

O'Flaherty, Wendy, and Mircea Eliade. "Androgynes." The Encyclopedia of Religion.

O’Neill, John P., ed. Notable Acquisitions 1975-1979. New York: Metropolitan Museum of Art. 1979.

Paananen, Victor N. William Blake. Boston: Twayne, 1977.

Padoux, Andre. "Tantrism: An Overview." The Encyclopedia of Religion.

Paley, Morton D. “"The Wonderful Originals'-Blake and Ancient Sculptures.” Blake and his Time. Ed.

Robert N. Essick, and Donald Pearce. Bloomington, IN: Indiana UP, 1978.

--. William Blake. Oxford: Phaidon, 1978.

Parker, William E. "Unitary Reality." Aperture. 13.3 (1967): 130-51.

Pascal, James Imperato. "Recent Exhibitions." African Arts. 22.1 (1988): 87-8.

Paudrat, Jean-Louis. "La Geste Dogon.” Connaissance des Arts. 51 1. (1994): 114-23.

Phillips, David. "Hermaphrodite." Man, Myth, And Magic.

Pointon, Marcia R. Milton and English Art. Toronto: U of Toronto P, 1970.

Popper, H. "Jacob Boehme.” Man. Myth. And Magic.

The Power of Myth. Prod. Catherine Tatge. Videocassettes. Mystic Fire Video, 1988. [Joseph Campbell on mythology]

Pramar, V.S. “Depiction of Mithuna on Domestic Houses of Gujarat." Marg. 38.4 (1986): 83-4.

The Psychology of Jung: Passions of the Soul. Prod. Brad Sanders. Videocassettes. Films For The Humanities \& Sciences, 1991. 
Punja, Shobita. "Divine Ecstasy: The Story of Khajuraho." Marg. 45.2 (1993): 71.

---. "Khajuraho: from Myth to Reality." Oriental Art. 39 (1993): 34-45.

Raine, Kathleen. Blake and Tradition. 2 vols. Princeton: Princeton UP, 1968.

--.. "William Blake." Man, Myth, and Magic.

---. William Blake. London: Longman's Green, 1951.

--- "C.G. Jung: A Debt Acknowledged." Jungian Literary Criticism. Ed. Richard P. Sugg. Evanston. IL: Northwestern UP, 1992. 167-76.

Redfield, Robert. "Art and Icon.” Aspects of Primitive Art. New York: (1959): 10-45.

Rees, A.L., and F. Borzello. The New Art History. Atlantic Highlands, NJ: Humanities, 1988.

Remembering Jung. Prod. Tee Bosustow. Videocassette. Insight Media, 1989.

Richardson, John Adkins. "Speculations on Dogon Iconography." African Arts. 11.1 (1977): 52-7.

Rossetti, William Michael. "Annotated Catalogue of Blake's Pictures and Drawings.” Life of William Blake. Ed. Alexander Gilchrist. London, 1863.

Rowland, Benjamin. The Art and Architecture of India: Buddhist, Hindu, Jain. Melbourne: Penguin, 1953.

Roy, Christopher D. African Sculpture: The Stanley Collection. Iowa City: U of Iowa Museum of Art, 1979.

-... The Dogon of Mali and Upper Volta. Munchen, Germany: Jahn, 1983.

Samuels, Andrew, and Bani Shorter, and Fred Plant. A Critical Dictionary of Jungian Analysis. London: Routledge, 1986.

Sanford, John Gordon. The Invisible Partners. New York: Paulist, 1980.

Sargant, William. "Sex." Man, Myth, And Magic.

Schwartz, Arturo. “Alchemy, Androgyny and Visual Artists." Leonardo. 13 (1980): 57-62.

Scott, William Bell. William Blake, Etchings from his Works. London, 1878.

Simmons, M. Ann. "Hermaphrodite/Androgyne." Encyclopedia of Comparative Iconography. Vol. 1. Ed. Hellen E. Roberts. Chicago: Fitzroy, 1998.

Singer, June. Androgyny. Garden City, NY: Anchor, 1977.

--.. The Unholy Bible: Blake, Jung and the Collective Unconscious. Boston: Sigo, 1986. 
Smith, Curtis D. Jung's Quest for Wholeness: A Religious and Historical Perspective. Albany, NY: State U of New York P, 1990.

Spector, Jack. "The State of Psychoanalytic Research in Art History.” The Art Bulletin. 70.1 (1988): 49-76.

Spini, Tito and Sandro Spini. Togu Na. New York: Rizzoli, 1977.

Steinberg, Leo. The Sexuality of Christ in Renaissance and in Modern... Chicago: U of Chicago P, 1996.

Steven, Anthony. Jung. Oxford: Oxford UP, 1994.

Storr, Anthony. Jung. New York: Viking, 1991.

Stuart, James, and Nicholas Revett. The Antiquities of Athens. London, 1858

Sullivan, Bruce M. comp. "Ardhanarisvara," "Cakra," "Goddess," "Kudalini," "Sakti," "Siva," and

“Tantra.” Historical Dictionary of Hinduism. Ed. Jon Woronoff. Lanham, MD: Scarecrow, 1997.

Tayler. Irene. Blake's Illustrations to the Poems of Gray. Princeton: Princeton UP, 1971.

Thayer, James S. "Amma." The Encyclopedia of Religion.

Thompson. Robert Farris. African Art in Motion. Los Angeles: U of California P, 1974.

Tripati, L.K. "The Erotic Scenes of Khajuraho and their Probable Explanation." Bharati. 3 (1959-1960): 40-60.

Tufte, Virginia. "Evil as Parody in the Paradise that Was Lost: Three Illustrators Interpret Milton's Book 4." Mosaic: A Journal for the Interdisciplinary Study of Literature. 21.2-3 (1988): 37-58.

Van Beek, Walter E.A. "Functions of Sculpture in Dogon Religion.” African Arts. 21.4 (1988): 58-65.

Van Meurs, Jos. Jungian Literary Criticism. Boston: Sigo, 1988.

Vogel, Susan Mullin. African Aesthetics: The Carlo Monzino Collection. New York: Center for African Art, 1986.

Walker, Barbara G. The Woman's Encyclopedia of Myths and Secrets. San Francisco: Harper, 1983.

--- The Crone: Woman Of Age, Wisdom, and Power. Cambridge, MA: Harper, 1985.

Walker, Benjamin. "Androgyny," and "Sex Mysticism." and "Siva." The Hindu World. Ed. Benjamin Walker. New York: Praeger, 1968.

--.. "Tantrism." Man, Myth, and Magic.

Watts, Alan W. The Two Hands of God. New York: Braziller. 1963. 
Waxler, Robert P. "The Virgin Mantle Displaced: Blake's Early Attempt." Modern Language Studies. 12.1 (1982): $45-53$.

Weil, Kari. Androgyny and the Denial of Difference. Charlottesville, VA: UP of Virginia, 1992.

Werner, Bette Charlene. Blake's Visions of the Poetry of Milton. London: Assn. UPs, 1986.

Willett, Frank. African Art. New York: Thames, 1993.

William Blake. Prod. and Dir. David Thomas. Videocassette. Films for the Humanities, 1996.

Wilson, Mona. The Life of William Blake. London: Oxford UP, 1971.

Wilton, Andrew. "Blake and the Antique." British Museum Yearbook. Ed. British Museum. Vol. I. London: British Museum, 1976.

The Wisdom of the Dream. Prod. Stephen Segaller. Videocassettes. SBS, 1990. [Jungian Psychology]

Witcutt, W.P. Blake: A Psychological Study. London: Hollis, 1946.

Woodward. Hiram W. Jr. "The Laksmana Temple, Khajuraho, and its Meanings." Ars Orientalis. 19 (1989): 27-48.

The World of Joseph Campbell: Transformations of Myth through Time. Dir. Roy A. Cox. Prod. Stuart L. Brown, and William Free. Videocassettes. Public Media Video, 1989.

The World Within. Prod Tee Bosustow. Videocassette. Insight Media, 1990. [Jungian Psychology]

Zaehner, Robert Charles. "Shiva." Man, Myth, and Magic.

Zimmer, Heinrich. The Art of Indian Asia: Mythology and Transformation. 2 vols. Ed. Joseph Campbell. New York: Pantheon, 1955.

Zimmer, Heinrich. Philosophies of India. Ed. Joseph Campbell. New York: Patheon. 1953.

Zolla, Elemire. The Androgyne. New York: Crossroad, 1981. 
B. Mason Cowell was born and raised in Louisville, Kentucky and is the son of Harold Mitchell Cowell and Mary Ann Rueve, both Louisville natives. He attended St. Martha Elementary School and St. Xavier High School both located in Louisville. In August 1989 he graduated from the University of Kentucky with a B.A. degree in Liberal Arts. In May 1993, Mason graduated from the Atlanta Institute for Art with an A.A. degree in Visual Communications (commercial art). Mason Cowell is a figure artist with his studio located in the Louisville area. Currently, he depicts the human form by using the various media of sketching, painting, illustrating and sculpting. 